First QUARTERLY TECHNICAL PROGRESS REPORT- Dated July 15, 1998

(For the period January 29, 1998 through June 30, 1998)

\title{
Southeast Geysers Cooperative Tracer Evaluation and Testing Program, for the Purpose of Estimating the Efficiency of Injection
}

\author{
U.S. Department of Energy- Financial Assistance Award \#DE-FG07-98ID13616
}

\section{Introduction}

The Southeast Geysers Cooperative Tracer Evaluation Program is a joint project located in the SE part of The Geysers geothermal field, in Lake and Sonoma Counties, California. The project is a cooperative project jointly undertaken by the Northern California Power Agency (NCPA), Calpine Corporation, Unocal Geothermal, Thermochem Inc. and the Energy and Geoscience Institute. NCPA is acting as the lead party of this group for purposes of administering the DOE Financial Assistance Award.

A new generation of environmentally benign vapor-phase tracers are proposed to be used to estimate the degree to which injectate is being recovered following the significant increase of injected volumes within the Southeast Geysers. An initial "Phase One" field evaluation of one of two candidate hydroflurocarbon compounds ("HFCs") was scheduled first, and if that proved successful, a "Phase Two" series of five single vapor-phase tracer field tests, and a sixth field test using tritiated water in combination with two separate vapor-phase tracers, are proposed to follow.

The increased injection has resulted from the startup of Southeast Geysers Effluent Pipeline operations, which has initially resulted in approximately doubling the amount of water available for injection within those portions of the Southeast Geysers reservoir operated by NCPA, Calpine, and Unocal. The proposed tracer tests will be conducted by Thermochem with the assistance of the Energy and Geoscience Institute (EGI). Two effluent injection wells on each operator's property are to be tested.

\section{Results}

On January 20, 1998 the Phase One injection test was begun with the injection of $240 \mathrm{lbs}$ of R134a (C2H2F4) into Calpine well "MLM-1", located in Section 26, T11N, R8W. The tracer was injected over a three hour period, into a $445 \mathrm{gpm}$ injection stream. Within hours after the tracer injection was complete tracer had already initially broken through to two neighboring wells, and over the course of the next three weeks about one-half of the 
original tracer quantity had been recovered, as contained in the injection derived steam produced from the surrounding production wells. Based on the R134a test results, which are nearly identical to results previously obtained by using tritium as the tracer, it is estimated that about $75 \%$ of the original tracer quantity was recovered at the end of two months, with essentially all of the tracer having now been recovered, six months after injection.

The details of this tracer test, and the results obtained, are contained in the attached paper titled "Evaluation of R134a as an Injection Water Tracer in the Southeast Geysers" by Joseph J. Beall (Calpine), Michael C. Adams (EGI) and Paul N. Hirtz (Thermochem). This paper has already been submitted to the Geothermal Resources Council for publication this fall.

\section{Future Plans}

Based on the success of the Phase One Tracer test using the new vapor-phase tracer R134a, the project participants are now proceeding toward conducting the Phase Two tracer tests as soon as practical. One of the consequences of R134a being so extremely detectable, to approximately $0.0015 \mathrm{ppb}$ by weight, is that it is taking far more time for the tracer to become sufficiently diluted so as to no longer be detectable in the steam being produced. Consequently, the time lapse needed between successive uses of R134a within the SE Geysers area will be longer than initially planned, and it already appears certain that the six additional tracer tests that are programmed in Phase Two will not all be completed by the end of this year. However, this should have no negative effect on the overall objectives of the project, nor on the results to be obtained.

Submitted by:

J.L. (Bill) Smith

Recipient Project Director

NCPA, Sr. Geologist 


\title{
EVALUATION OF R134A AS AN INJECTION WATER TRACER IN THE SOUTHEAST GEYSERS
}

\author{
Joseph J. Beall', Michael C. Adams ${ }^{2}$, Paul N. Hirtz ${ }^{3}$ \\ 'Calpine Corporation, Santa Rosa, CA 95401 \\ ${ }^{2}$ Energy and Geosciences Institute, Salt Lake City, UT 84108 \\ ${ }^{3}$ Thermochem, Inc., Santa Rosa, CA 95403
}

\begin{abstract}
Greatly increased injection in the Southeast Geysers into an increased number of injection wells has amplified the need for new artificial tracers to evaluate the recovery of injection as steam and to map the movement of injection derived steam (IDS) in the reservoir. Two artificial tracers of IDS, tritium and the freon compound, R13, have been successfully employed in previous Geysers injection studies. The latter is no longer manufactured, as the "CFC" freons have been replaced with new, environmentally benign, "HFC" freon compounds. Among these is R134a, which was chosen for evaluation as an IDS tracer.

For this test, 240 lbs. of R134a were injected into injection well MLM-1. Comparison with a 1995 tritium test of MLM-1 indicates similar behaviors for the two tracers. The reservoir injectate boiling model best supported by the combined results of the tritium and R134a tracer tests is one of complete boiling at a well defined front, rather than continuous separation of steam along an injectate flow path in the reservoir.
\end{abstract}

\section{Introduction}

During the late 1980's. Geysers steam production began declining at a high rate. As a consequence, the field's total generation potential fell from a peak of $1600 \mathrm{MW}$ in 1987 to about $1000 \mathrm{MW}$ currently (April 1998). This decline in steamflow focused attention on the strategic use of power plant condensate injection to enhance productivity through the recovery of injection derived steam (IDS). The success of those early efforts to enhance steam production (Enedy, et al., 1991; Goyal and Box, 1992; Beall, 1993) stimulated interest in acquiring outside sources of injection water to sustain The Geysers reservoir. Since The Geysers is a vapor dominated reservoir, injection of power plant condensate results in the replacement of only $20 \%$ to $25 \%$ of the total mass withdrawal from the reservoir. In 1997, a consortium of industry and government succeeded in putting into operation a 29 mile pipeline (the Southeast Geysers effluent pipeline, or "SEGEP") to transport waste and lake water from the City of Clearlake to The Geysers. This was the culmination of a six year effort.

In September 1997, injection of water from SEGEP began. By November, SEGEP was continuously providing large flows of injection water, essentially doubling the injection rate in the Southeast Geysers from about 3,000,000 lbs/hr to approximately $6,000,000 \mathrm{lbs} / \mathrm{hr}$. Because 
Beall, Adams and Hirtz

of the high injection rates into a greatly increased number of injection wells, a need was recognized for tracer studies to evaluate the rate of recovery of injection as steam and to map the movement of injection derived steam (IDS) plumes in the reservoir. The large number of injection wells in use also creates a need for multiple tracers so that IDS plumes from neighboring injection wells can be traced simultaneously. Except for tritium, the only artificial tracer which has proven effective in The Geysers is the freon compound R13 (Beall, et al., 1994). Another freon, R12, was tested and found to be unstable under reservoir conditions (Adams, et al., 1991). R12 and R13 are chlorinated fluorocarbon compounds (CFC's) and are damaging to the earth's protective ozone layer. Consequently, they have been phased out of commercial production (remaining stocks have become very expensive) and new freon compounds which are not damaging to the ozone layer have been developed. These are the hydrofluorocarbons (HFC's). The most common (and inexpensive) of these is R134a, which was chosen for a preliminary test for its functionality as an IDS tracer. Table 1 lists some of the pertinent chemical/physical parameters of R134a and R13.

\begin{tabular}{|c|c|c|c|c|}
\hline \multicolumn{5}{|c|}{ TABLE 1} \\
\hline Tracer: & Fonnula & $\begin{array}{l}\text { Detection: } \\
\text { lonver winit: }\end{array}$ & 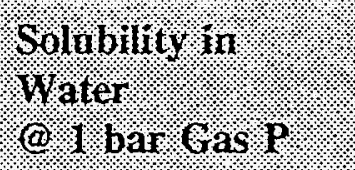 & Yapor pressurer \\
\hline R134a & $\mathrm{C}_{2} \mathrm{H}_{2} \mathrm{~F}_{4}$ & $0.015 \mathrm{ppb}_{\mathrm{w}}$ & 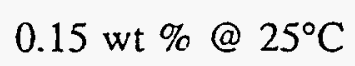 & 6.62 bars @ $25^{\circ} \mathrm{C}$ \\
\hline R13 & $\mathrm{CClF}_{3}$ & $0.3 \mathrm{ppb}_{\mathrm{w}}$ & 0.01 wt $\% @ 25^{\circ} \mathrm{C}$ & 36.2 bars @ $21.1^{\circ} \mathrm{C}$ \\
\hline
\end{tabular}

* Varies with total noncondensible gas concentration. Limits given are for approximately 1500 ppm total NCG.

A preliminary laboratory test of the chemical stability of $\mathrm{R} 134 \mathrm{a}$ was conducted at $280^{\circ} \mathrm{C}$. The results of this initial test suggest that minor to negligible thermally induced chemical decay is likely at the temperature of the Southeast Geysers reservoir (approximately $240^{\circ} \mathrm{C}$ ).

MLM-1, a Calpine injection well in the Unit 13 segment of the Southeast Geysers steamfield, was chosen as the injector for this preliminary evaluation of R134a because it had been used for a tritium tracer test in July 1995. Consequently, it was felt that the results of the tritium test would provide a basis for interpreting the behavior of the R134a. Originally, it was intended to conduct this experiment prior to the initiation of SEGEP water injection in order to have reservoir conditions similar to those during the 1995 tritium test (i.e., low total injection rates in the Units 13 and 16 steamfield). Problems in perfecting an analytical technique for very low level measurements of $\mathrm{R} 134 \mathrm{a}$ (down to about $0.015 \mathrm{ppb}_{\mathrm{w}}$ ) necessitated postponements, however, until about two months after SEGEP was in full operation. Nevertheless, the results of the test of 
R134a as an IDS tracer indicate that it behaves very similarly to tritium and thus has high potential for use in The Geysers, and elsewhere, for estimating the recovery of injectate as steam and mapping the flow of IDS in the reservoir.

\section{Injection Procedure}

MLM-1, like all properly functioning Geysers injection wells accepts water under partial vacuum at the wellhead. Liquified R134a is fed through an electrically heated probe inserted into the water line. The R134a is thereby vaporized and ice clotting at the end of the probe is prevented. The R134a is metered into the well by utilizing a needle valve to control flow and an electronic balance interfaced with a computer to monitor and record the mass injection rate.

On January 20, 1998, 240 lbs. of R134a were injected into MLM-1 during a three hour period. During this time, the injection rate was held at $445 \mathrm{gpm}$. The tracer concentration in the injection stream was therefore $360 \mathrm{ppm}$. This concentration, while much greater than those used in R13 tracer tests at SMUD and Bear Canyon (129 and 103 ppm, respectively; Beall, et al., 1994 ) is more than offset by R134a's greater solubility (Table 1). Steam samples were taken from three nearby production wells about two hours after tracer injection was completed. As in the 1995 tritium test, tracer had already broken through to production wells McKinley 10 and McKinley 11.

\section{Tracer Recovery}

Figures 1 and 1a show the concentration of R134a in steam from various wells as a function of time. Figure 2 shows a similar plot of tritium activity versus time for the 1995 tritium tracer test. Figures 1 and 2 are semi-log plots and show the tracer concentrations versus time curves to be very similarly shaped. Moreover, the highest peak concentrations for tritium in Figure 2 are found in McKinley 11, Barrows 6 and McKinley 10, respectively. The same wells, in the same order, produced the highest concentrations of R134a.

Some significant differences are also apparent. Wells 958-10 and MLM-4 in the R134a test are among the group of wells producing high tracer concentrations. These wells did not produce steam with relatively high tritium activities during the 1995 test.

Figure 1a, plotted on linear axis scales, shows that the tracer concentration versus time curves have the same "steep on the front side, gradual on the back side" shape which is characteristic of a tracer "spike" passing through a production well bore.

Figure 3 shows, for both tracer tests, the recovery of tracer versus time. Tritium is shown on the left $\mathrm{Y}$ axis and R134a on the right. Full scale represents $80 \%$ of the tracer in both cases. The cumulative recovery versus time curves for both tracers are very similar through about the first 13 days. Subsequently, the R134a curve and its projection fall below the tritium curve. During 
Beall, Adams and Hirtz

the tritium test, all production wells produced at their maximum capacities. During the first 24 days of the R134a test, the group of six wells which produced most (96\%) of the recovered tracer produced at an average of $95 \%$ of capacity due to intermittent curtailments. Had there been no curtailments and tracer concentrations remained as measured (possibly not a totally valid assumption) the cumulative fraction of the $R 134$ a recovered by day 24 would be as represented by the triangle in Figure 3. The difference between the tritium and R134a curves at that point would be very small. Extrapolating the actual curves, cumulative recovery of tritium eventually reaches about $75 \%$ while $\mathrm{R} 134 \mathrm{a}$ reaches about $63 \%$. Tracer recovery in both projections has essentially ended in 90 to 100 days.

[Insert Figures 1, 1a, 2 and 3 on a single, landscape page (see example with illustrations) at nearest page break.]

It is probable that nearly all of the tracer is eventually recovered. Budget constraints limit the number of samples which can be taken and thus the number of wells which can be sampled. Fast paths in the reservoir may allow IDS to migrate beyond the nearby producers to wells which are not sampled. Figure 4 shows, next to the steam entry midpoints (not the wellhead locations) the peak tracer concentration (in ppb's) followed by the day (rounded to the nearest 0.5 ) on which the peak arrived. Note that the peak concentrations at Barrows 6 and 958-10 are much higher than at McKinley 15 and MLM-4 even though the latter are significantly closer to the MLM-1 injection well.

\section{[Insert Figure 4]}

\section{Pressure-Temperature Conditions in the Injection Well Bore}

Downhole pressure measurements in the MLM-1 injection well indicate that at the injection rate maintained during tracer injection a water level was established at a depth of about 3600 feet. Injection zones in the well are within the depth interval from 4400 feet to 6400 feet. Consequently, pressures at the exit points of water from the well bore range from about 300 psi to 1000 psi. Temperatures in the well bore throughout the injection interval were undoubtedly well below the boiling points due to the cooling effect of long term injection (over four years).

\section{Tracer Breakout Relative to Water Boiling Curve}

The liquid-vapor curve for water plus $350 \mathrm{ppm}$ R134a (Figure 5) was calculated based on limited data and certain assumptions. No published data are known which describe the distribution coefficient of R134a between water vapor and liquid at temperatures above $25^{\circ} \mathrm{C}$. However, Adams (1995) describes a method to extrapolate fluorocarbon solubilities to higher temperatures by transforming the Henry's Law constants $(\mathrm{Kh})$ to volatility ratios (B). B represents the ratio of the molal concentration of the gas in steam to that in the liquid. It has been shown empirically that $\log (\mathrm{B})$ is an approximately linear function of temperature below $300^{\circ} \mathrm{C}$ to $350^{\circ} \mathrm{C}$ 
(Drummond, 1981). Experimental measurements of the solubility of $\mathrm{SF}_{6}$ in water at temperatures up to $230^{\circ} \mathrm{C}$ by Mroczek (1997) agree well with those predicted by Adams (1995), demonstrating that the extrapolation can be successful at the temperatures found in The Geysers. The compressibility factors required for the transformation of $\mathrm{Kh}$ to $\mathrm{B}$ were calculated from the critical constants compiled in Adams et al. (1991) using the three-parameter corresponding states correlation of Lee and Kesler (1975).

The method described above is not directly applicable to the R134a datum because it is a single point and some of the critical constants are not known. Instead, the slope of solubility versus temperature was taken from a close analogue, R23, and the intercept was calculated from the one known datum at $25^{\circ} \mathrm{C}$. The resulting equation is:

$$
\log (B)=5.28576+.00835 \times t
$$

Where $B=$ steam/water solubility ratio, and $t=$ temperature in degrees centigrade.

Beall, et al., 1994, showed that the calculated liquid-vapor phase boundary for water plus 100 ppm of R13 was only a few degrees lower than the boiling curve for pure water at reservoir pressures above $200 \mathrm{psi}$ (Figure 5). The significance of this is that during heating, the R13 remains dissolved in the injectate almost until the boiling curve of water is reached. In Figure 5 , arrows indicate the boiling points of pure water and water plus $350 \mathrm{ppm}$ of $\mathrm{R} 134 \mathrm{a}$ at a reservoir pressure of 190 psia. The temperature difference between those points is $17^{\circ} \mathrm{C}$. However, it is likely that the R134a concentration is substantially lowered by dilution prior to the onset of boiling. This is the expected consequence of the injected $350 \mathrm{ppm}$ "spike" mixing with and diffusing into a greater volume of water in the reservoir. At a concentration of $100 \mathrm{ppm}$ of $\mathrm{R} 134 \mathrm{a}$, the liquid-vapor boundary is depressed by only about $4^{\circ} \mathrm{C}$ from that of pure water.

\section{[Insert Figure 5]}

\section{Residence Time of Injectate in Reservoir}

The conclusion was reached by Beall, et al. (1994) that water injected into portions of The Geysers reservoir characterized by low pressure and low liquid saturation (i.e., drawn down by production) has a very short residence time. Reservoir boiling of injectate was interpreted to occur rapidly under those circumstances. The current study confirms that finding with the results that $50 \%$ recovery was obtained in three weeks for the tritium test and approximately four weeks for the R134a test.

\section{Complete Boiling at a Front Versus Steam Separation along a Path}

A question posed by Beall, et al. (1994) which could not be answered by freon tracers alone is whether boiling is complete at a distinct "front" or whether boiling begins at some point after the 
Beall, Adams and Hirtz

water leaves the well bore and continues as the water migrates outward into the formation. The strong similarities (Figures 1-3) between recovery and concentration curves for tritium (which cannot concentrate in an early separating steam fraction) and $\mathrm{R} 134 \mathrm{a}$ point to complete boiling at a front as the relevant model for injectate boiling in relatively pressure depleted portions of The Geysers reservoir.

\section{Conclusion}

Initial testing, both in the laboratory and field, suggest that R134a is chemically stable at reservoir temperatures of about $240^{\circ} \mathrm{C}$. The preliminary field test of $\mathrm{R} 134 \mathrm{a}$ appears to have demonstrated its utility as a tracer of IDS. The similarities between the behavior of R134a and tritium are apparent as shown in the graphs of concentration versus time for steam produced from nearby wells. Cumulative recoveries versus time are also very similar. The reservoir injectate boiling model which is best supported by the combined results of tritium and R134a tracer tests, is one of complete boiling at a distinct front. The minor uncertainties that remain regarding the use of R134a can be cleared by a test involving simultaneous injection of it and tritium into the same well so that the results can be compared "side by side".

\section{Acknowledgements}

This paper was prepared with the support of the U.S. Department of Energy (DOE) Award No. DE-FG07-98ID13616. However, any opinions, findings, conclusions or recommendations expressed herein are those of the authors. Funding for MCA was provided by DOE under Contract No. DE-AC07-95ID13274. The authors gratefully acknowledge the assistance of T. A. Freeman in preparing the manuscript.

\section{References}

Adams, M. C., Moore, J. N. and Hirtz, P., 1991. Preliminary assessment of halogenated alkanes as vapor-phase tracers. Proceedings of the $16^{\text {th }}$ Annual Workshop on Geothermal Reservoir Engineering, Stanford University, p. 57-62.

Adams, M. C., Beall, J. J., Enedy, S. L. and Hirtz, P. N., 1991. The application of halogenated alkanes as vapor-phase tracers: A field test in the Southeast Geysers. Geothermal Resources Council Transactions, v. 15, p. 457-463.

Adams, M. C., 1995. Vapor, liquid, and two-phase tracers for geothermal systems. International Geothermal Congress, Proceedings, p. 1875-1880.

Beall, J. J., 1993. The history of injection recovery in the Units 13 and 16 area of The Geysers steamfield. Geothermal Resources Council Transactions, v. 17, p. 211-214. 
Beall, J. J., Adams, M. C., Hirtz, P. N., 1994. R-13 tracing of injection in The Geysers. Geothermal Resources Council Transactions, v. 18, p. 151-159.

Drummond, S. E., Jr., 1981. Boiling and mixing of hydrothermal fluids: Chemical effects on mineral precipitation. Ph. D. thesis, The Pennsylvania State University.

Enedy, S., Enedy, K., Maney, J., 1991. Reservoir response to injection in the Southeast Geysers. Proceedings of the $16^{\text {th }}$ Annual Workshop on Geothermal Reservoir Engineering, Stanford University, p. 75-82.

Goyal, K. P. and Box, W. T., Jr., 1992. Injection recovery based on production data in Unit 13 and Unit 16 areas of the Geysers field. Proceedings of the $17^{\text {h }}$ Annual Workshop on Geothermal Reservoir Engineering, Stanford University, p. 103-110.

Lee, B. I. and Kesler, M. G., 1975. A generalized thermodynamic correlation based on threeparameter corresponding states. AIChE Journal, v. 21, p. 510-527.

Mroczek, E. K., 1997. Henry's law constants and distribution coefficients of sulfur hexafluoride in water from $25^{\circ}$ to $230^{\circ} \mathrm{C}$. Journal of Chemical and Engineering Data, v. 42, p. 116-119. 


\section{R134a vs TIME}

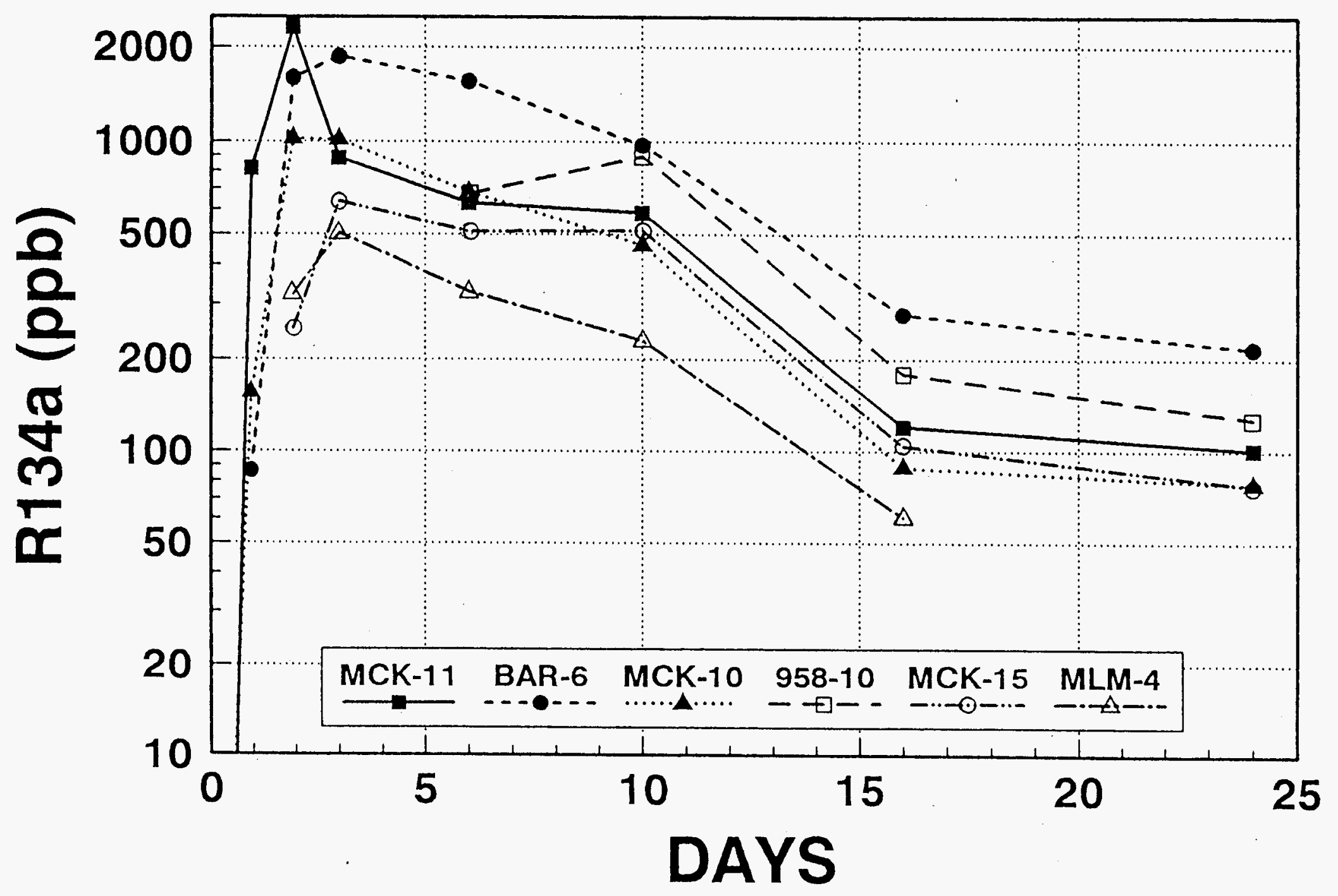

Figure 1. Concentrations of R134a versus time for steam produced from production wells near the MLM-1 injection well. 


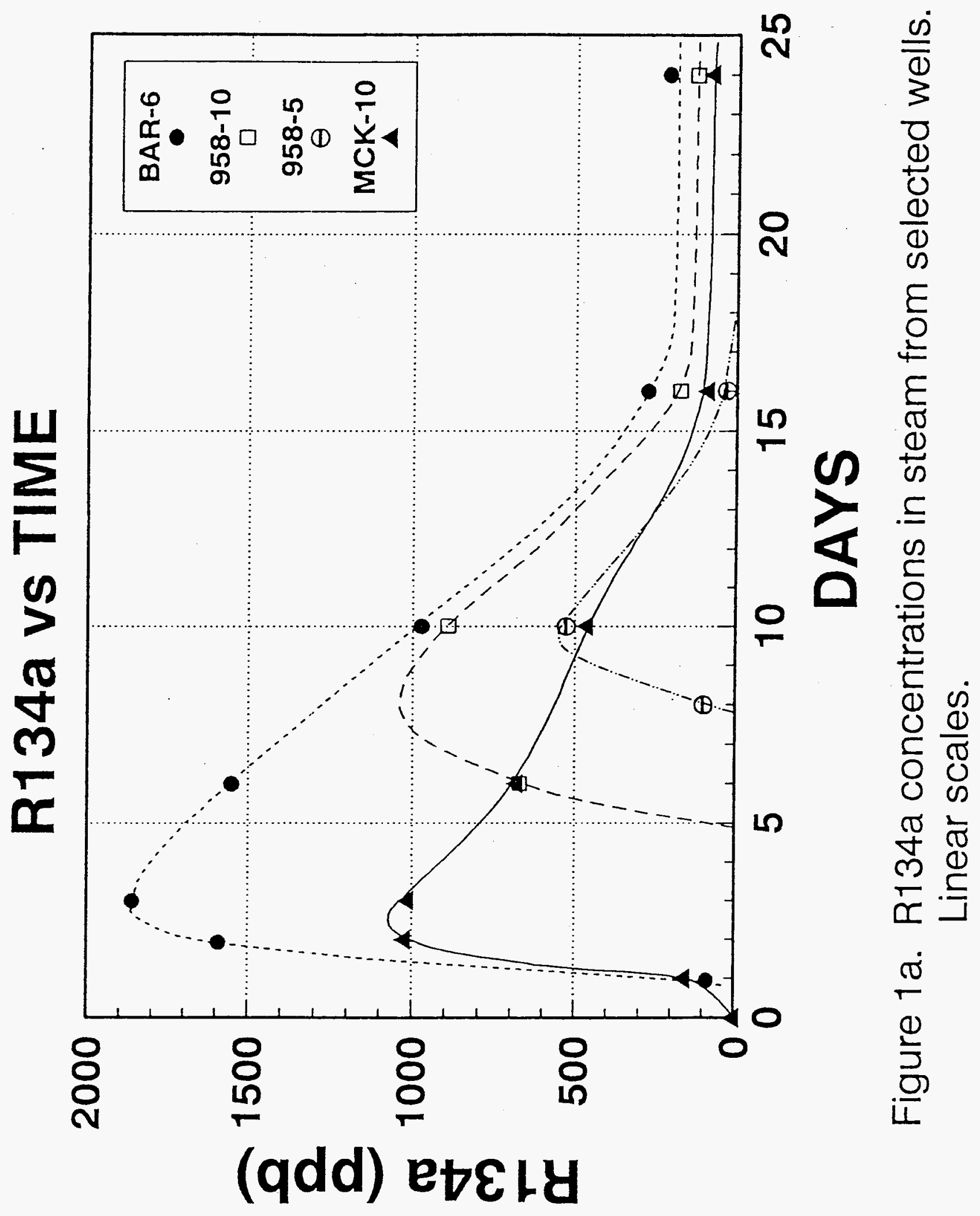




\section{TRITIUM ACTIVITY vs TIME}

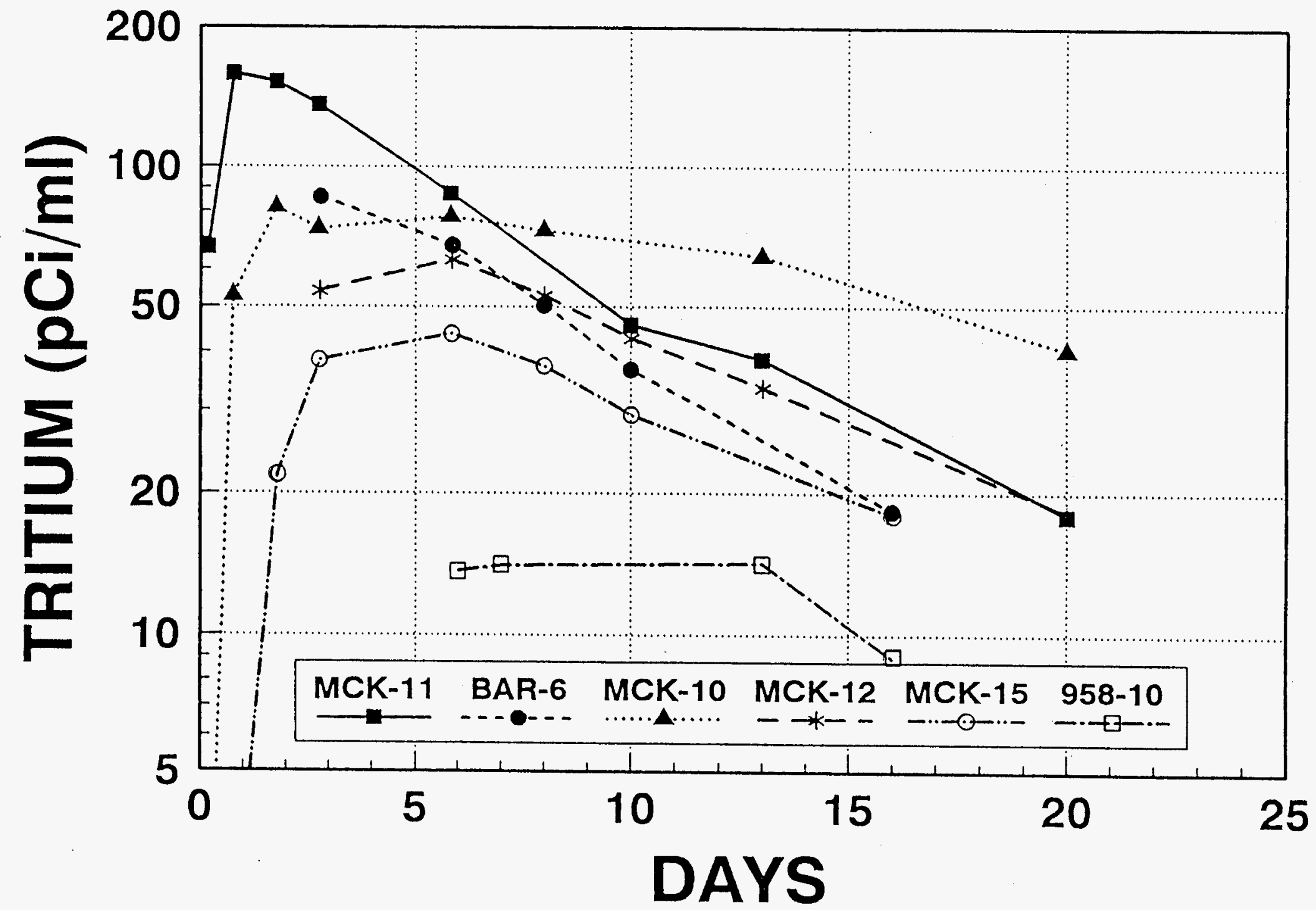

Figure 2. Tritium activities versus time for steam produced from production wells near the MLM-1 injection well (1995 test). 


\section{CUMULATIVE TRACER RECOVERED}

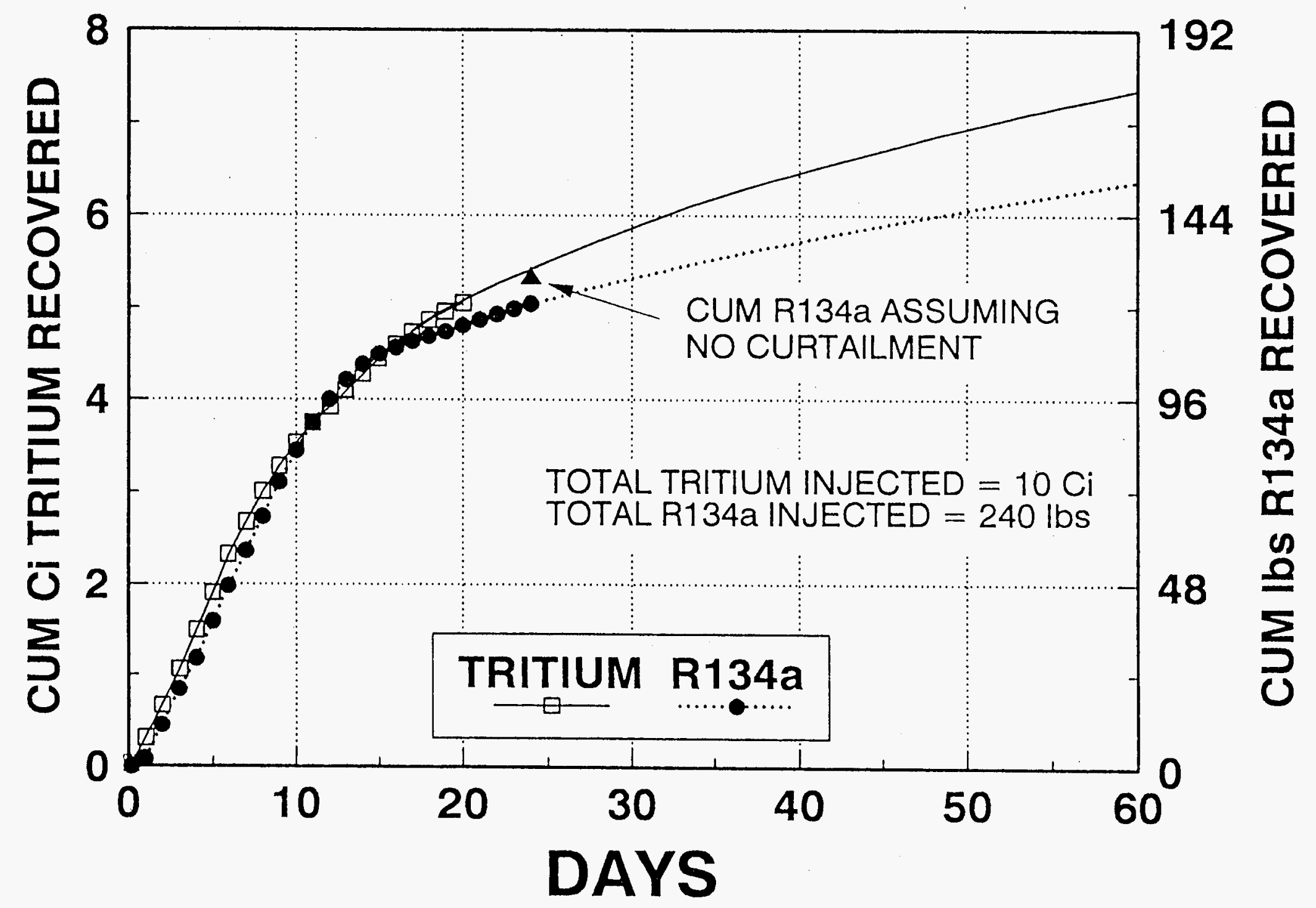

Figure 3. Cumulative tritium and R134a recovered versus time for tracer injected into MLM-1 in 1995 and 1998, respectively. 


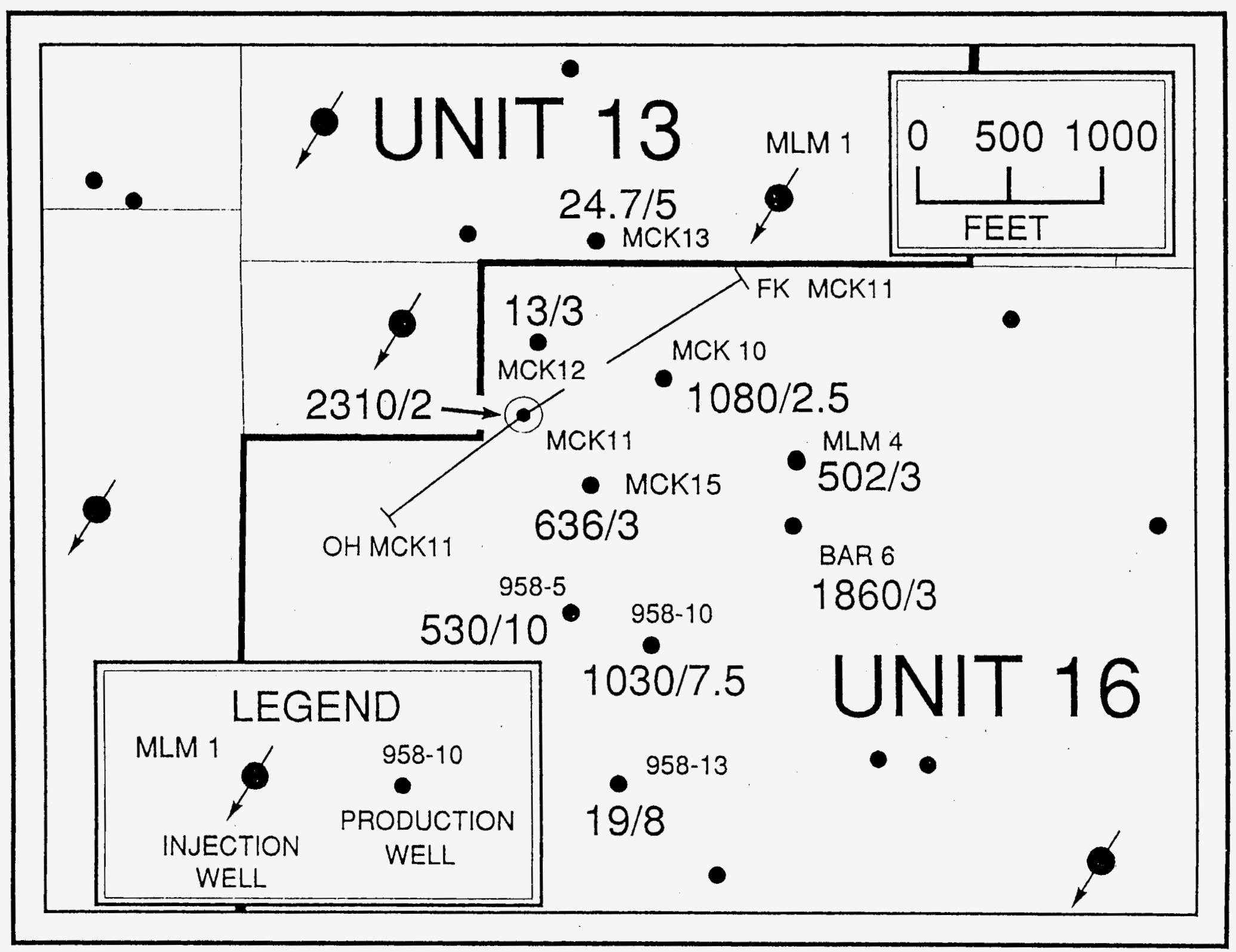

Figure 4. Maximum R134a concentration (ppbw, first number) and day of peak (second number). Deepest steam entries in original hole and fork of MCK11 connected by line. 


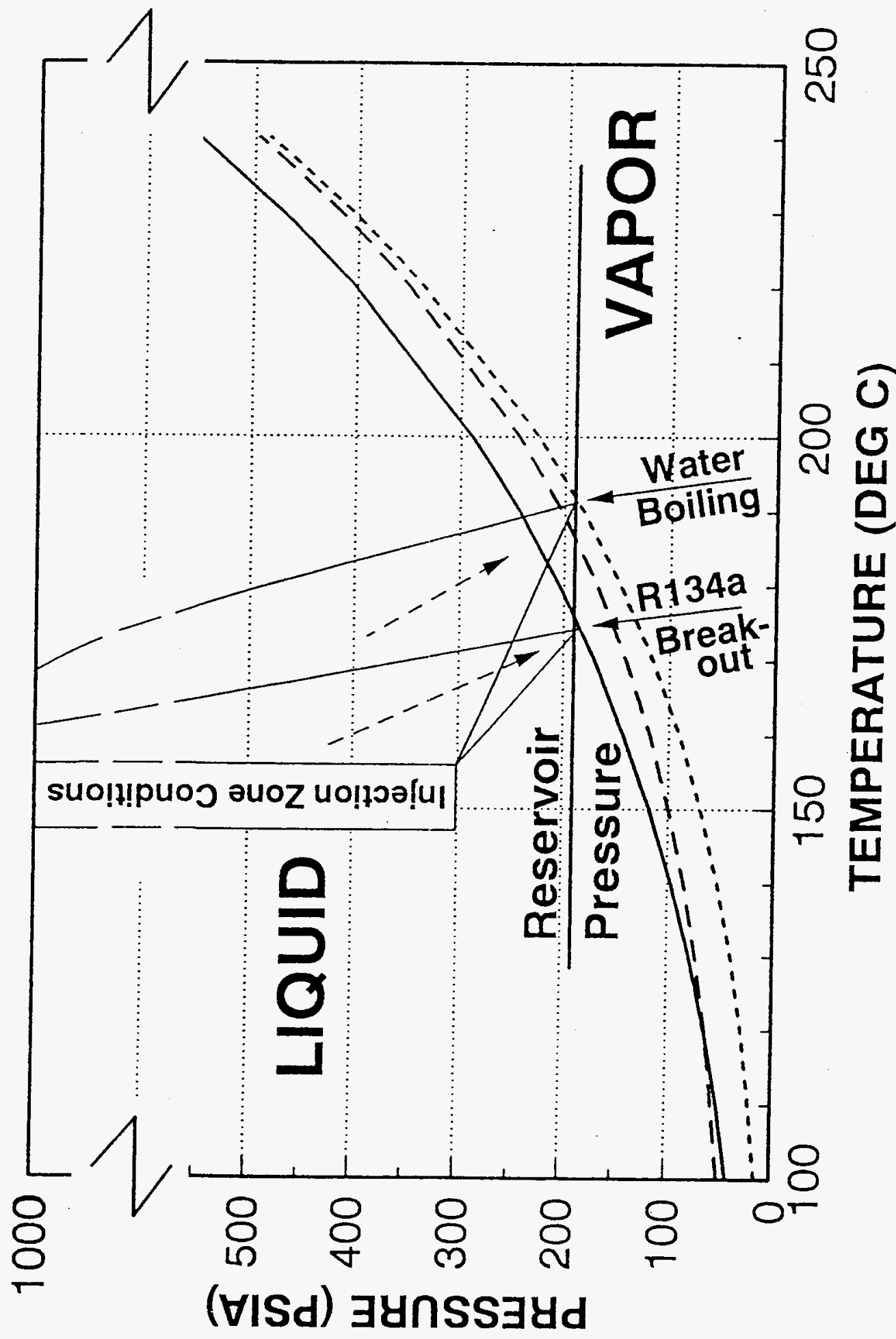

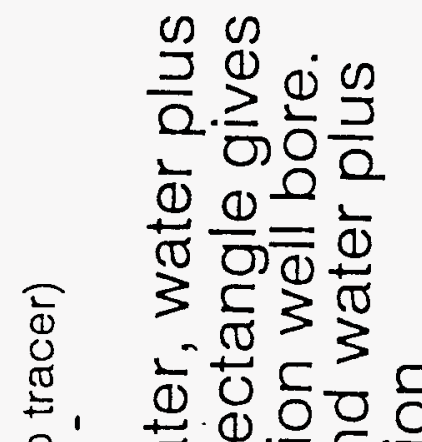

늄

0 ह : 3 क

U :원

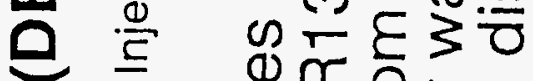

山 m 造这市

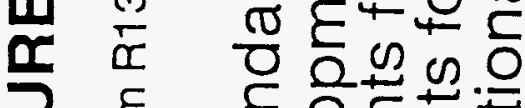

$F$ 은 इ

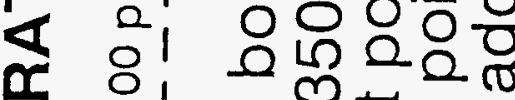

- 1 ब

$+\quad \pi \leqq$

\% ㄴำ

ले ठั워워

즐 을 응

E $>>$ O

응 웅응

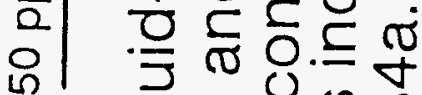

फ़ न्ज ल

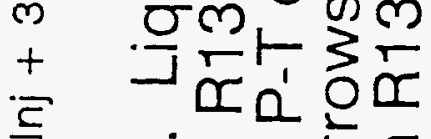

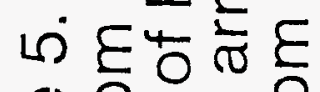

응워응

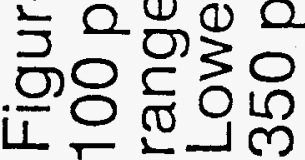


Second QUARTERLY TECHNICAL PROGRESS REPORT- Dated October 26, 1998

(For the period July 1, 1998 through September 30, 1998)

\title{
Southeast Geysers Cooperative Tracer Evaluation and Testing Program, for the Purpose of Estimating the Efficiency of Injection
}

\author{
U.S. Department of Energy- Financial Assistance Award \#DE-FG07-98ID13616
}

\section{$\underline{\text { Introduction }}$}

The Southeast Geysers Cooperative Tracer Evaluation Program is a joint project located in the SE part of The Geysers geothermal field, in Lake and Sonoma Counties, California. The project is a cooperative project jointly undertaken by the Northern California Power Agency (NCPA), Calpine Corporation, Unocal Geothermal, Thermochem Inc. and the Energy and Geoscience Institute. NCPA is acting as the lead party of this group for purposes of administering the DOE Financial Assistance Award.

A new generation of environmentally benign vapor-phase tracers is being used to estimate the degree to which injectate is being recovered following the significant increase of injected volumes within the Southeast Geysers. The significantly increased injection has resulted from the startup of Southeast Geysers Effluent Pipeline (SEGEP) operations, which have initially resulted in approximately doubling the amount of water available for injection within those portions of the Southeast Geysers reservoir operated by NCPA, Calpine, and Unocal.

An initial "Phase One" field evaluation of one of the two candidate hydroflurocarbon compounds ("HFCs") was conducted first, and as reported in the previous Quarterly Technical Progress Report, that Calpine test proved to be successful. Consequently, a "Phase Two" series of tracer tests has been proposed to follow, which will include as many as five single vapor-phase tracer field tests, plus a multiple tracer field test that simultaneously uses tritiated water in combination with both of the vapor-phase tracers.

\section{$\underline{\text { Results }}$}

Two separate tracer injection tests were conducted during the reporting period, with the results to date summarized as follows: 
1. On August 10, 1998 Unocal injected $240 \mathrm{Ibs}$ of $\mathrm{R} 134 \mathrm{a}\left(\mathrm{C}_{2} \mathrm{H}_{2} \mathrm{~F}_{4}\right)$ into Unocal well "BEF 42B-33", located in Section 33, T11N, R8W. Steam produced from 20 surrounding production wells has been periodically sampled and analyzed for tracer returns. By the end of September, 50 days after the tracer was injected, samples had been collected on 12 different days, and on each occasion from between a minimum of two up to a maximum of 17 different wells. Sample collections for this test are expected to be complete by the end of October. Measurable tracer returns have been recorded within a 5000 foot radius of the injection well, in 18 Unocal wells and two neighboring Calpine wells. First arrival times have varied from two to six days, while the time necessary to reach a maximum concentration has varied from three to as many as 30 days.

Additional active monitoring, as part of the overall program to assess the early effects of the recently introduced SEGEP operations, has included sample collection for determining any recent changes in either steam condensate or non-condensable gas chemistry. Those results will not be available until late October or early November, 1998. Unocal is also actively monitoring the physical parameters of the steam now being produced, including temperature, pressure, and flow rate. Temperatures have remained stable to date, while pressures and flow rates have increased, relative to the conditions that existed prior to the startup of SEGEP operations. A quantification of the total flow rate changes is not yet possible, owing to the lingering effects of the long periods of curtailed production that occurred between January and July, 1998.

2. On August 18, 1998 NCPA began the planned multiple tracer test by injecting into NCPA well P-1 (Section 1, T10N, R8W) $245 \mathrm{lbs}$ of R134a, followed immediately by 204 lbs of R23. During approximately the same time a 10 curie dose of tritium was introduced into the water being injected down well P-1. Sampling of steam from the most nearby production wells began that same day 8 hours after the first introduction of tracer material, and by the end of September (about 6 weeks later) 475 samples have been collected and analyzed from 34 different surrounding production wells. The return concentrations of R134a and R23, the "vapor-phase" tracers, and of tritium were determined on the day of injection (Day 1) and subsequently on Days 2, 3, 5, 8, 10, 14, $17,24,31$, and 38 in steam from between a minimum of three up to a maximum of 27 different wells on each occasion.

The preliminary results obtained to date in general indicate that the vapor-phase tracers have advanced faster and further from the injection well than has the tritium, with R23 being perhaps slightly the faster of the two different hydroflurocarbon compounds used. For example, at production well E-4 located 2,300 feet from P-1, the maximum concentration of R23 was measured on Day 3, the maximum for R134a was on Day 5, and the maximum measured tritium concentration was on Day 14. However, the results so far are not universally as systematic as in this example, and the possible causes for the different variations observed to date are still being evaluated. By Day 38, measurable tracer returns have been recorded up to 4,600 feet from the injection well for the vapor- 
phase tracers, and for tritium, up to 3,600 feet away. More results are to be obtained before a thorough understanding of the relative behavior of these tracers is developed and described.

3. In addition to the above activities, on September 22, 1998 Calpine (Joe Beall) presented at the Geothermal Resources Council Annual Meeting the technical paper titled "Evaluation of R134a as an Injection Water Tracer in the Southeast Geysers", authored by Joseph J. Beall (Calpine), Michael C. Adams (EGI) and Paul N. Hirtz (Thermochem).

\section{$\underline{\text { Future Plans }}$}

Unocal has plans for their second hydroflurocarbon vapor-phase tracer injection test to begin later this year, in their other well that injects water delivered by the SEGEP project.

NCPA is still monitoring the continued spreading of the tracers introduced in well P-1 in mid-August. Consequently, the timing of the second NCPA injection test is still yet to be determined, as it will have to await the dissipation of the tracers introduced in the P-1 test. That could possible be as late as early next year.

After the close of this quarterly reporting period, which ended September 30, 1998, on October $20^{\text {th }}$ Calpine injected $210 \mathrm{lbs}$ of R23 in their McKinley 1 well, located in Section $26, T 11 \mathrm{~N}, \mathrm{R} 8 \mathrm{~W}$. The results of this test are now actively being determined.

As mentioned in the previous progress report, the time lapse needed between successive uses of R134a and R23 within the SE Geysers area will be longer than initially planned, and that the additional tracer tests to be conducted will not all be completed by the end of this year. However, this should have no negative effect on the overall objectives of the project, nor on the results to be obtained.

Submitted by:

J.L. (Bill) Smith

Recipient Project Director

NCPA, Sr. Geologist 
Third QUARTERLY TECHNICAL PROGRESS REPORT- Dated January 28, 1999

(For the period October 1, 1998 through December 31, 1998)

\title{
Southeast Geysers Cooperative Tracer Evaluation and Testing Program, for the Purpose of Estimating the Efficiency of Injection
}

\author{
U.S. Department of Energy- Financial Assistance Award \#DE-FG07-98ID13616
}

\section{Introduction}

The Southeast Geysers Cooperative Tracer Evaluation Program is a joint project located in the SE part of The Geysers geothermal field, in Lake and Sonoma Counties, California. The project is a cooperative project jointly undertaken by the Northern California Power Agency (NCPA), Calpine Corporation, Unocal Geothermal, Thermochem Inc. and the Energy and Geoscience Institute. NCPA is acting as the lead party of this group for purposes of administering the DOE Financial Assistance Award.

A new generation of environmentally benign vapor-phase tracers is being used to estimate the degree to which injectate is being recovered following the significant increase of injected volumes within the Southeast Geysers. The significantly increased injection has resulted from the startup of Southeast Geysers Effluent Pipeline (SEGEP) operations, which have initially resulted in approximately doubling the amount of water available for injection within those portions of the Southeast Geysers reservoir operated by NCPA, Calpine, and Unocal.

An initial "Phase One" field evaluation of one of the two candidate hydroflurocarbon compounds ("HFCs") was conducted first, and as reported in the previous Quarterly Technical Progress Reports, that Calpine test proved to be successful. Consequently, a "Phase Two" series of tracer tests has followed, which will include as many as five single vapor-phase tracer field tests, plus the multiple tracer field test that simultaneously used tritiated water in combination with both of the vapor-phase tracers.

\section{$\underline{\text { Results }}$}

Continued sampling and evaluation was conducted for the two previous tracer injection tests separately begun by Unocal and NCPA in the previous reporting period, and Calpine initiated a new injection test in November, 1998. The results are summarized as follows: 
On August 18, 1998 NCPA began a multiple tracer test by injecting into NCPA well P-1 $245 \mathrm{lbs}$ of R134a and $204 \mathrm{lbs}$ of R23 over a period of 3 hours and 20 minutes. At approximately the same time a 13 curie dose (not a 10 curie dose, as previously reported) of tritium contained in $440 \mathrm{cc}$ of water was injected into P-1. Sampling of steam from the most nearby production wells began that same day, and by the end of December (about 19 weeks later) 547 samples had been collected and analyzed from 34 different surrounding production wells. The return concentrations of R134a and R23, the "vapor-phase" tracers, were first determined on the day of injection (Day 1) and last determined on October 13 (Day 57). Tritium concentrations have been determined for some wells as recently as December 7 (Day 112).

The preliminary results obtained to date indicate that the vapor-phase tracers have in general advanced faster and further from the injection well, and with a somewhat different distribution pattern, compared to tritium. Figure 1 shows the Tritium Recovery Curves for a selected group of 12 surrounding production wells, through October 20 (Day 64). The locations of these wells are shown in Figure 3, which illustrates the cumulative amount of tritium recovered by well through Day 79 (November 4, 1998). Figure 2 shows that $37 \%$ of the total amount of tritium injected had been recovered by Day 66 , which is noticeably less than the $75 \%$ recovery of R-134a and the $93 \%$ recovery of R-23 by Day 56. Figure 4 illustrates the R-23 Recovery Curves for 9 of the same 12 wells used in Figure 1, and a map of the cumulative recoveries through Day 56 is included as Figure 5. A comparison of the two cumulative recovery maps (Figures 3 and 5) demonstrates that the $\mathrm{R}-23$ vapor-phase tracer has moved preferentially northwesterly, while the Tritium has moved about as equally to the southeast as to the northwest. A number of factors are being evaluated to determine the probable reasons for this difference.

\section{Calpine Well McKinley-1 R-23 Tracer Test}

On October 20, 1998, 210 lbs of R-23 were injected into Calpine's McKinley-1 injection well. Figure 6 shows the cumulative known recovery based on sampling of those wells listed in Table 1. Figure 6 shows that by Day 30 the recovery curve has flattened to the extent that the extrapolated curve will reach a maximum of about $23 \%$ (about $44 \mathrm{lbs}$.). This result is somewhat surprising due to the fact that several other tracer tests in the Southeast Geysers (both tritium and freon) have resulted in cumulative recoveries of $60 \%$ or more.

Figure 7 shows a map of the maximum $\mathrm{R}-23$ concentration (in $\mathrm{ppm}_{\mathrm{w}}$ ) measured in each well sampled. The concentration (in computer scientific notation) is followed by a 
slash and then the day on which that sample was taken (Day 0 is the day of injection). For example, $8.2 \mathrm{E}-2 / 7$ represents a maximum concentration of $0.082 \mathrm{ppm}_{\mathrm{w}}$ for a sample taken on Day 7. The southern-most wells (956A-4, 958-7 and 958-14) were only sampled once and therefore may not represent peak values.

The reason for the low apparent cumulative recovery of R-23 from the McKinley-1 tracer test is uncertain. It is possible that tracer was produced in large quantities from wells which were outside the sampled area. The sample coverage, however, is believed to have been adequate (based on previous tests) to have prevented this, except perhaps in the extreme southwest part of Unit 13. Other explanations could include the separation of an early tracer spike, that could have been produced from a well during a period in which that well was not sampled.

\section{Calpine's Observed Changes in Flow Rates \& NCG Trends Due to SEGEP Injection}

Figure 8 shows a plot of the Combined Steam Flow Rate to PG\&E. Units $13 \& 16$ vs Time, and Figure 9 shows the molar noncondensible gas (NCG) to steam ratio plotted versus the steam flow rate for the Units 13 \& 16 steam. Since 1987, the NCG to steam ratio in the Units 13-16 area has increased systematically with decreasing steam flow, following the well-defined power curve illustrated in Figure 9. If the SEGEP Project had never been constructed and put into operation, extrapolation of the prior trends displayed in Figures 8 and 9 would suggest that by August 1998 the steam flow to Units 13 and 16 would probably have declined to about 2.4 million $\mathrm{lbs} / \mathrm{hr}$, and the NCG to steam ratio would have increased to about 13.7 moles of NCG per 10,000 moles of steam. However, because there has been an unprecedented increased rate of injection in the Units 13 and 16 area since SEGEP became fully operational in November 1997, major discontinuities have developed in both the steam flow rate and NCG concentration trends. In August 1998 the NCG was about $36 \%$ less than would have been predicted, at 8.77 moles of NCG per 10,000 moles of steam, and the steam flow rate was about $12.5 \%(300,000 \mathrm{lbs} / \mathrm{hr})$ more than would otherwise be expected.

Figures 10 and 11 (for Units 13 and 16, respectively) each show both steam flow rate and $\mathrm{H}_{2} \mathrm{~S}$ concentration plotted versus time. The two curves, in both graphs, are approximately mirror images of each other, indicating an inverse relationship between the steam flow rate and the $\mathrm{H}_{2} \mathrm{~S}$ concentration. This relationship holds from 1987 through 1997. In both units, however, the trend is abruptly terminated in 1998. Based on the tenyear trend, the decrease in flow rate to Unit 13 in 1998 should have been accompanied by a slight increase in $\mathrm{H}_{2} \mathrm{~S}$, but in fact the $\mathrm{H}_{2} \mathrm{~S}$ concentration actually decreased $18 \%$ from $120 \mathrm{ppm}$ to $98 \mathrm{ppm}$. (see Figure 10). At Unit 16 a somewhat similar 1998 discontinuity is seen in the $\mathrm{H}_{2} \mathrm{~S}$ trend, as the $\mathrm{H}_{2} \mathrm{~S}$ concentration is significantly less than would have been previously predicted. The only reasonable explanation for these departures from the well 
established trends is that the enormous increase in injection rates since November 1997 has had a major dilution effect on the noncondensible gas concentrations.

It is reasonable to expect that both total $\mathrm{NCG}$ and $\mathrm{H}_{2} \mathrm{~S}$ will begin to rise again. The combined Units 13-16 trend (of NCG plotted against steam flow rate) may rise along a curve parallel to the prior-established trend, as indicated by the dashed line on Figure 9. Or alternatively, in the future it may be possible that their rate of increase will be reduced from that previously established trend, if the percentage of injection-derived steam continues to increase, as is the present expectation based on a continuation of full SEGEP operations.

\section{Unocal Well BEF42B-33 R-134a Tracer Injection Test}

Unocal GTO-sponsored activity during the $4^{\text {th }}$ Quarter reporting period consisted of completion of a tracer study on BEF42B-33, one of two Unocal injection wells being used to inject SEGEP water. Tracer testing had been initiated in Unocal well BEF42B-33 on August 10,1998 with the introduction of $240 \mathrm{lbs}$ of $\mathrm{R} 134 \mathrm{a}\left(\mathrm{C}_{2} \mathrm{H}_{2} \mathrm{~F}_{4}\right)$. Subsequently, sampling of steam from well groups ranging from 4 to 17 in number has occurred. Sampling frequency changed from once per day in early testing to approximately once per two weeks as the test neared completion. The test was concluded on October 6, 1998.

Data collected from the BEF42B-33 tracer study indicate that injected waters can be rapidly converted to steam, move quickly in the reservoir, and are recovered in significant quantity over relatively short time periods. Figure 12 presents the recovery curves for those production wells that experienced the greatest returns during the test. First arrival times less than or equal to four days was observed in several wells. Significant tracer return was observed in GDC29 after only two days, meaning that injected tracer material had been flashed to steam and was transported over 2,000 feet laterally (see Figure 13) within 48 hours. The highest recovery concentration occured in well GDCF14A-27 on Day 4 following tracer injection. This well is laterally displaced from the injection well by more than 3,000 feet, and its response demonstrates the rapid high-volume conversion to steam and rapid transport. Integration of the return curve data (Figure 12) with appropriate production well flow data indicates that $59 \%$ of the injected tracer was recovered during the two month test, as illustrated by Figure 14.

\section{Future Plans}

Unocal has plans for their second hydroflurocarbon vapor-phase tracer injection test to begin later this year, probably about June, in Well DV-11 which is their other well that injects water delivered by the SEGEP project. 
NCPA is still monitoring the continued spreading of the tracers introduced in well P-1 in mid-August. The timing of the second NCPA injection test is scheduled for late spring 1999 , although which injection well will be tested has not yet been finally decided.

Calpine has tentatively identified their Well $956-1$ as the probable injection well to be used for their final tracer test to be conducted within this present GTO program. That test is similarly scheduled to begin in early summer, 1999.

Submitted by:

J.L. (Bill) Smith

Recipient Project Director

NCPA, Sr. Geologist 


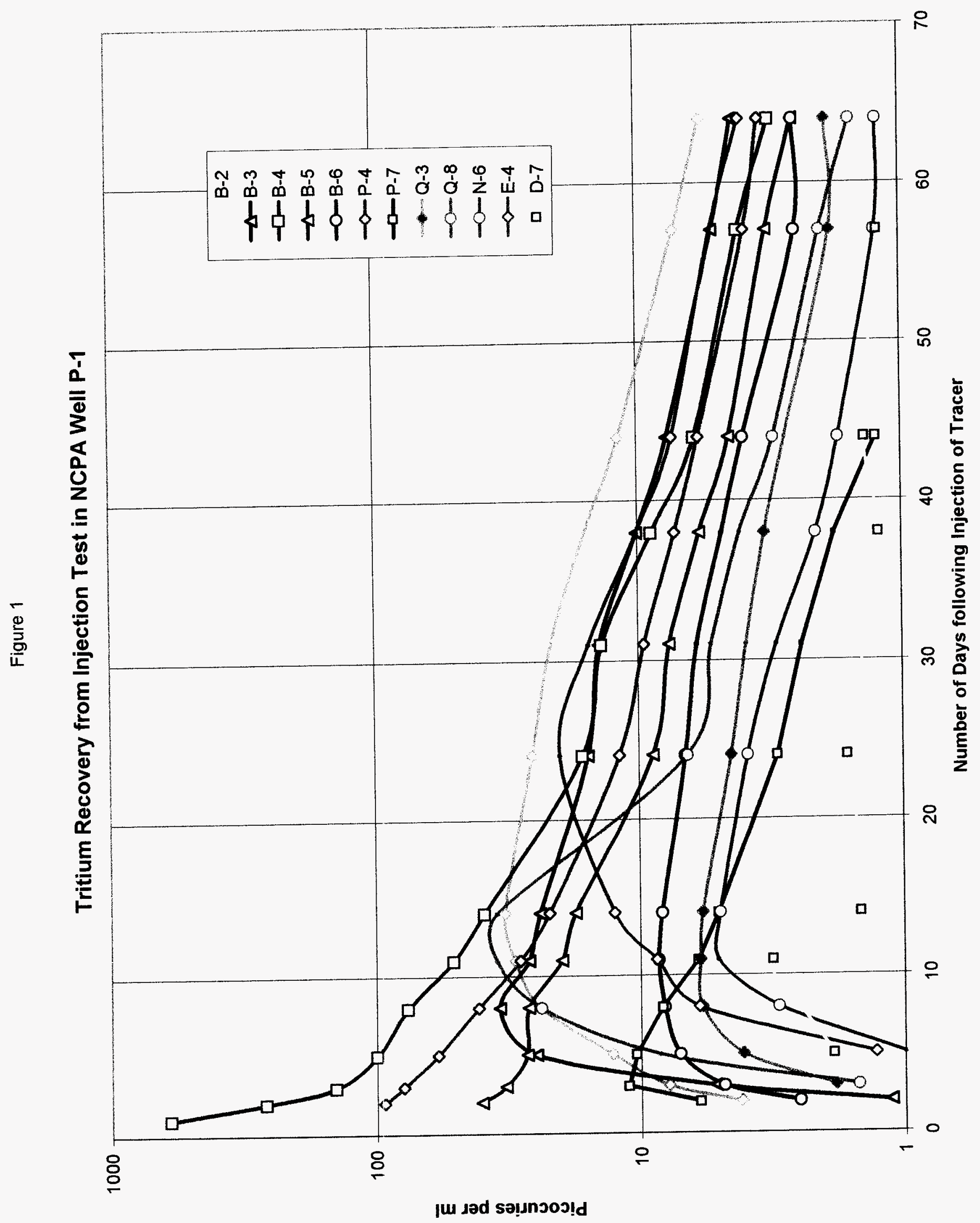




\section{Cumulative Recovery of Multiple Tracers Injected in NCPA well P-1}

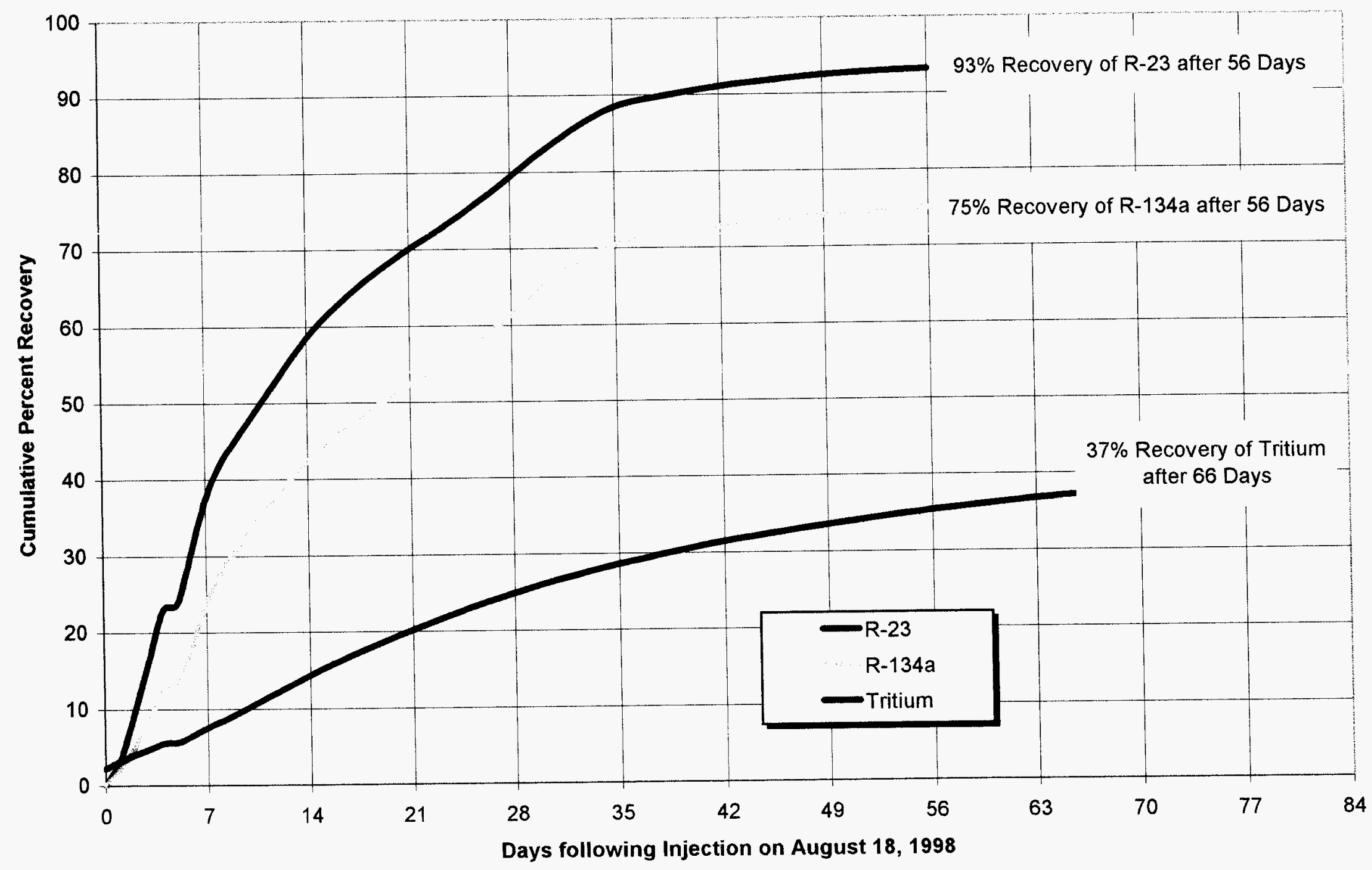


Figure 3- NCPA P-1 Tracer Injection Test

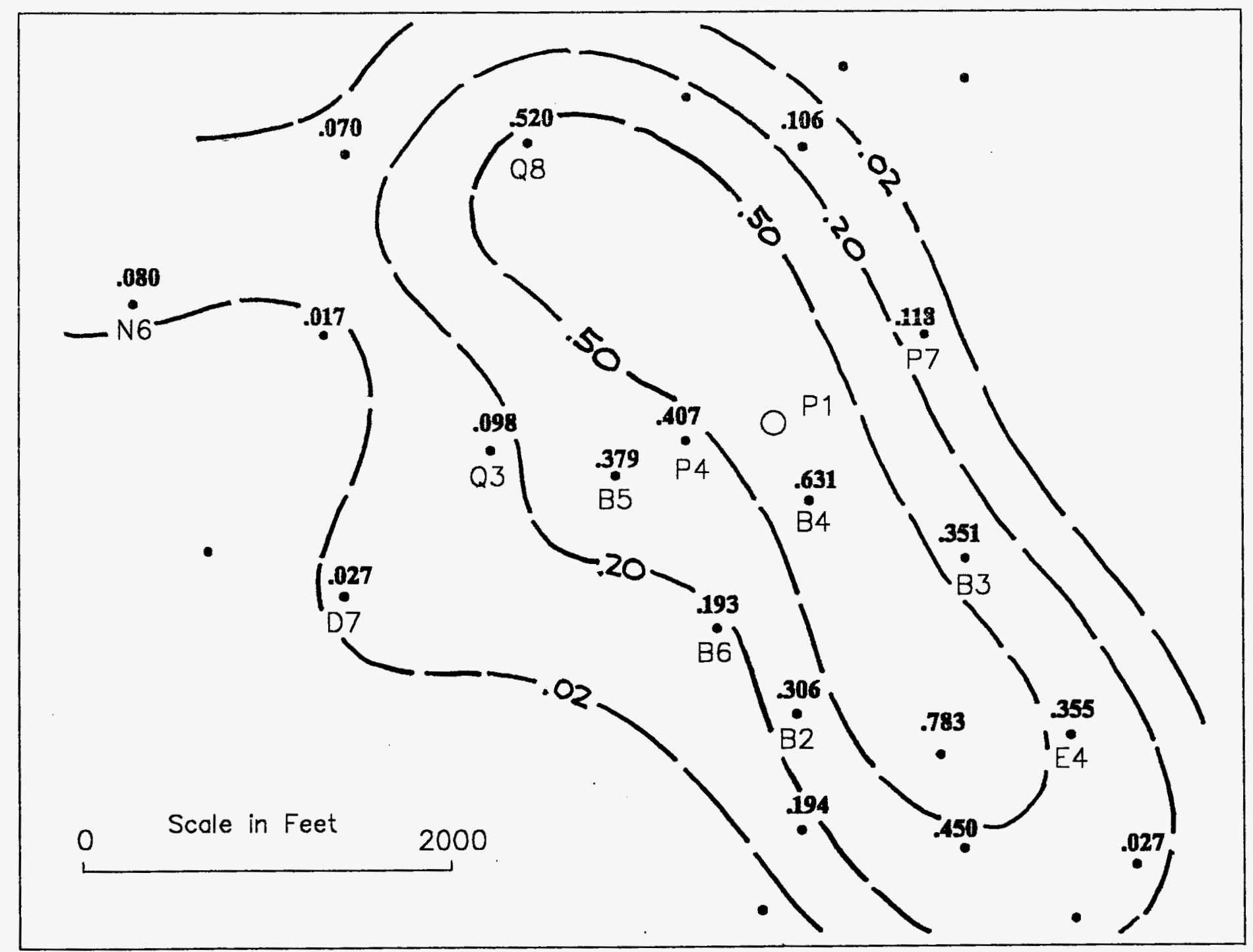

Cumulative Recovery of Tritium (in Curies) Day 79 following August 18, 1998 Injection 


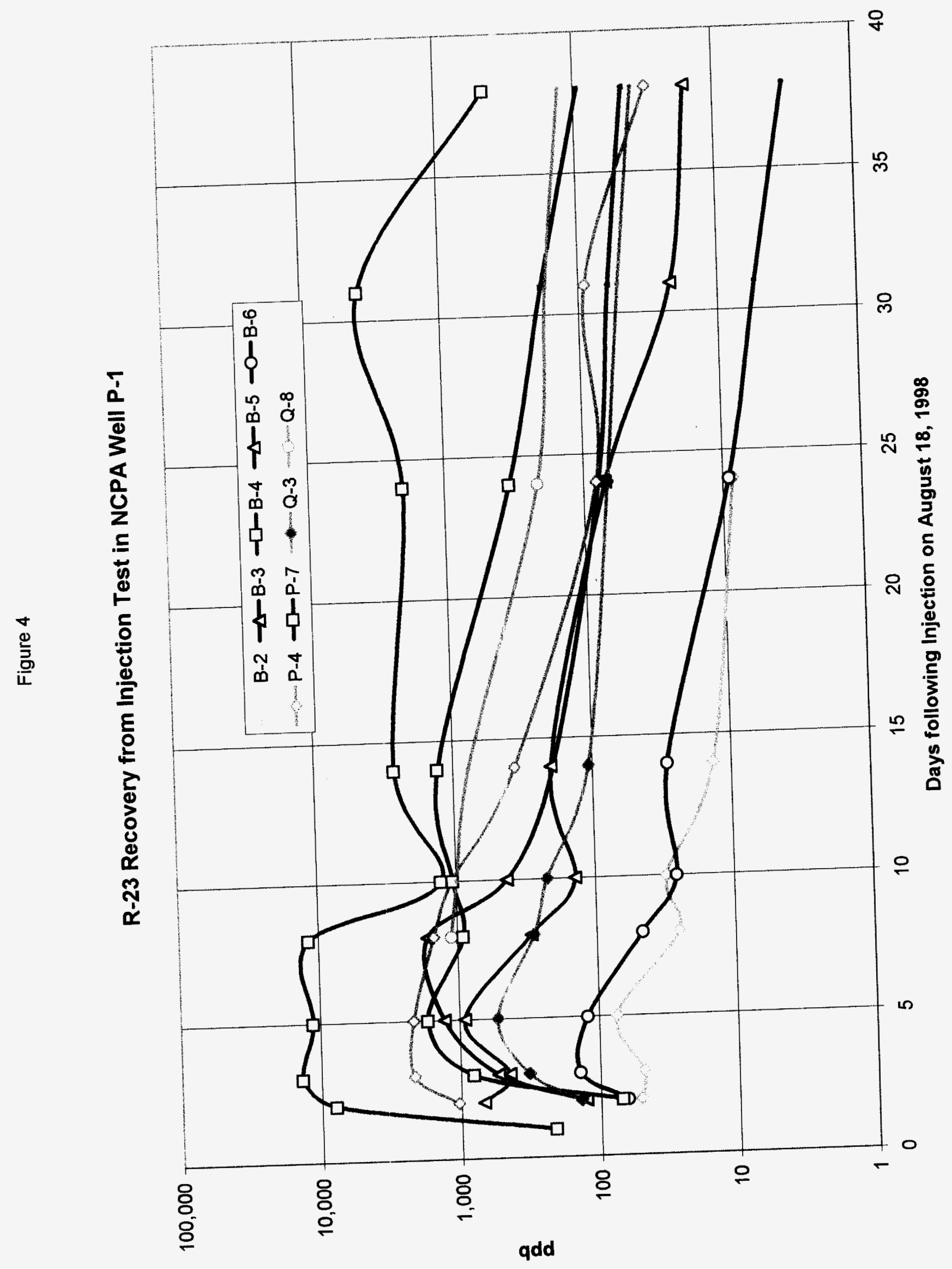


Figure 5- NCPA P-1 Tracer Injection Test

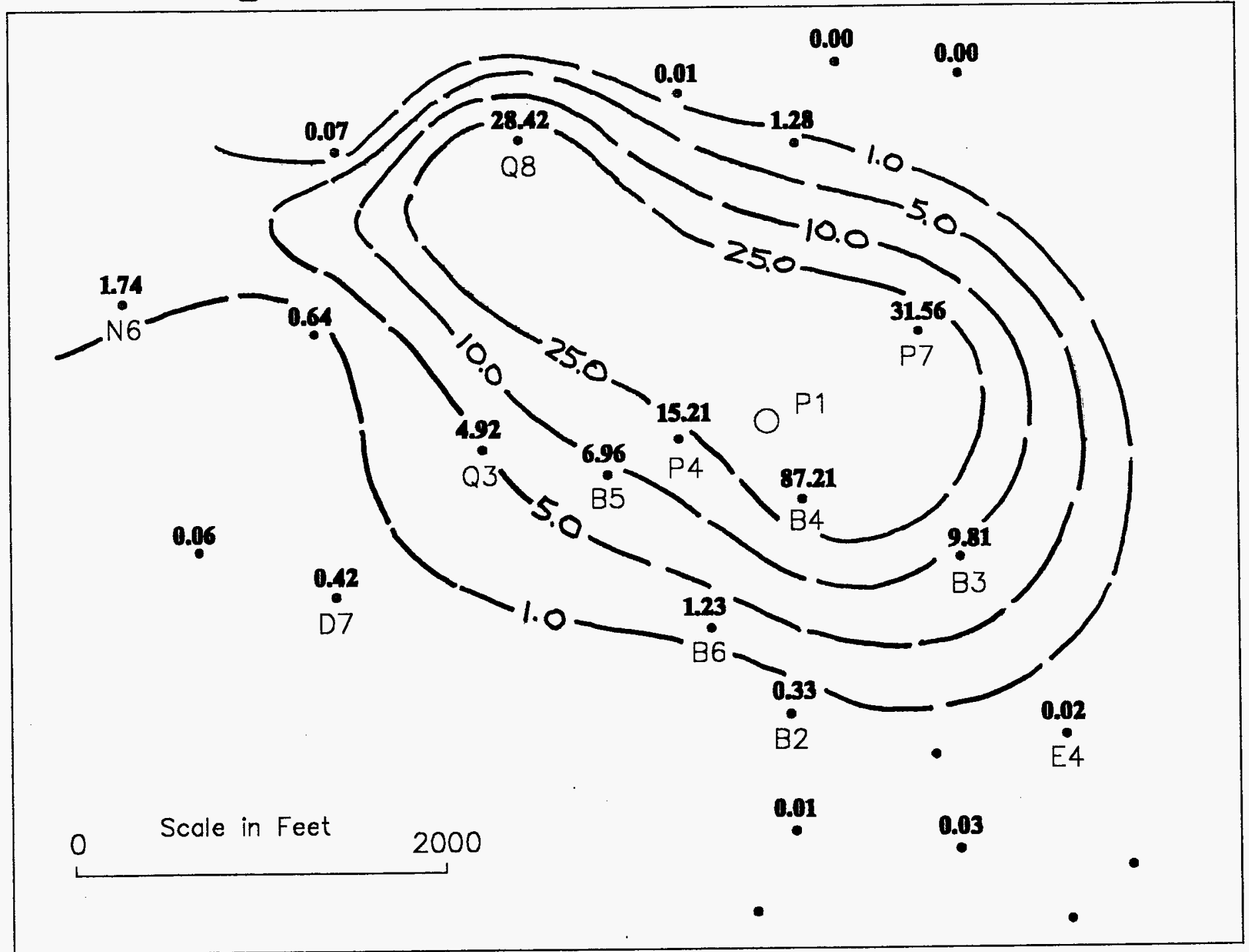

Cumulative Recovery of R-23 Tracer (in Pounds) Day 56 following August 18, 1998 Injection 


\section{FIGURE 6}

\section{MCKINLEY 1 R23 TRACER TEST}

CUMULATIVE RECOVERY OF R23

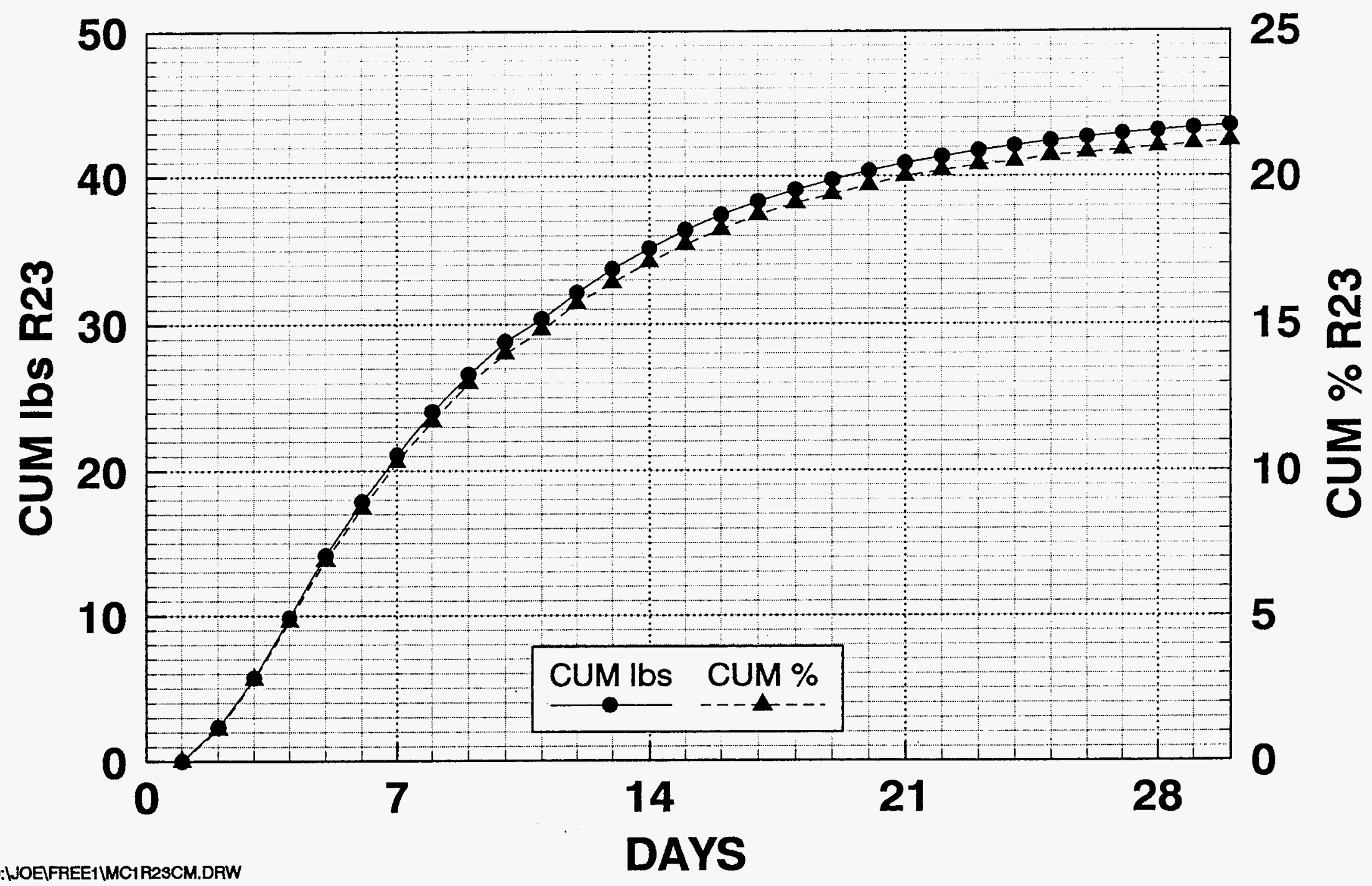




\section{TABLE 1}

MCK-1 R23 TRACER TEST

\begin{tabular}{|c|c|c|c|c|c|c|c|c|c|}
\hline & $\begin{array}{l}\text { 10/20/98 } \\
\text { DAYO }\end{array}$ & $\begin{array}{l}\text { 10/21/98 } \\
\text { DAY } 1\end{array}$ & $\begin{array}{l}\text { 10/23/98 } \\
\text { DAY } 3\end{array}$ & $\begin{array}{l}\text { 10/24/98 } \\
\text { DAY } 4\end{array}$ & $\begin{array}{l}\text { 10/27/98 } \\
\text { DAY } 7\end{array}$ & $\begin{array}{l}\text { 10/30/98 } \\
\text { DAY 10 }\end{array}$ & $\begin{array}{c}11 / 5 / 98 \\
\text { DAY } 16\end{array}$ & $\begin{array}{l}11 / 12 / 98 \\
\text { DAY } 23\end{array}$ & $\begin{array}{l}\text { 11/19/98 } \\
\text { DAY } 30\end{array}$ \\
\hline TH-10 & ND & 9.85E-04 & $7.96 \mathrm{E}-01$ & & 5.36E-01 & & 1.39E-01 & 3.76E-02 & $2.98 E-02$ \\
\hline$\overline{T H-1}$ & ND & ND & ND & & & & & $6.10 \mathrm{E}-03$ & \\
\hline$M C-12$ & ND & $3.69 \mathrm{E}-04$ & $7.88 \mathrm{E}-01$ & & 7.94E-01 & & $1.01 \mathrm{E}-01$ & & $1.68 \mathrm{E}-02$ \\
\hline$M C-13$ & ND & ND & $8.10 \mathrm{E}-02$ & & $1.38 E-01$ & $1.08 \mathrm{E}-01$ & & $1.36 \mathrm{E}-02$ & \\
\hline$M C-9$ & & $2.54 E-03$ & $6.27 E-01$ & & $3.06 E-01$ & & $1.60 \mathrm{E}-01$ & & $2.70 E-02$ \\
\hline MC-11 & & $1.27 E-04$ & 5.08E-02 & & $6.81 E-02$ & & $1.90 \mathrm{E}-02$ & & $4.10 E-03$ \\
\hline TH-3 & & & ND & & & & & $4.60 \mathrm{E}-03$ & \\
\hline ABEL-1 & & & ND & & ND & & ND & & \\
\hline MLN-7 & & & 5.67E-03 & & $6.63 E-03$ & $3.12 E-03$ & & & \\
\hline TH-6 & & & ND & & & & & & \\
\hline MCK-3 & & & $1.43 \mathrm{E}-02$ & & $1.40 E-01$ & $3.40 E-01$ & & $7.84 \mathrm{E}-02$ & $5.28 E-02$ \\
\hline MCK-10 & & & $7.06 \mathrm{E}-02$ & & $1.44 \mathrm{E}-01$ & $1.33 E-01$ & & & $6.19 E-03$ \\
\hline MCK-15 & & & & $5.91 \mathrm{E}-02$ & 8.21E-02 & $6.08 E-02$ & & & $4.24 E-03$ \\
\hline MLM-4 & & & & & ND & & & & \\
\hline $958-5$ & & & & & ND & & & & \\
\hline $958-10$ & & & & & ND & & & & bottle broke \\
\hline $956 A-5$ & & & & & $1.70 E-02$ & & $2.94 E-02$ & $1.25 E-02$ & \\
\hline BAR-6 & & & & & ND & & & & \\
\hline $958-13$ & & & & & & 8.27E-03 & & 4.08E-03 & \\
\hline $958-11$ & & & & & & $6.50 E-04$ & & & \\
\hline $956 A-4$ & & & & & & $4.35 \mathrm{E}-03$ & & & \\
\hline $958-7$ & & & & & & & $3.03 E-03$ & & \\
\hline WOLFE-1 & & & & & & & ND & & \\
\hline EFFU-1 & & & & & & & ND & & \\
\hline $958-14$ & & & & & & & & & $1.71 E=03$ \\
\hline & & & & & & & & & \\
\hline & & & & & & & & & \\
\hline
\end{tabular}




\section{FIGURE 7}

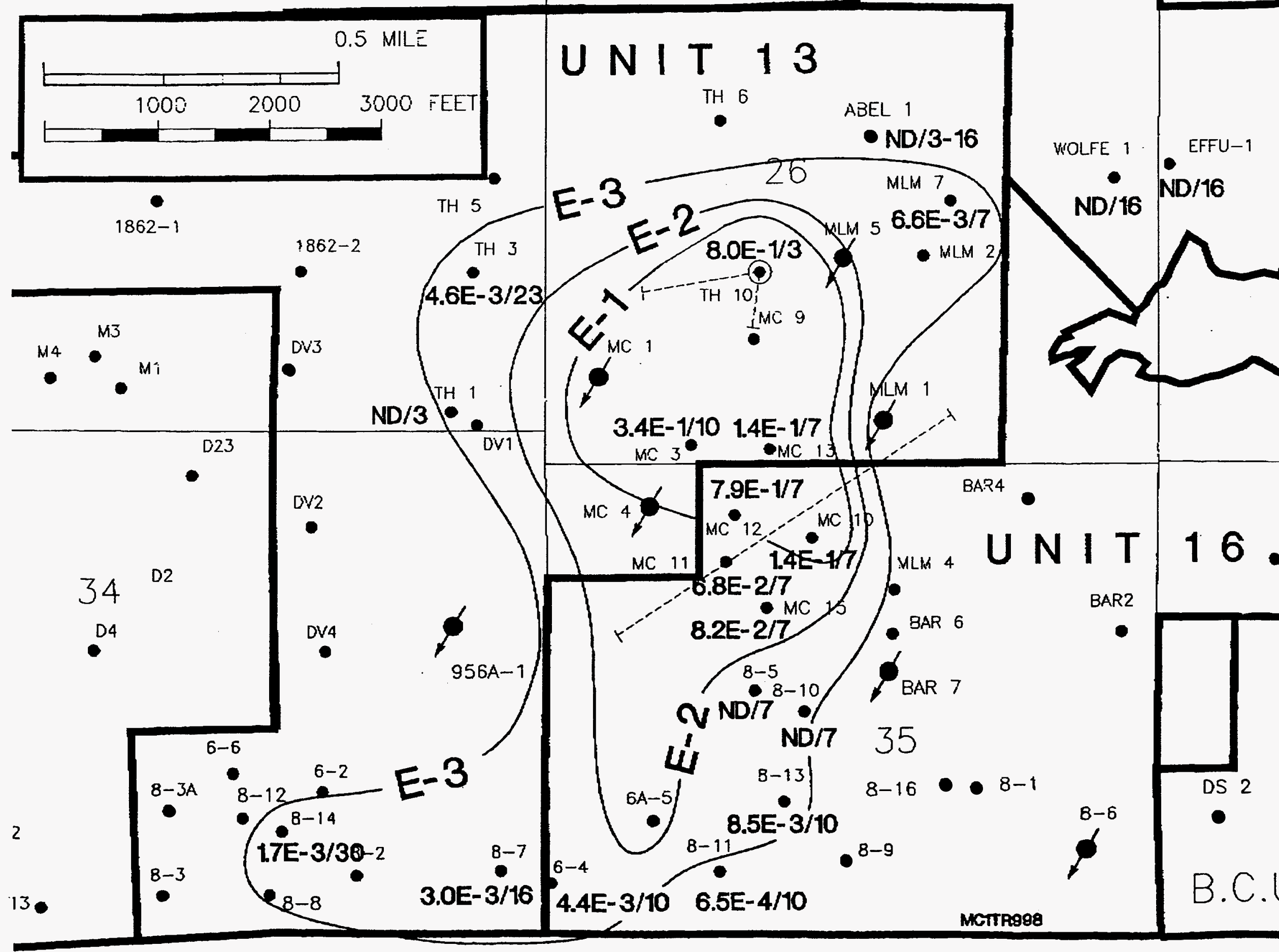




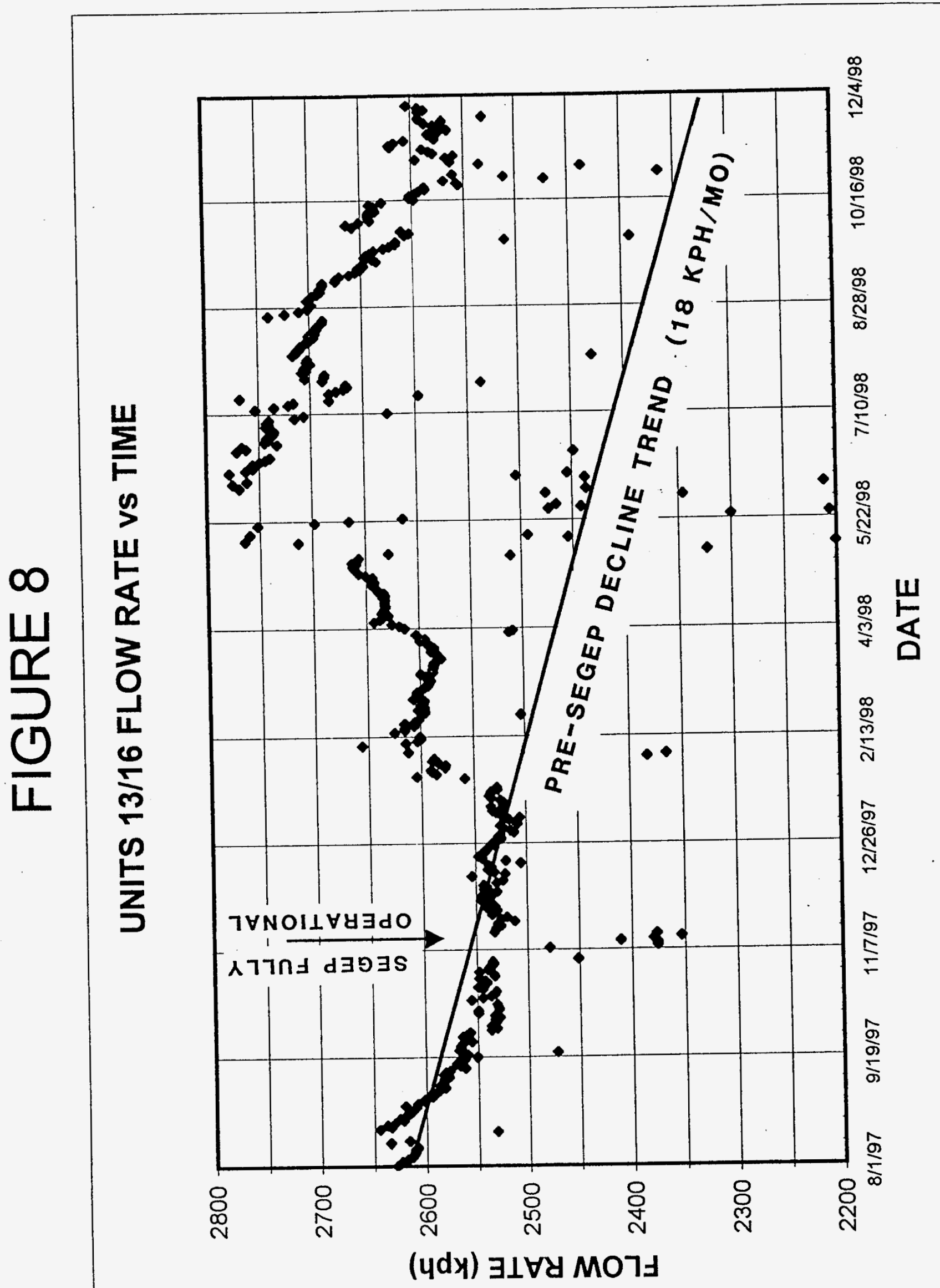




\section{FIGURE 9}

\section{TOTAL FLOW RATE vS NCG TO STEAM RATIO UNITS 13 and 16}

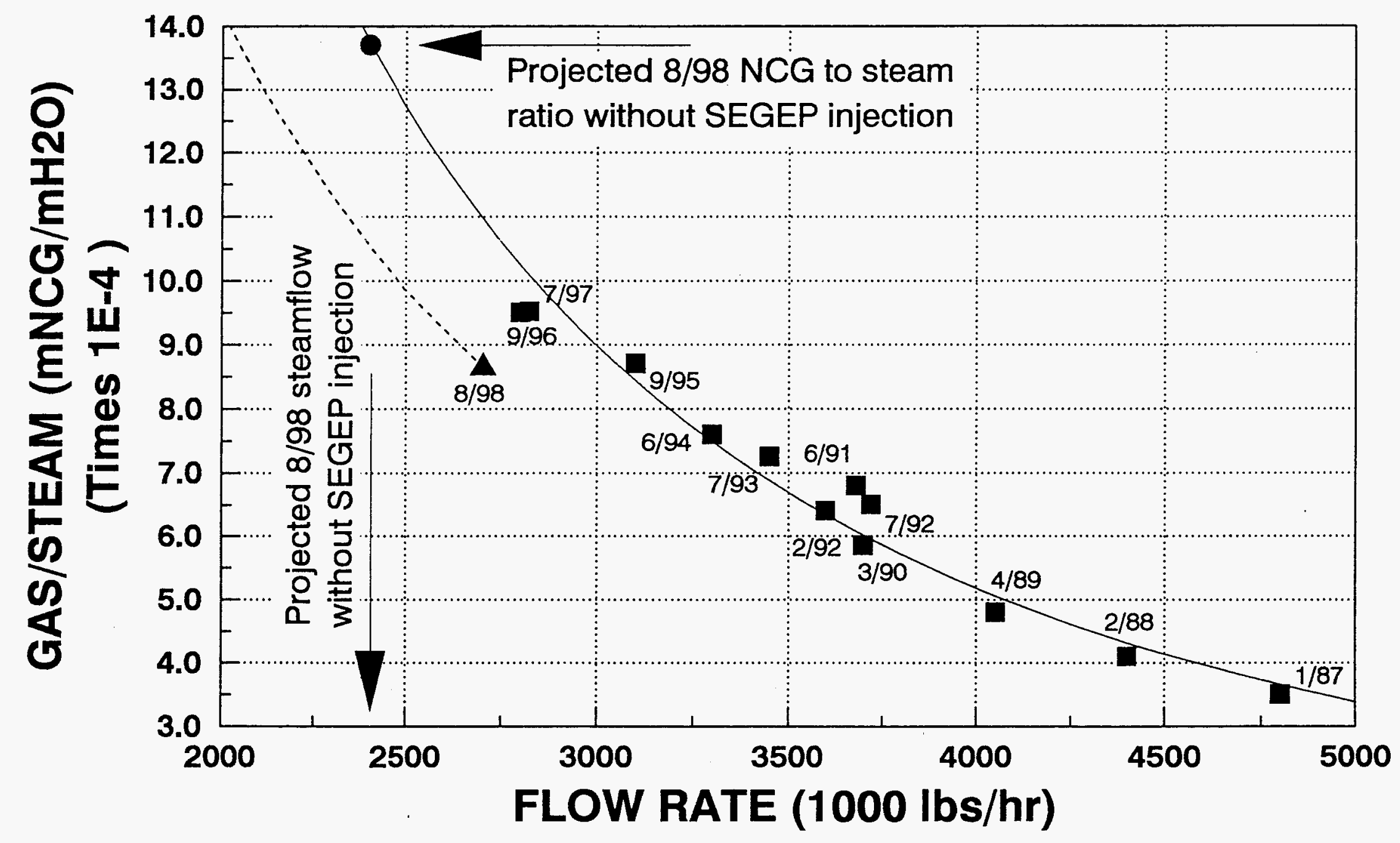




\section{FIGURE 10}

\section{UNIT 13 STEAM FLOW RATE AND MASS RATIO OF H2S TO STEAM VS TIME}

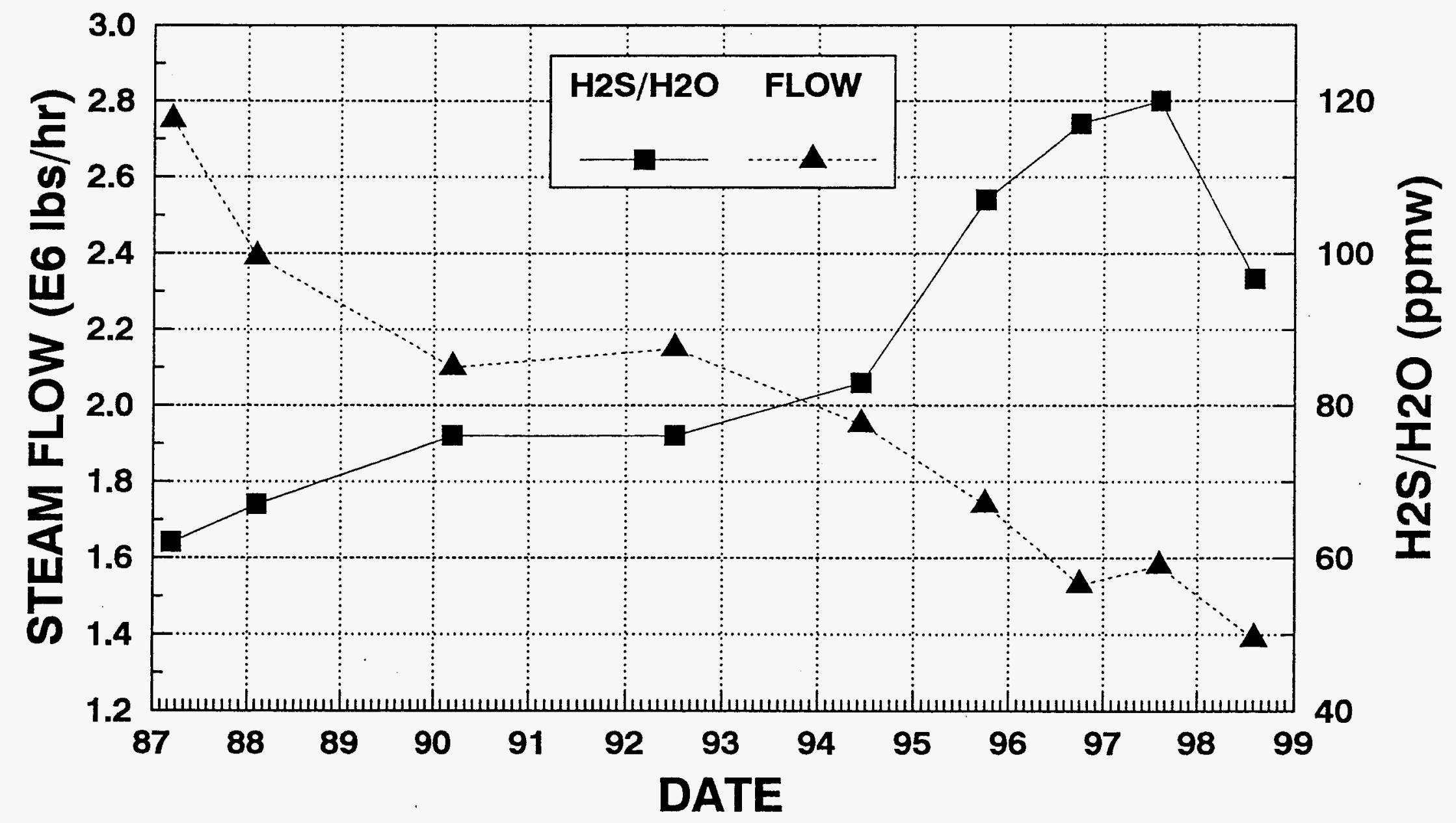


FIGURE 11

\section{UNIT 16 STEAM FLOW RATE AND MASS RATIO OF H2S TO STEAM VS TIME}

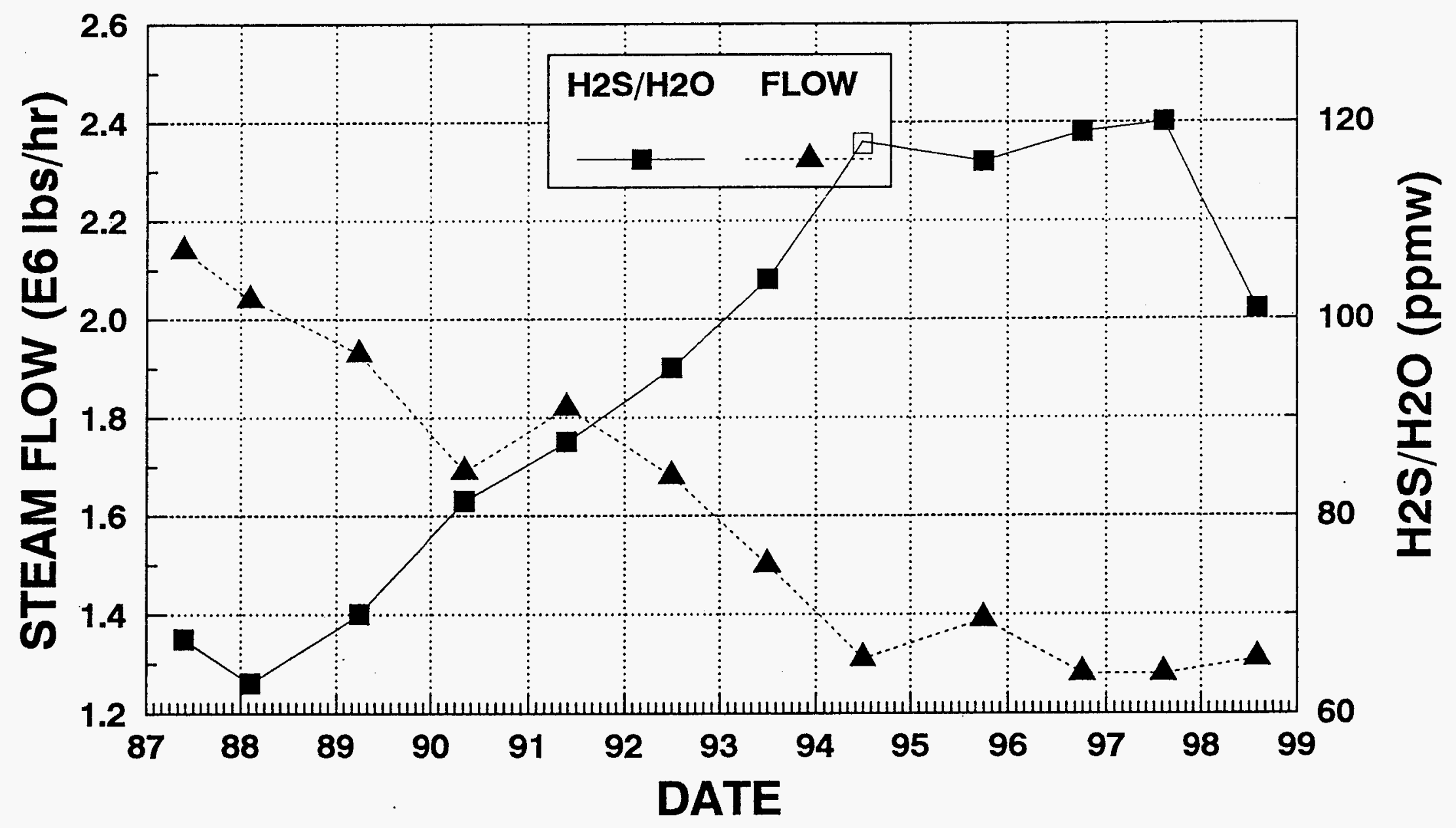




\section{Greatest Returns 42B-33 Tracer Test}

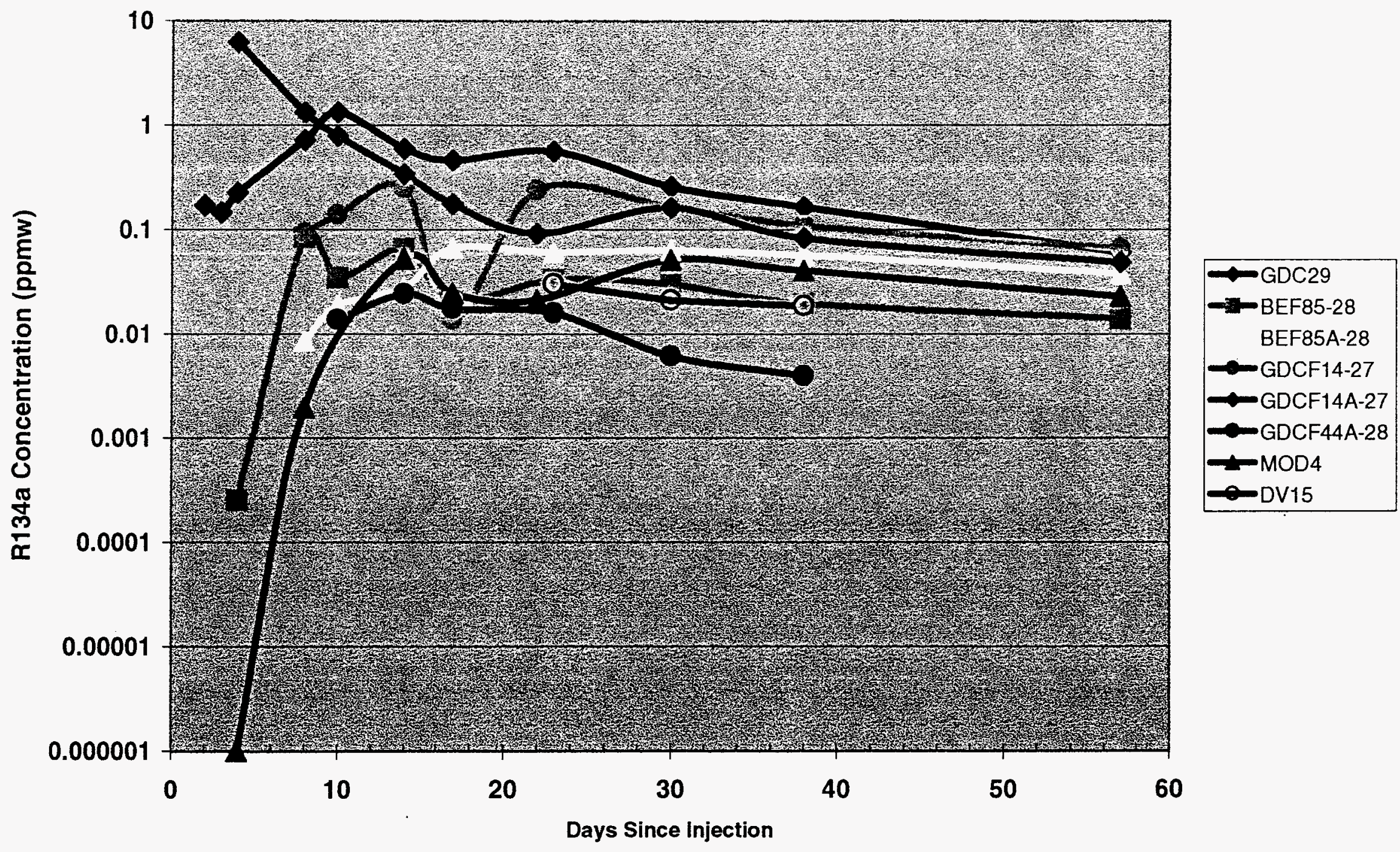

Figure 12 Tracer recovery in wells having the greatest returns 


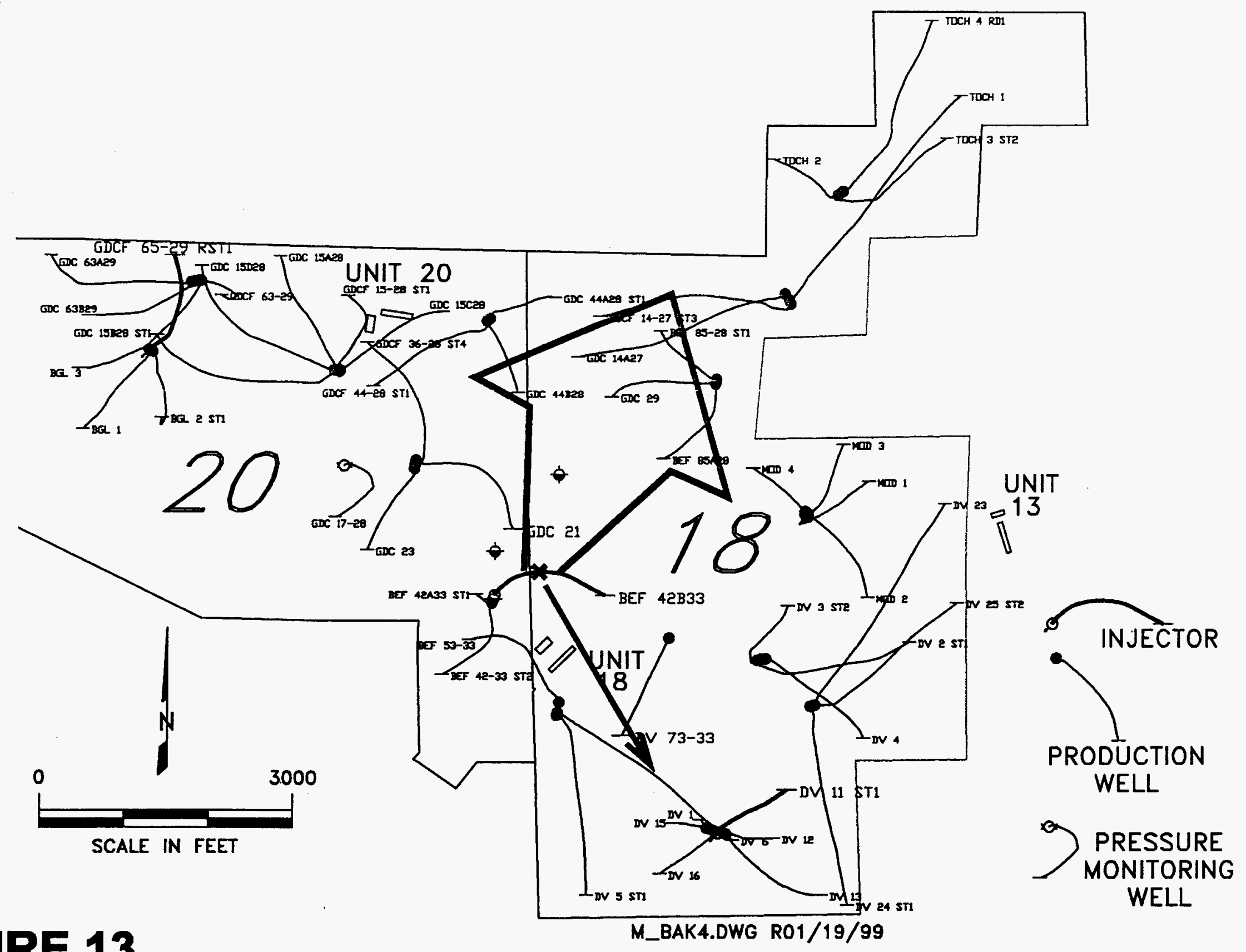

FIGURE 13.

M_BAK4.DWG R01/19/99 


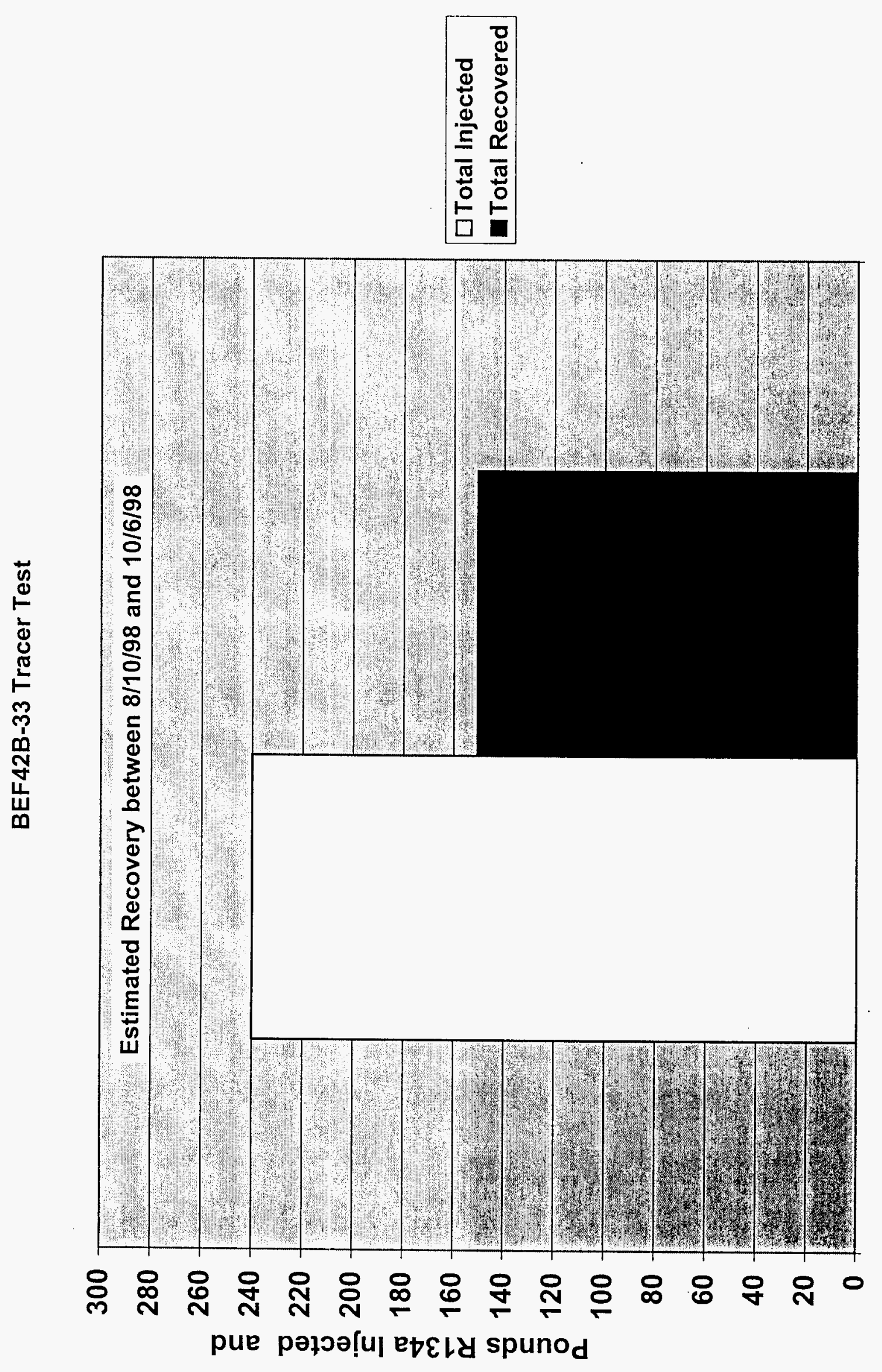

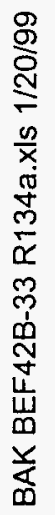

$\infty$
0
$\frac{0}{0}$
$\frac{1}{0}$
$\frac{0}{6}$
$\frac{1}{0}$

న్య

$\frac{0}{\infty}$

$\frac{1}{0}$

莕

궁

d)

ठ용

음

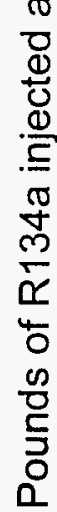

$\frac{7}{5}$ 
Fourth QUARTERLY TECHNICAL PROGRESS REPORT- Dated April 29, 1999

(For the period January 1, 1999 through March 31, 1999)

\section{Southeast Geysers Cooperative Tracer Evaluation and Testing Program, for the Purpose of Estimating the Efficiency of Injection}

U.S. Department of Energy- Financial Assistance Award \#DE-FG07-98ID13616

\section{Introduction}

The Southeast Geysers Cooperative Tracer Evaluation Program is a joint project located in the SE part of The Geysers geothermal field, in Lake and Sonoma Counties, California. The project is a cooperative project jointly undertaken by the Northern California Power Agency (NCPA), Calpine Corporation, Unocal Geothermal, Thermochem Inc. and the Energy and Geoscience Institute. NCPA is acting as the lead party of this group for purposes of administering the DOE Financial Assistance Award.

A new generation of environmentally benign vapor-phase tracers is being used to estimate the degree to which injectate is being recovered following the significant increase of injected volumes within the Southeast Geysers. The significantly increased injection has resulted from the startup of Southeast Geysers Effluent Pipeline (SEGEP) operations, which have initially resulted in approximately doubling the amount of water available for injection within those portions of the Southeast Geysers reservoir operated by NCPA, Calpine, and Unocal.

An initial "Phase One" field evaluation of one of the two candidate hydroflurocarbon compounds ("HFCs") was conducted first, and as reported in the previous Quarterly Technical Progress Reports, that Calpine test proved to be successful. Consequently, a "Phase Two" series of tracer tests has followed, which will include as many as five single vapor-phase tracer field tests, plus the multiple tracer field test that simultaneously used tritiated water in combination with both of the vapor-phase tracers.

\section{$\underline{\text { Results }}$}

Continued sampling and evaluation was conducted for the previous tracer injection test begun by NCPA in the previous reporting period, and Calpine initiated a new injection test in February, 1999. The results are summarized as follows: 


\section{NCPA Well P-1 Multiple Tracer Injection Test}

On August 18, 1998 NCPA began a multiple tracer test by injecting into NCPA well P-1 245 lbs of R134a and 204 lbs of R23 over a period of 3 hours and 20 minutes. At approximately the same time a 13 curie of tritium contained in $440 \mathrm{cc}$ of water was injected into P-1. Sampling of steam from the most nearby production wells began that same day, and by the end of December (about 19 weeks later) 547 samples had been collected and analyzed from 34 different surrounding production wells. The return concentrations of R134a and R23, the "vapor-phase" tracers, were first determined on the day of injection (Day 1) and last determined on October 13 (Day 57). Tritium concentrations were determined for 13 wells on January 14, 1999 (Day 150), completing the sampling and analysis work for this test.

The results of this test indicate that the vapor-phase tracers have in general advanced faster and further from the injection well, and with a somewhat different distribution pattern, compared to tritium. About $40 \%$ of the total amount of tritium injected had been recovered by Day 150 , which is noticeably less than the $75 \%$ recovery of R-134a and the $93 \%$ recovery of R-23 by Day 56 . A comparison of cumulative recovery maps demonstrates that the vapor-phase tracers moved preferentially northwesterly, while the Tritium has moved about as equally to the southeast as to the northwest. A number of factors are being evaluated to determine the probable reasons for this difference. Of primary importance is the fact that the area to the south and southeast of P-1 is less depleted and has higher reservoir pressures, while the area to the northwest of P-1 has lower pressures and is relatively high in super heat.

\section{Calpine Well 956A-1 Tracer Test}

On February 23, 1999244.4 lbs of R-134a were injected into Calpine's 956A-1 injection well. Figure 1 shows the Day 8 recovery concentrations. For the preliminary data reviewed to date, it appears that the cumulative recovery of tracer for this test will probably not exceed 27 to $30 \%$, similar to what has been recently experienced for the R23 tracer test in Calpine Well McKinley-1.

Submitted by:

\section{Borcsinix}

J.L. (Bill) Smith

Recipient Project Director

NCPA, Sr. Geologist 


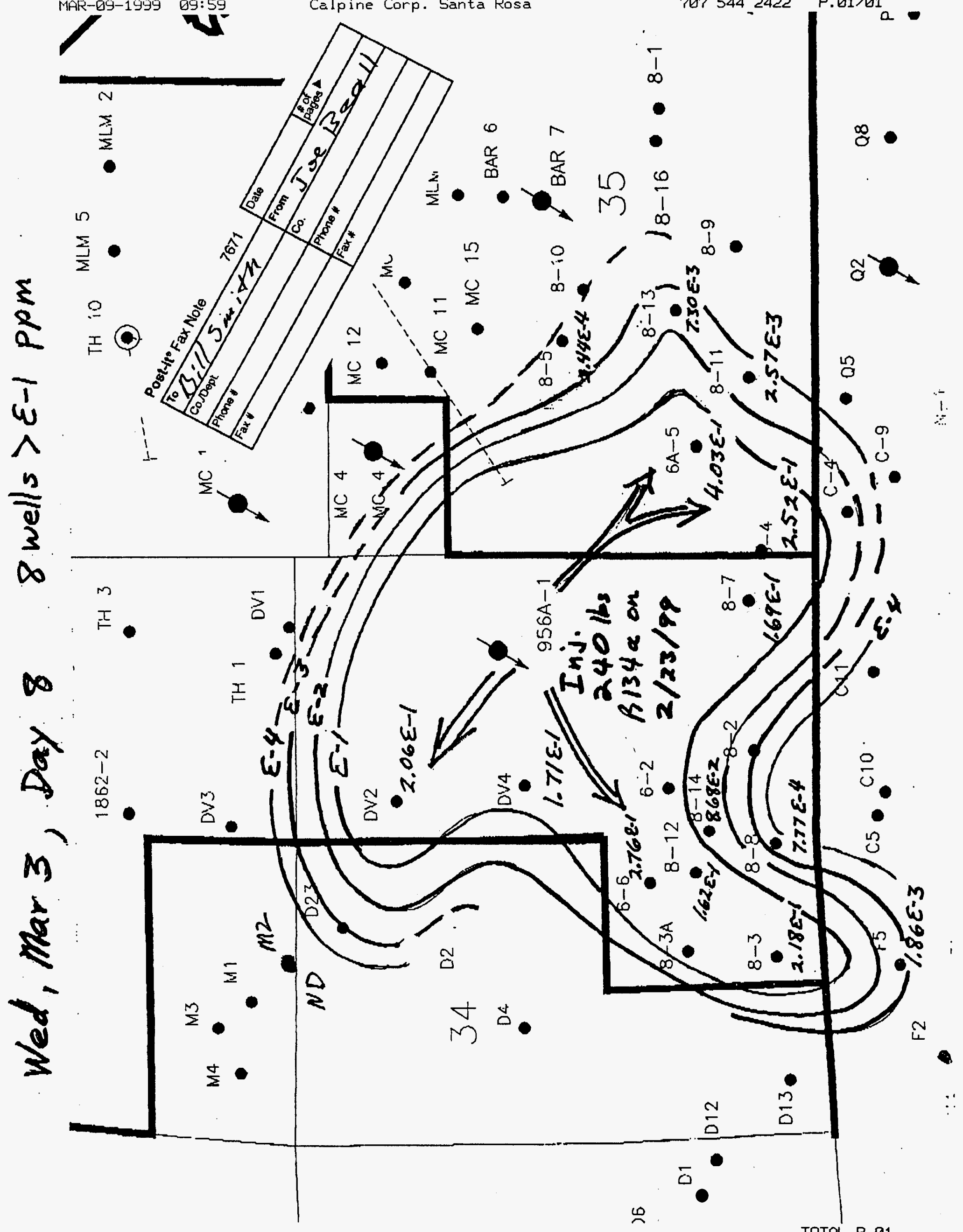

TOTRL P.01 
Fifth QUARTERLY TECHNICAL PROGRESS REPORT- Dated July 26, 1999

(For the period April 1, 1999 through June 30, 1999)

\section{Southeast Geysers Cooperative Tracer Evaluation and Testing Program, for the Purpose of Estimating the Efficiency of Injection}

U.S. Department of Energy- Financial Assistance Award \#DE-FG07-98ID13616

\section{Introduction}

The Southeast Geysers Cooperative Tracer Evaluation Program is a joint project located in the SE part of The Geysers geothermal field, in Lake and Sonoma Counties, California. The project is a cooperative project jointly undertaken by the Northern California Power Agency (NCPA), Calpine Corporation, Unocal Geothermal, Thermochem Inc. and the Energy and Geoscience Institute. NCPA is acting as the lead party of this group for purposes of administering the DOE Financial Assistance Award.

A new generation of environmentally benign vapor-phase tracers is being used to estimate the degree to which injectate is being recovered following the significant increase of injected volumes within the Southeast Geysers. The significantly increased injection has resulted from the startup of Southeast Geysers Effluent Pipeline (SEGEP) operations, which have initially resulted in approximately doubling the amount of water available for injection within those portions of the Southeast Geysers reservoir operated by NCPA, Calpine, and Unocal.

An initial "Phase One" field evaluation of one of the two candidate hydroflurocarbon compounds ("HFCs") was conducted first, and as reported in the previous Quarterly Technical Progress Reports, that Calpine test proved to be successful. Consequently, a "Phase Two" series of tracer tests has followed, which has so far included four single vapor-phase tracer field tests, plus the multiple tracer field test that simultaneously used tritiated water in combination with both of the vapor-phase tracers.

\section{$\underline{\text { Results }}$}

The most recent injection test was begun in February 1999, and the results evaluated during this reporting period are summarized as follows: 


\section{Calpine Well 956A-1 Tracer Test}

On February 23, 1999244.4 lbs of R-134a were injected into Calpine's 956A-1 injection well. The water injection rate was $1380 \mathrm{gpm}$ while tracer was metered into the water at about $1.3 \mathrm{lbs}$./minute. This resulted in a tracer concentration in the injected water of 115 ppm.

Production wells were sampled periodically for 52 days, to April 15 . Wells producing significant amounts of tracer peaked in concentration between days 4 and 10 (Figure 1). The highest concentration, 0.5 ppmw, was obtained for two wells, 956A-6 and D\&V4. These peak concentrations occur as early spikes in the R134a concentration versus time plots (Figure 1).

Figures 2 and 3 are contour maps of produced steam R134a concentration on days 2 and 8 , respectively. A comparison of the two maps shows that the general trend of tracer movement and distribution was already well established on day 2 . Table 1 summarizes all of the analytical data for this test.

Figures 2 and 3 indicate that tracer movement was to the southwest, northwest and southeast. Strong movement of injection-derived-steam to the southwest from 956A-1 has been previously well documented by steam chemistry for many years.

Cumulative tracer recovery versus time is graphed in Figure 4 . The plot indicates that recovery will probably reach $24 \%$. This is very close to the value obtained from the earlier McKinley-1 R23 test that was begun on October 20, 1998. In reality, most of the tracer will ultimately be produced, but because the tracer material is disseminated into a very large quantity of diluting water it is therefore recovered very slowly at low concentrations.

\section{Future Plans}

Calpine began a new test on July 15, 1999 that will be discussed in the next quarterly report.

Submitted by:

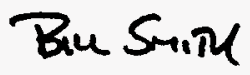

J.L. (Bill) Smith

Recipient Project Director

NCPA, Sr. Geologist 
FIGURE 1

\section{6-1 R134a TRACER TEST [R134a] vs TIME}

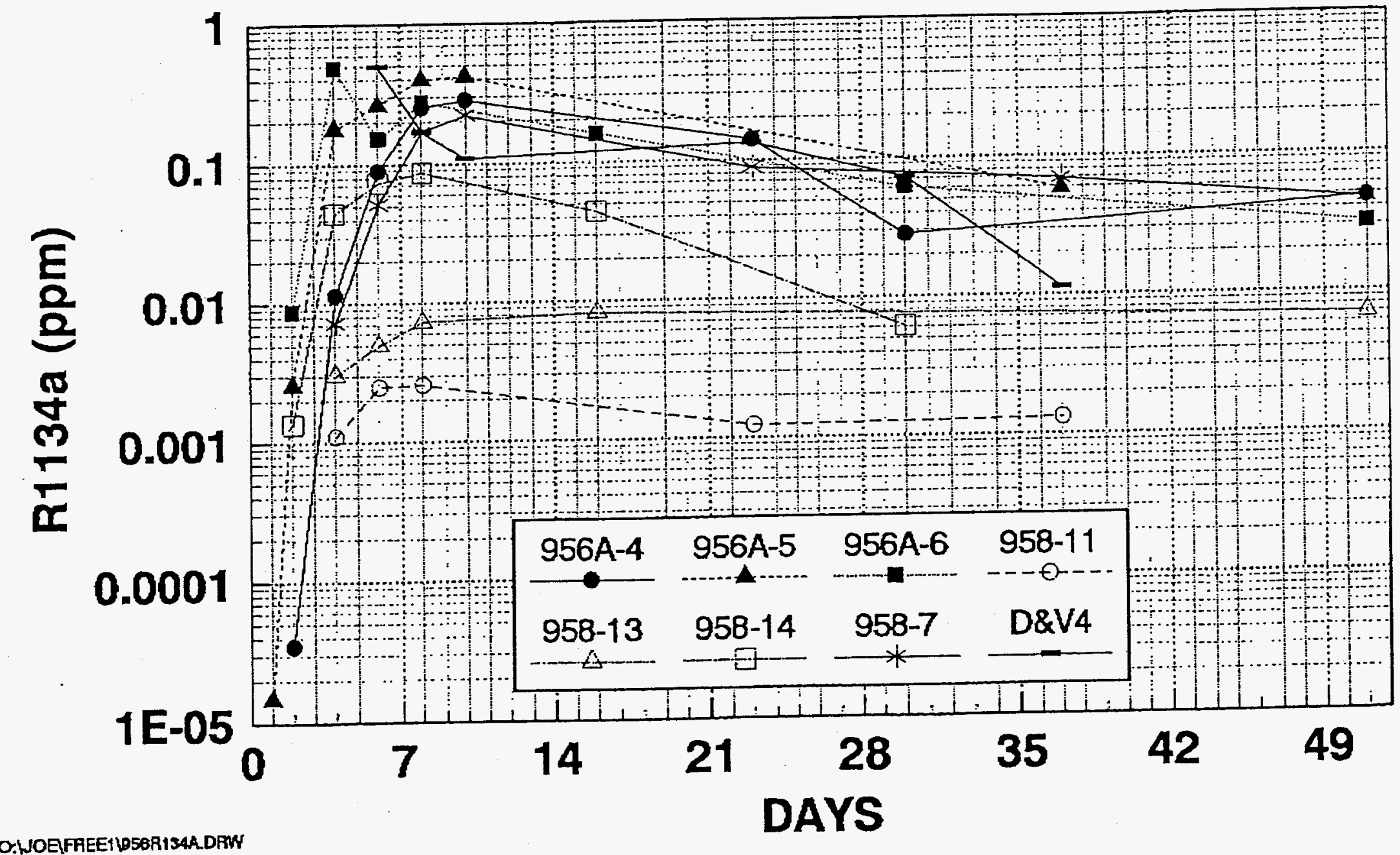


Figure 2. $956 \mathrm{~A}-1$ test. R134a tracer concentration on day 2 (2/25/99).

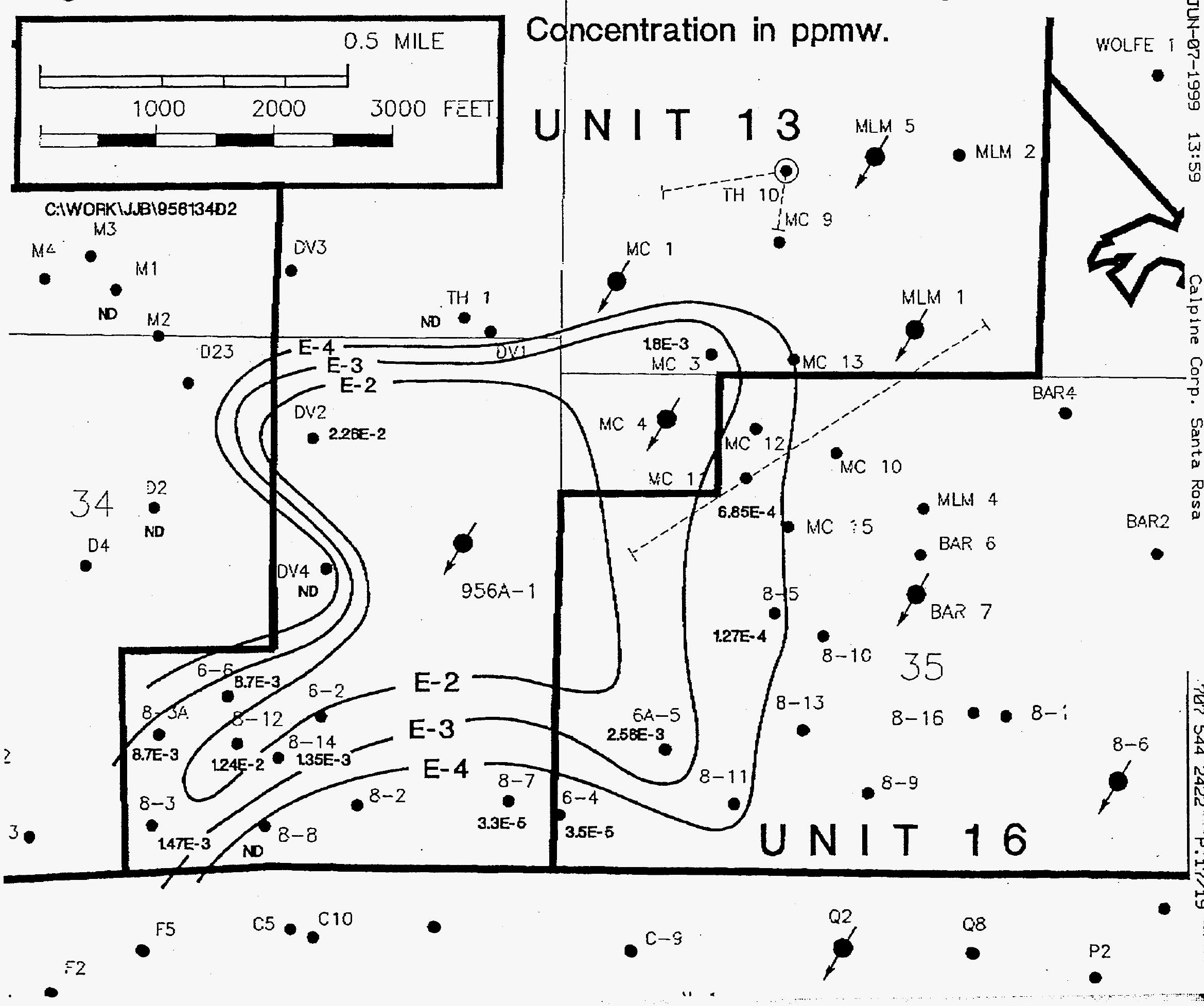


Figure 3. 956A-1 test. R134a trader concentration on day $8(3 / 3 / 99)$.

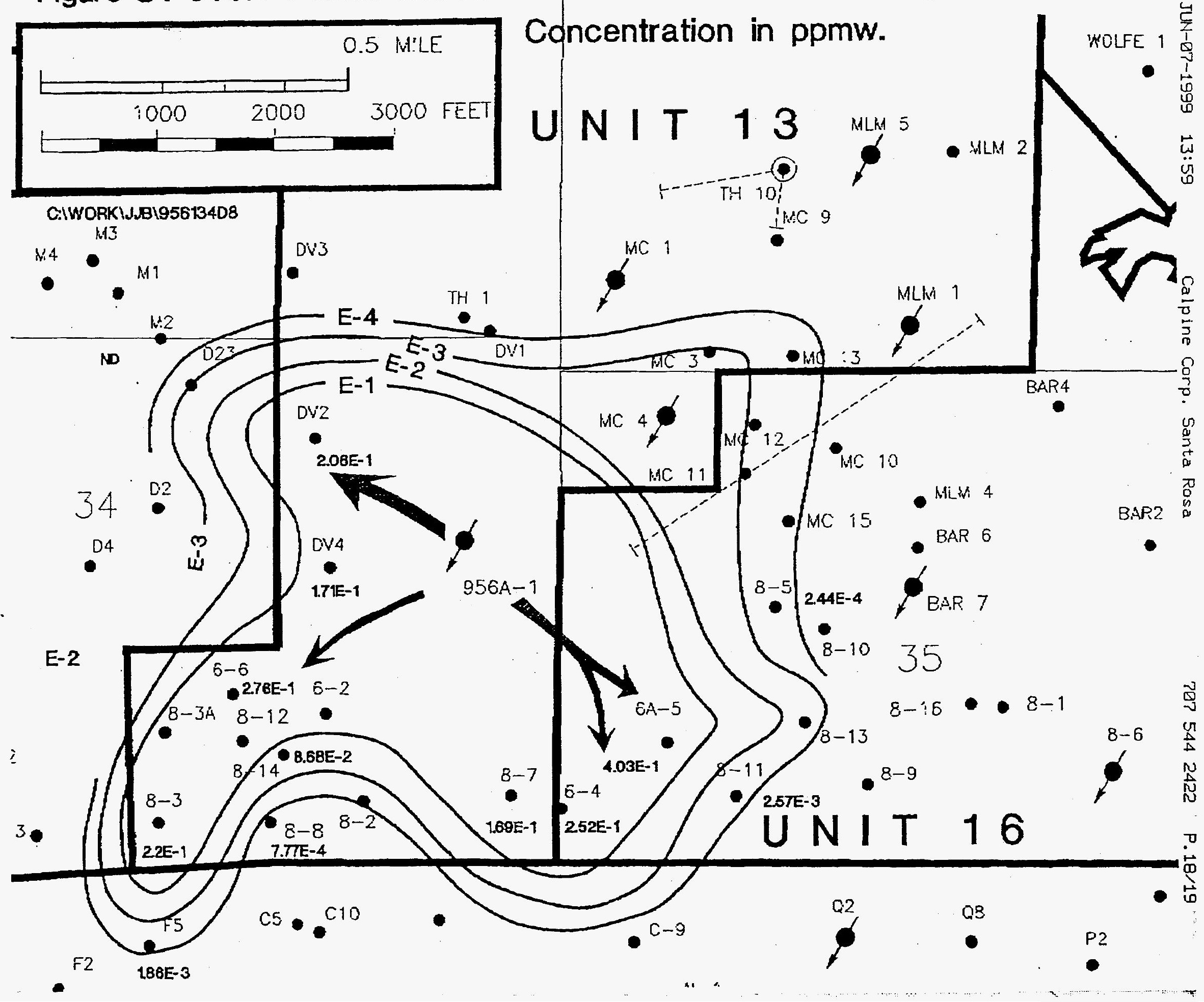


FIGURE 4

\section{A-1 R134a TRACER TEST CUMULATIVE RECOVERY OF R134a}

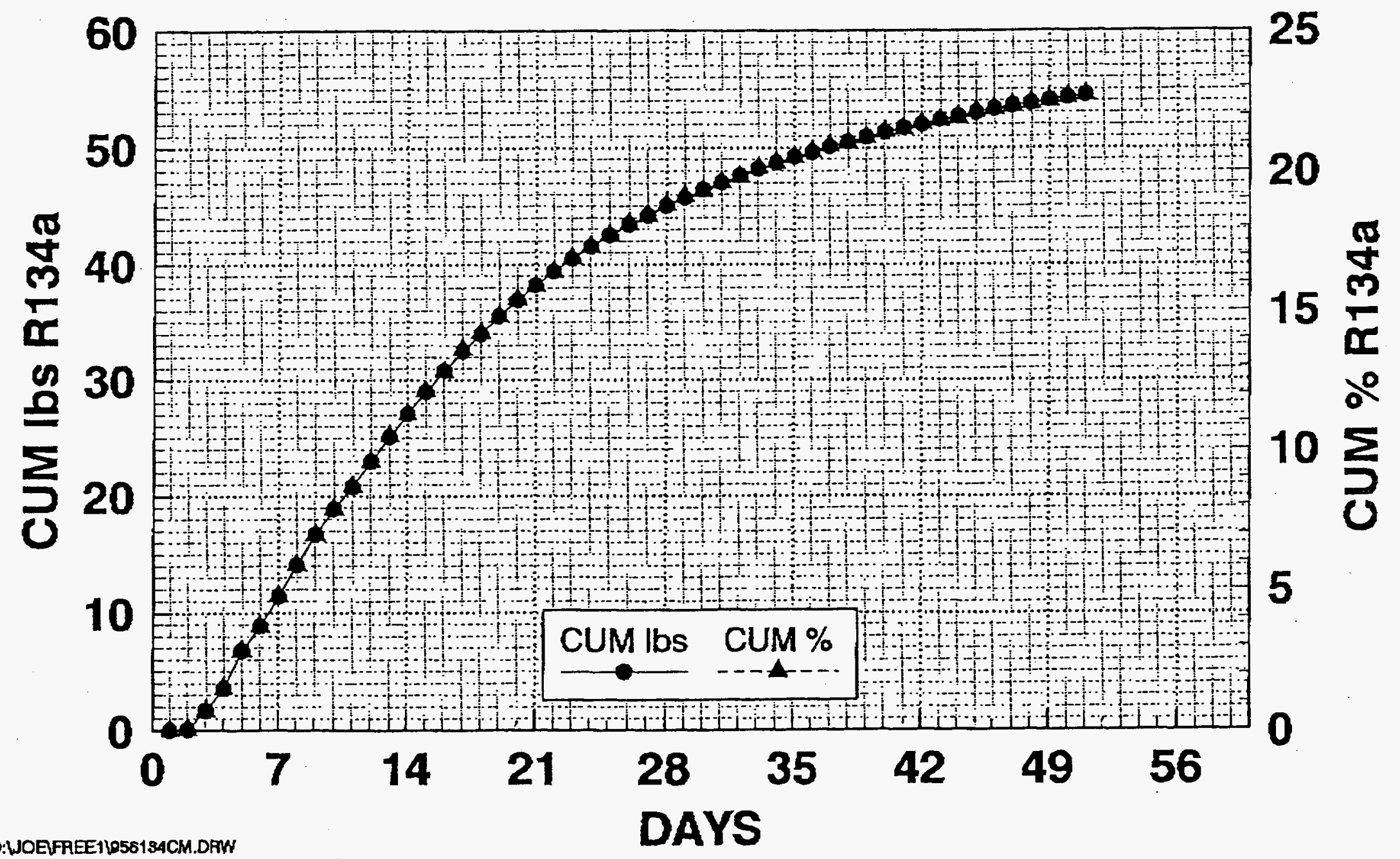




\section{TABLE 1}

\$56-1 R134a TRACER TEST

O:LOEITRACERSLS6I1134a

\begin{tabular}{|c|c|c|c|c|c|c|c|c|c|c|c|c|}
\hline . & 2 23199 & $2 / 2499$ & $2 / 25 / 99$ & 2/27/99 & $311 / 89$ & $313 / 98$ & $3 / 5 / 99$ & $3 / 11 / 99$ & $3 / 18499$ & $3 / 25 / 99$ & 41199 & 416198 \\
\hline$\therefore$ & DAYO & DAY 1 & DAY 2 & DAY 4 & DAY 6 & DAY 8 & DAY 10 & DAY 16 & DAY23 & DAY3D & DAY37 & DAY51 \\
\hline $958 \mathrm{~A}-4$ & & ND & $3.51 E-05$ & $1.15 E-02$ & B.93E-02 & 2.52E-01 & 2.84E-01 & & 1.40E-01 & 2.81E-02 & & $4.75 E-02$ \\
\hline $966 A-6$ & 2.78E-D5 & 4.26E 05 & 2.5EE-03 & $1.78 \mathrm{E}-01$ & 264E-D1 & 4.03E-01 & 4.97E-01 & & $8.69 E-02$ & & $5.85 E-02$ & \\
\hline $956 A-6$ & & ND & $8.72 E-03$ & 4.90E-01 & 1.52E-01 & $2.76 \mathrm{E}-01$ & & 1.60E-01 & & $6.14 E-02$ & & $3.13 E-02$ \\
\hline $958-11$ & & & & $1.10 \mathrm{E}-03$ & $249 E-03$ & 2.57E-03 & & & $1.23 E-03$ & & $1.31 \mathrm{E}-03$ & \\
\hline $958-12$ & ND & ND & $1.24 E-02$ & 1.63E-01 & 1.56E-01 & $1.62 E-01$ & . & 9.60E-02 & & $2.15 E-02$ & & \\
\hline 958.13 & & & & 3.03E-03 & 4.99E-03 & $7.30 \mathrm{E}-03$ & & B.23E-03 & & & & $6.94 \mathrm{E}-03$ \\
\hline $958-14$ & & ND & $1.35 E-003$ & 4.47E-02 & $7.35 \mathrm{E}-02$ & $8.68 E-02$ & & $4.41 \mathrm{E}-02$ & & $6.14 E-03$ & & \\
\hline $958-16$ & & & & 5.79E-04 & & & & & & & & \\
\hline $958-2$ & & ND & & & & & & & & & & \\
\hline $95 \mathrm{~B}-3$ & & & 1.47E-03 & 7.31E-02 & $1.75 E-01$ & $2.18 \mathrm{E}-01$ & & 1.33E-01 & & $6.29 E-02$ & & $2.34 E-02$ \\
\hline $968-5$ & 7.24E- 05 & $1.01 E-04$ & $1.27 E-04$ & & $7.96 \mathrm{E}-04$ & 2.44E-D4 & & & & & & \\
\hline $958-7$ & & $\therefore$ ND & NO & $7.23 \mathrm{E}-03$ & 5.16E-02 & 1.69E-01 & 222E-01 & & $8.80 E-02$ & & $6.91 \mathrm{E}-02$ & $4.67 \mathrm{E}-02$ \\
\hline $968-8$ & & & ND & 2.93E-04 & 9.1BE-O4 & $7.77 E-04$ & & & & & & \\
\hline $0 \& V_{-2}$ & & 7.95E-05 & 2.35E-02 & 1.04E-01 & $133 \mathrm{E}-01$ & 2.06E-01 & 1.87E-OI & & $7.09 \mathrm{E}-02$ & & $5.48 E-02$ & \\
\hline D\&V-4 & ND & ND & ND & ND & 5.01E-01 & 1.71E-D1 & 1.09E-01 & & 1.32E-01 & $7.27 \mathrm{E}-02$ & 1.13E-02 & \\
\hline DV-2 & & ND & ND & ND & NA & & ND & & & & & \\
\hline $\mathbf{F} \boldsymbol{s}$ & & & & & 4.16E-03 & $1.86 \mathrm{E}-03$ & & & & & & \\
\hline MCK-1I & & 5.57E-04 & 6.85E-D4 & $1.06 \mathrm{E}-03$ & $7.79 \mathrm{E}-04$ & & & & & & & \\
\hline MCK-13 & & & & & $5.68 \mathrm{E}-04$ & & & & & & & \\
\hline MCK 3 & 2.80E-03 & $3.03 \mathrm{E}-03$ & 4.5BE-03 & 3.8BE-00 & $\mathrm{NA}$ & & & & & & & \\
\hline MOD-Z & & & No & ND & $N A$ & ND & & ND & & & & \\
\hline TH-1 & & ND & ND & ND & & & & ND & & & & \\
\hline C9 (NCPA) & & & & & & & & $1.99 \mathrm{E}-02$ & 1.25E-02 & & 9.25E-03 & \\
\hline Q5 (NCPA) & & & & & & & & ND & & & & \\
\hline DV24 & & & & & & & & B.79E-04 & & & & \\
\hline $968-3 \mathrm{~A}$ & & & & & & & & & & 2.55E-03 & & \\
\hline
\end{tabular}


Sixth QUARTERLY TECHNICAL PROGRESS REPORT- Dated October 28, 1999

(For the period July 1, 1999 through September 30, 1999)

\title{
Southeast Geysers Cooperative Tracer Evaluation and Testing Program, for the Purpose of Estimating the Efficiency of Injection
}

\author{
U.S. Department of Energy- Financial Assistance Award \#DE-FG07-98ID13616
}

\section{Introduction}

The Southeast Geysers Cooperative Tracer Evaluation Program is a joint project located in the SE part of The Geysers geothermal field, in Lake and Sonoma Counties, California. The project is a cooperative project jointly undertaken by the Northern California Power Agency (NCPA), Calpine Corporation, Unocal Geothermal, Thermochem Inc. and the Energy and Geoscience Institute. NCPA is acting as the lead party of this group for purposes of administering the DOE Financial Assistance Award.

A new generation of environmentally benign vapor-phase tracers is being used to estimate the degree to which injectate is being recovered following the significant increase of injected volumes within the Southeast Geysers. The significantly increased injection has resulted from the startup of Southeast Geysers Effluent Pipeline (SEGEP) operations, which have initially resulted in approximately doubling the amount of water available for injection within those portions of the Southeast Geysers reservoir operated by NCPA, Calpine, and Unocal.

An initial "Phase One" field evaluation of one of the two candidate hydroflurocarbon compounds ("HFCs") was conducted first, and as reported in the previous Quarterly Technical Progress Reports, that Calpine test proved to be successful. Consequently, a "Phase Two" series of tracer tests has followed, which has so far included five single vapor-phase tracer field tests, plus the multiple tracer field test that simultaneously used tritiated water in combination with both of the vapor-phase tracers.

\section{Results}

The most recent injection test was begun in July 1999, and the results evaluated during this reporting period are summarized as follows: 


\section{Calpine Well MLM-5 Tracer Test}

On July 22, 1999248.3 lbs of R-134a were injected into Calpine's MLM-5 injection well. The water injection rate was $500 \mathrm{gpm}$ while tracer was metered into the water at about $1.2 \mathrm{lbs} . /$ minute. This resulted in a tracer concentration in the injected water of about 30 ppm (ppmw).

Production wells were sampled periodically over the next 41 days and analyzed for R134a, as shown in the accompanying table. The accumulation graph shows concentrations of tracer in steam versus time for a number of production wells.

Calculations of tracer recovery and preparation of maps showing the movement and distribution of tracer in the reservoir are now in preparation. They will be provided with the next quarterly report.

\section{Publication of Technical Progress Report, GRC Transactions, October 17-20, 1999}

A technical progress report was prepared during the reporting period for presentation and publication by the Geothermal Resources Council. The attached paper, titled "Tracing Effluent Injection Into The SE Geysers- A Progress Report" has been recently published in the GRC Transactions, Vol. 23, pp341-345.

Submitted by:

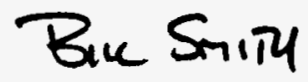

J.L. (Bill) Smith

Recipient Project Director

NCPA, Sr. Geologist 
MLM-5 R134a TRACER TEST

\begin{tabular}{|c|c|c|c|c|c|c|c|c|c|c|}
\hline & $7 / 22 / 99$ & $7 / 23 / 99$ & $7 / 25 / 99$ & $7127 / 99$ & $7129 / 99$ & 7/31/99 & $8 / 3 / 99$ & $8 / 11 / 99$ & $8 / 20 / 99$ & 9/1/99 \\
\hline & DAY O & DAY 1 & DAY 3 & DAY 5 & DAY 7 & DAY 9 & DAY 12 & DAY 20 & DAY 29 & DAY 41 \\
\hline TH 6 & & $x$ & $<1.54 \mathrm{E}-04$ & $1.70 \mathrm{E}-03$ & 2.01E-03 & & & & $<2.46 \mathrm{E}-04$ & \\
\hline TH 10 & & $\bar{x}$ & $1.25 \mathrm{E}-03$ & $<4.90 \mathrm{E}-04$ & $3.86 \mathrm{E}-04$ & & & & 2.35E-03 & $7.74 \mathrm{E}-04$ \\
\hline MCK 13 & & $x$ & 2.57E-01 & 4.91E-01 & 1.25E-01 & $1.31 E-01$ & & 2.95E-02 & 3.08E-02 & $6.87 E-03$ \\
\hline MLM 2 & & $x$ & 8.62E-03 & $7.13 E-02$ & 6.66E-02 & $3.68 E-02$ & $1.60 \mathrm{E}-02$ & 2.33E-02 & $8.33 E-03$ & \\
\hline MLM 7 & & $\bar{x}$ & $4.50 \mathrm{E}-03$ & 1.21E-02 & $1.72 E-02$ & $2.51 E-02$ & $3.63 E-03$ & $x$ & $3.05 E-02$ & $4.71 \mathrm{E}-03$ \\
\hline ABEL 1 & & $x$ & 5.71E-03 & $4.18 E-03$ & $3.26 E-03$ & & & & $<2.14 \mathrm{E}-04$ & \\
\hline WOLFE 1 & & $x$ & $8.94 E-02$ & $2.00 \mathrm{E}-01$ & 6.66E-01 & $2.74 E-01$ & 1.01E-01 & 2.57E-02 & 1.18E-02 & \\
\hline EFFU 1 & & $\bar{x}$ & $1.53 E-03$ & $2.21 E-03$ & $3.56 \mathrm{E}-03$ & $3.34 E-03$ & $1.90 \mathrm{E}-04$ & & & \\
\hline MCK 11 & & & & $3.12 E-01$ & $1.96 E-01$ & 2.17E-01 & 1.16E-01 & $2.18 E-02$ & 1.73E-02 & \\
\hline MCK 10 & & & & & $1.50 \mathrm{E}-01$ & $1.22 \mathrm{E}-01$ & $8.29 \mathrm{E}-02$ & $1.88 \mathrm{E}-02$ & & \\
\hline MCK 12 & & & & & 6.25E-04 & & & $2.00 \mathrm{E}-03$ & & \\
\hline MLM 4 & & & & & $4.23 \mathrm{E}-01$ & $2.88 E-01$ & $2.06 E-01$ & $7.44 E-02$ & $3.71 \mathrm{E}-02$ & \\
\hline $958-10$ & & & & & $1.48 \mathrm{E}-01$ & $5.92 E-02$ & $3.36 \mathrm{E}-02$ & $9.07 E-03$ & & \\
\hline MCK 15 & & & & & $6.31 \mathrm{E}-02$ & $3.47 \mathrm{E}-02$ & $2.68 E-02$ & $1.19 \mathrm{E}-02$ & & \\
\hline BAR 6 & & & & & $4.26 \mathrm{E}-01$ & $2.83 E-01$ & $2.06 \mathrm{E}-01$ & $1.06 \mathrm{E}-01$ & $3.53 \mathrm{E}-02$ & \\
\hline 958-13 & & & & & $1.95 \mathrm{E}-02$ & 5.39E-03 & 4.60E-03 & $x$ & & \\
\hline $958-5$ & & & & & & & $1.44 \mathrm{E}-02$ & 7.40 E- 03 & & \\
\hline $956 \mathrm{~A}-5$ & & & & & & & $3.68 \mathrm{E}-03$ & $x$ & $4.26 E-02$ & $2.14 E-03$ \\
\hline $958-9$ & & & & & & & $3.84 E-03$ & $\bar{x}$ & $1.72 E-03$ & \\
\hline $958-11$ & & & & & & & 1.03E-03 & & & \\
\hline $958-16$ & & & & & & & $1.03 E-03$ & & & \\
\hline MCK 9 & & & & & & & & & $<2.43 E-04$ & \\
\hline & & & & & & & & & & \\
\hline & & & & & & & & & & \\
\hline & & & & & & & & & & \\
\hline & & & & & & & & & & \\
\hline
\end{tabular}




\section{MLM 5 R134a TRACER TEST} [R134a] vs TIME

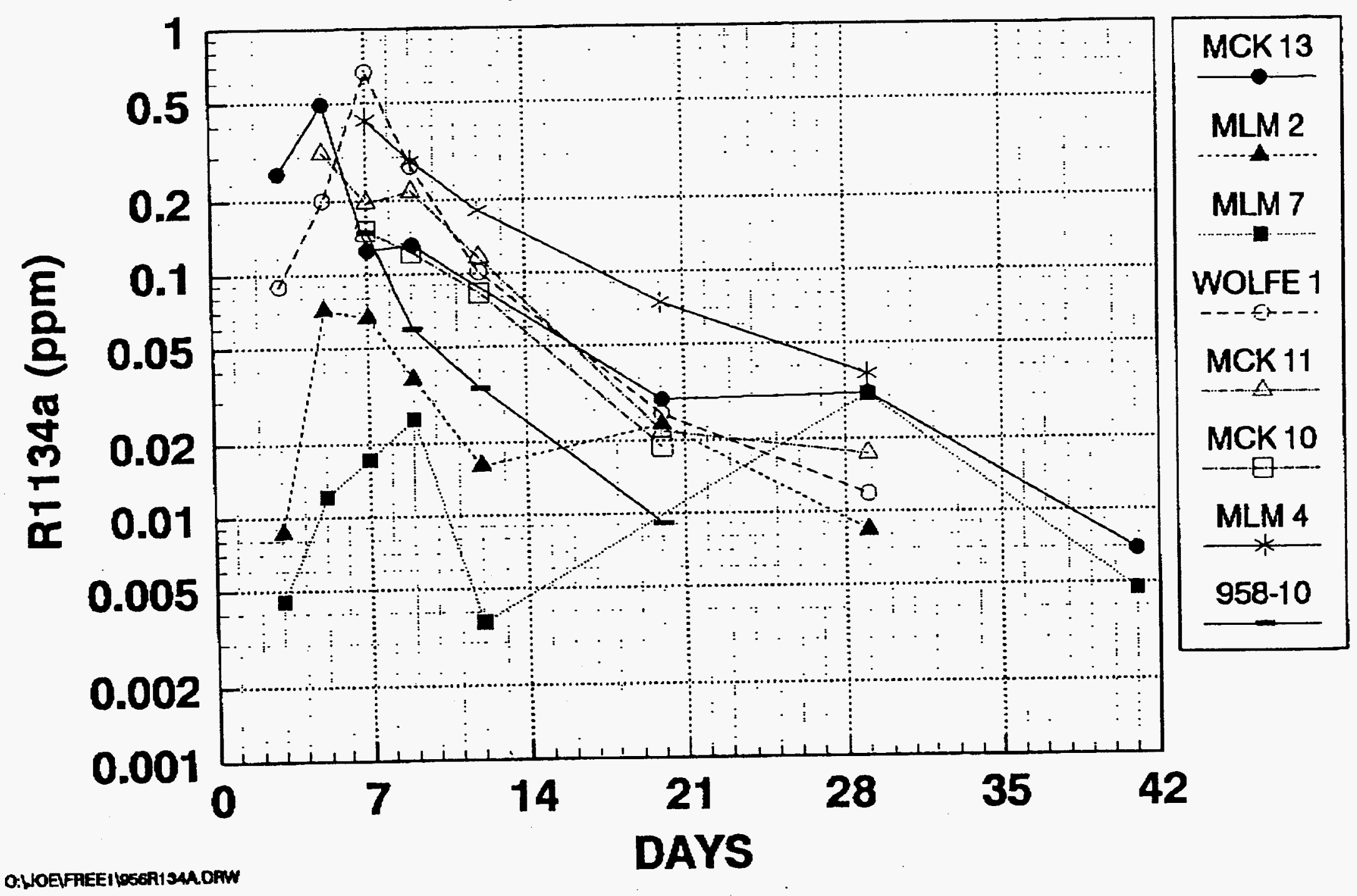




\title{
Tracing Effluent Injection Into The SE Geysers-A Progress Report
}

\author{
Michael C. Ádams', Joseph J. Beall' ${ }^{2}$, Paul Hirtz ${ }^{3}$, Brian A. Koenig', and J.L. Bill Smith ${ }^{5}$ \\ ${ }^{1}$ Energy \& Geoscience Institute, Salt Lake City UT 84103 \\ ${ }^{2}$ Calpine Corp., Santa Rosa CA 95401 \\ ${ }^{3}$ Thermochem, Inc., Santa Rosa CA 95403 \\ ${ }^{4}$ Formerly of Unocal Geothermal and Power Operations Group \\ ${ }^{5}$ Northern California Power Agency, Middletown CA 95461
}

\begin{abstract}
Six field tests using two new environmentally benign gaseous tracers have been conducted in the Southeast Geysers since the startup of the Southeast Geysers Effluent Pipeline. The results of the tests show that steam from SEGEP water is rapidly distributed around the injection wells along northeast-southwest and northwest-southeast paths, traveling up to a kilometer within one day. Recovery of the new tracers ranged up to $93 \%$, indicating that the tracers are stable under the conditions found in The Geysers normal reservoir.
\end{abstract}

\section{Introduction}

A new generation of environmentally benign vapor-phase tracers has been used in tracer tests over the past year to estimate the degree to which injectate is being recovered following the significant increase of injected volumes within the Southeast Geysers. The increase resulted from the startup of the Southeast Geysers Effluent Pipeline (SEGEP), which brings water from Clear Lake and the Lake County Water Treatment Plant to the Southeast Geysers. The pipeline is an innovative concept that uses wastewater to recharge the reservoir, increasing the power-producing lifetime of the field. Construction of the pipeline was jointly funded by the operators at The Geysers, DOE, and several other federal, state, and local agencies (Dellinger and Allen, 1996). Water from the pipeline has more than doubled the amount injected into the Southeast Geysers, a part of the geothermal reservoir where injection-derived steam previously constituted only about 25 to $30 \%$ of the steam produced (Enedy et al., 1992).

To assist in evaluating the effectiveness of the increased injection, the distribution of water into the reservoir needed to be defined using tracers. Naturally occurring tracers were considered, but exhaustive chemical analysis of the water delivered by the pipeline revealed no distinctive compounds (MCA, un-. published data), nor would the steam derived from the water have an isotopic composition significantly different from that of the reservoir (JJB, unpublished data). Consequently, a project consisting of several chemical-tracer tests was proposed to the Geothermal Technology Organization. The proposal was approved and DOE, the Northern California Power Agency (NCPA), Calpine Corporation, and Unocal Geothermal jointly funded several injection tests. The Energy \& Geoscience Institute (EGI) developed the tracers and Thermochem, Inc. injected, sampled, and analyzed the tracers.

Unfortunately, the only proven chemical vapor-phase tracer at the time was R-13, which was being phased out of production because of its potential effect on ozone in the upper atmosphere. However, hydrofluorocarbons developed as replacements for chlorofluorocarbons such as $\mathrm{R}-13$ are now in widespread use in the refrigeration industry. Two such compounds, R-134a (tetrafluoroethane) and R-23 (trifluoromethane), were chosen as potential replacements for $\mathrm{R}-13$ based on their properties, cost, and availability. Therefore, the injection tests also served as a thorough evaluation of the new tracers (Adams, 1999; Beall et al., 1998).

This paper provides brief summaries of the six tracer tests performed to date. The most recent of the six tests is still in progress, but is included because the recovery curves are well beyond their peaks and sufficient data have already been compiled to determine the likely recoveries and flow directions.

\section{Injection Method}

All of the Freon and HFC tracers tested at The Geysers, including R-12, R-13, R-23 and R-134a, were obtained as liquified gases in cylinders under their vapor pressure ( 5 to 30 bar). The cylinders were equipped with dip tubes or inverted to deliver the pressurized liquid. The tracers were injected through a probe inserted at the injection wellhead. The probe was electrically heated or steam-jacketed to vaporize the liquid before mixing with the injection water, thus preventing ice formation and potential blockage at the point of injection. The mass injection rate of the tracers was metered by an electronic balance interfaced to a computer, which calculated the mass rates and cumulative totals injected.

The injection rate of the tracers was determined by the water injection rate and the solubility of the compound injected. This injection method insures that the tracer is completely dissolved 
in the injection fluid as it enters the reservoir and does not form a premature vapor phase. The tracer injection interval was typically 2 to 6 hours, which kept the gases under their solubility limit and extended the duration of the return curves, increasing resolution.

Thermochem developed the analytical methods for the Freon's and HFC's, with detection limits on the order of 10 to 100 parts per trillion, by using a gas enrichment procedure coupled with gas chromatography (GC). A megabore porous polymer capillary column was used to separate the tracers from each other and potentially interfering compounds and a modified Halogen-Specilic Detector (HSD) was used for detection.

\section{Test Summaries}

The tests were conducted by Calpine in Units 13 and 16, by Unocal in Units 18, and in the eastem portion of NCPA's property (Figure 1). The first test was conducted in January, 1998, approximately 3 months after SEGEP water was added to the injection mix in the SE Geysers. The water can be directed into as many as 24 different injection wells. It is expected that the number and location of injection wells that actually receive SEGEP water will change with time, depending on its effect on the neaby production wells. The tracer tests were designed to provide data for the evaluation of these local effects as well as the overall impact on steam production and the longevity of the field. Each test is brielly described below. The relevant test parameters and results are listed in Table 1 and the flow directions derived from the test data are shown on Figure 1.

\section{Calpine, Well MLM-1}

The first tracer test in this series took place on January 20 , 1998. Two hundred and forty pounds of R-134a were injected into well MLM-1 over a period of three hours. Of the ten wells monitored, three showed large returns (ppm) and seven showed

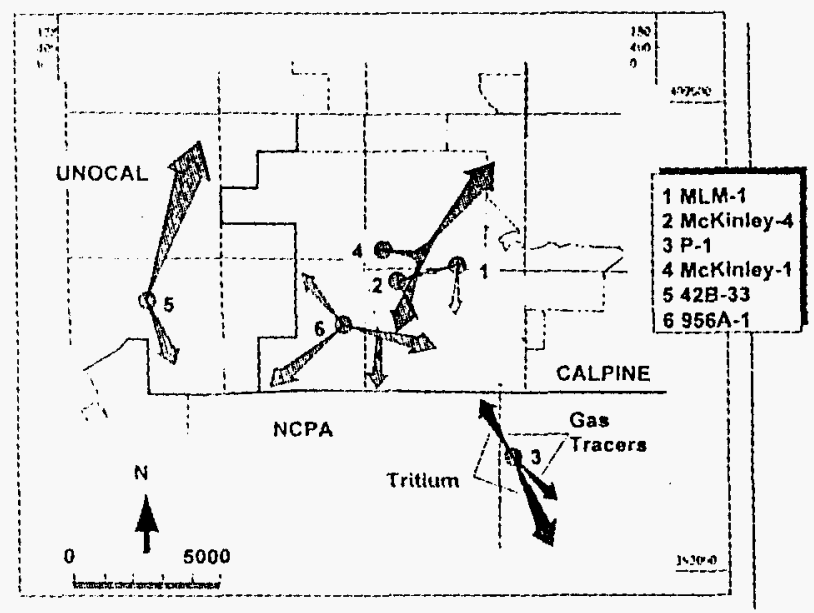

Figure 1. Flow directions (arrows) deduced from the tracer test data for each injection well (circles). The size of the arrows is not proportional to the injectate recovery. All of the flow directions were derived from gas tracer data, with the exception of the NCPA test. Tritium was used in that test as well as the gas tracers, and the flow directions indicated by each type of tracer are labeled.

Table 1. Summary table of the tracer tests performed to date. The - symbol indicales insufficient data to estimate the parameter.

\begin{tabular}{|c|c|c|c|c|c|c|}
\hline Injection Well & $M L M-1$ & McKinley-4 & $P-1$ & $B E F 42 B-33$ & McKinley-1 & $956 A-1$ \\
\hline Operator & Calpine & Calpine & NCPA & Unocal & Calpine & Calpine \\
\hline Date of Injection & January, 1998 & April, 1998 & August, 1998 & August, 1998 & October, 1998 & February, 1999 \\
\hline Tracer & $\mathrm{R}-134 \mathrm{a}$ & R-134a & R-134a; R-23; Tritium & R-134a & $\mathrm{R}-23$ & $R-134 a$ \\
\hline Recovery $(\%)$ & 63 & - & $75 ; 93 ; 39$ & 59 & 23 & 27 \\
\hline $\begin{array}{l}\text { Weight Injected } \\
\text { (Ibs or Ci) }\end{array}$ & 245 & 121 & $246 ; 207 ; 13$ & 295.6 & 196.2 & 244.4 \\
\hline $\begin{array}{l}\text { Time Duration Injected } \\
\quad(\min .)\end{array}$ & 175 & 91 & $84 ; 94 ; 185$ & 54 & 154 & 194 \\
\hline Wells Sampled & 10 & 8 & 31 & 26 & 24 & 24 \\
\hline Wells with & & & & & $\because$ & \\
\hline Tracer Detected & 10 & 5 & 30 & 17 & 17 & 19 \\
\hline $\begin{array}{l}\text { Number of } \\
\text { Samples Taken }\end{array}$ & 51 & 23 & $167 ; 168 ; 255$ & 128 & 69 & 107 \\
\hline Length of test (days) & 35 & 69 & $56 ; 56 ; 149$ & 57 & 31 & $>24$ \\
\hline $\begin{array}{l}\text { Maximum Peak Conc. } \\
\qquad(\mathrm{ppm} \text { or } \mathrm{pCi} / \mathrm{ml})\end{array}$ & 2.4 & 0.1 & $11 ; 14 ; 5 . E-2$ & 6.3 & 0.8 & 0.5 \\
\hline $\begin{array}{l}\text { Min Peak Conc. } \\
\quad(\mathrm{ppm} \text { or } \mathrm{pCi} / \mathrm{ml})\end{array}$ & $1.4 \mathrm{E}-2$ & $3 . E-3$ & 1.E-5; 3.E-4; 9.E-5 & 6.E-2 & 7.E-2 & $8.0 E-4$ \\
\hline Latest Peak Time (days) & 10 & - & $14 ; 14 ; 57$ & 30 & 10 & 16 \\
\hline Earliest Peak Time (days) & 2 & 4 & $2 ; 2 ; 1$ & 3 & 3 & 2 \\
\hline
\end{tabular}


moderate returns (ppb). This test was conducted to determine the feasibility of using the newly proposed tracer R-134a. As discussed in Beall et al. (1998), the similarity to previous tritium tracer tests in this well and the high recovery of the tracer was taken as evidence that the tracer had performed as expected. The estimated recovery of the tracer was $63 \%$, which is similar to that of tritium tests conducted in this area (Beall et al., 1998). Flow from the injection well was oriented in a southerly and southwesterly direction, which is also similar to the tritium tracer test results.

\section{Calpine, Well McKinley-4}

The second test also took place on Calpine property, on April 17, 1998. One hundred and twenty one pounds of R-134a were injected into well McKinley-4 over a period of one hour and 31 minutes. Of the eight wells monitored, three showed large returns, two showed minor returns, and three showed none. The peak concentrations, $0.1 \mathrm{ppm}$, were the lowest in this series of tests, presumably due to the lesser amount of tracer used. The earliest peak occurred four days after injection, two days later than those in the previous test. The longer arrival time may indicate a proportionately longer residence time of the injected water before it reaches the boiling interface. Recovery of the tracer was not estimated for this test because of the small number of samples. The tracer data indicated that the flow from this well is oriented to the east, northeast, and southeast.

\section{Unocal, Well BEF42B-33}

Unocal injected $240 \mathrm{lbs}$. of R-134a into well BEF42B-33, one of the two Unocal wells being used to inject SEGEP water, on August 10, 1998. Thirty-one wells were monitored for the tracer, and 132 samples were analyzed. The sampling frequency ranged from once per day in the early days of the test to once per two weeks as the test neared completion. The test was concluded on October 6, a span of 57 days.

Transit times to several of the wells were rapid. Significant tracer return occurred in GD29, for example, after only two days, meaning that injected tracer material had been flashed to steam and was transported over 2,000 feet laterally within 48 hours. The highest recovery concentration was found in steam from well GCF14A-27 on day 4 following tracer injection. This well is laterally displaced from the injection well by more than 3,000 feet, and its response demonstrates the rapid, high-volume conversion to steam and rapid transport. Fifty-nine percent of the $\mathrm{R}-134 \mathrm{a}$ was recovered during the two-month test. The steam flow was found to be primarily to the northeast, with a minor component to the southeast.

\section{NCPA, Well P-1}

On August 18, 1998, NCPA began the only multiple-tracer test of this series by injecting 245 lbs. of R-134a, 204 lbs. of R23 , and 13 curies of tritiated water (tritium) into well P-1. The tracers were injected almost simultaneously over a period of 3 hours and 20 minutes. Sampling of steam from nearby production wells began the same day, and by the end of December (about 19 weeks later) 590 samples had been collected from 34 different surrounding production wells and analyzed for at least one of the tracers. The return concentrations of $R-134 \mathrm{a}$ and R-23 were first determined on the day of injection and last determined on day 57 . Tritium concentrations were determined for some wells as far out as day 149 because of its long return times in the southern wells.

Tracers were found in thirty of the thirty-one wells sampled for this test. Peak concentrations of the gas tracers ranged from the lower parts per trillion to 14 parts per million (by weight). The peak concentrations were encountered as early as two days and as late as 14 days, or 57 days in the case of the tritium tracer.

The data indicate that the vapor-phase tracers have in general advanced faster and further from the injection well, and with a somewhat different distribution pattern, compared to tritium. The difference between the types of tracers is illustrated by the different recoveries of the tracers by day $57,75 \%$ and $93 \%$ for R-134a and R-23, respectively, and only $37 \%$ for tritium. Both the gas tracers and tritium indicated a northwest-southeast flow pattern, but the tritium tracer had a broader and more extended southern distribution. The disparity in the directions and magnitudes are similar to the results of an earlier tracer test of Unocal's DV-11 injection well (Adams, 1995; Voge et al., 1994).

\section{Calpine, Well McKinley-1}

On October 20, 1998, 210 lbs. of R-23 were injected into Calpine's McKinley-1 injection well. Seventy samples were taken from twenty-five surrounding wells. Despite the good sample coverage, by day 30 the recovery curve had flattened to the extent that the extrapolated curve would only reach a maximum of about $23 \%$. This was somewhat surprising in light of the fact that several other tracer tests in the Southeast Geysers, both tritium and gas tracers, have resulted in cumulative recoveries of $60 \%$ or more. Tracer recovery and the inferred injection flow was oriented in a south to south-southwest direction.

\section{Calpine, Well 956A-1}

Injection into 956A-I took place on February 23, 1999. Injection time and tracer quantity were similar to the other Calpine tests in this area. Although the test has not yet been completed, it appears that the recovery will be approximately $27 \%$. The flow directions inferred from the test are primarily southeast and southwest, with a minor component to the northwest.

\section{Discussion}

The tracer tests were largely successful. Recoveries of the gas tracers ranged from 23 to $93 \%$, demonstrating that thermal stability is not an issue for the new tracers in the normal Geysers reservoir. Sampling and analysis of the new tracers also proved 
effective; detection limits are now down to a million times lower than the peak concentrations of the tracer returns in this series of tests. The costs were reasonable, averaging about $\$ 15,000$ to $\$ 20,000$ per test.

Two issues were brought up by the results of these tests. The first is related to the low tracer recoveries in the 956A-1 and McK-1 lests. As discussed in (Goyal, 1999), high-rate injection into this part of the reservoir has been ongoing since 1989, and the enthalpy of some of the production wells in this area has decreased slightly. Goyal attributes this cooling to a "thermal front" from the sustained, high-rate injection. The cooling combined with the large volume of water allows extensive dilution of the tracers before boiling occurs. In addition, some of this water goes deep, as shown by the microearthquake cross-section (Beall et $a l$, in prep.). These two factors would decrease the release rate of the tracers, in turn decteasing the recovery of the tracers in the production steam. Because the gas tracers fractionate preferentially to the steam phase, any decrease in recovery due to an extended liquid phase would be amplified with respect to a soluble tracer such as tritium. Therefore, high-volatility tracers may be useful in the early detection of high liquid saturation around an injection well.

The second issue is also related to the high volatility of $R$ 134a and R-23. Early tests in which the results of tracer tests using the gas tracers were compared to those using tritium, ammonia, or stable isotopes indicated that they gave qualitatively similar answers (Adams et al., 1991; Beall et al., 1994; Beall et al., 1998; Beall et al., 1989). It was concluded from these data that boiling was essentially complete at a well-defined front, which would produce no bias from the high volatility of the gas tracers. In the current series of tests we included one in which tritiated water was injected simultaneously with the gas tracers. Figure 2 shows the ratio per well of the total tracer recovery for the two types of tracers, tritiated water and R-134a. Three producers near the injection well displayed gas tracer recoveries that exceeded tritium recoveries by a factor of greater than two.

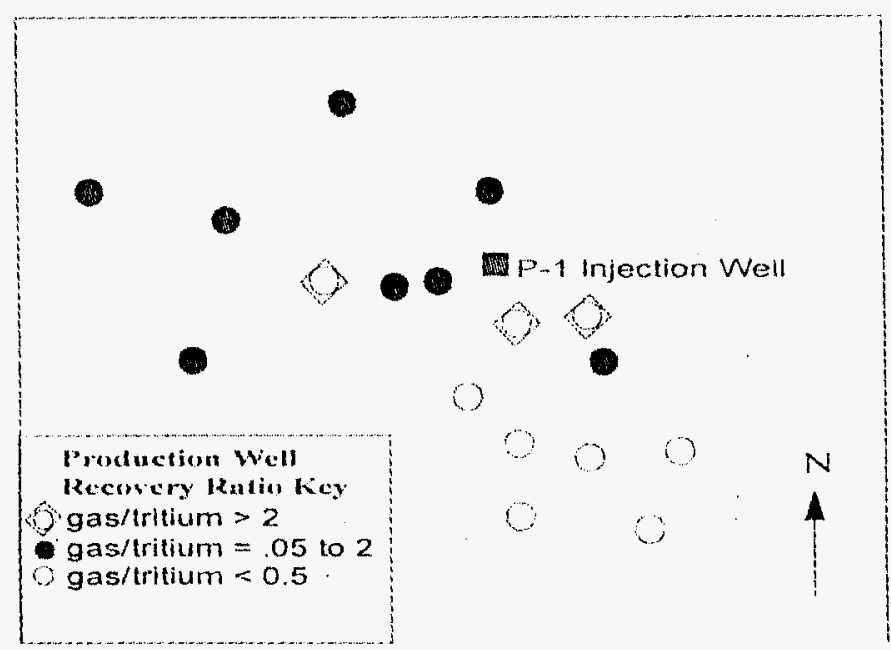

Figure 2. Relationshp of the dowmhole location (center of steam) of the production wells to the gas/tritium recovery ratio.
Eight wells, seven of which lie northwest of the injection well, showed gas/tritium recovery ratios of between one-haif and two. In six wells that lie south-southeast of the injector the ratio was less than one-half. In these wells the tritium tracer peaks arrived up to three weeks later than in the more northerly wells.

The probable explanation for these relative differences in Iracer recoveries lies with the fact that the area to the southsoutheast of the P-1 injector is relatively less depleted and consequently more water-saturated than the area immediately to the north. Since the injector itself lies in the more depleted area, the gas tracers fractionated to the steam phase at first boiling. The steam phase flowed primarily north, following the pressure gradient. Some of the liquid, which would be affected

Table 2. Recovery percentages and ratios for both types of tracers used in the NCPA tracer test. The injection well was P-1. Only wells for which analyses of both types of tracers are equally distributed over time are shown.

\begin{tabular}{|c|c|c|c|c|c|c|}
\hline \multirow{2}{*}{$\begin{array}{c}\text { Produc- } \\
\text { tion } \\
\text { Well }\end{array}$} & \multicolumn{3}{|c|}{ Recovery $(\%)$} & \multirow{2}{*}{$\begin{array}{c}\text { Earliest } \\
\text { Peak }\end{array}$} & \multirow{2}{*}{$\begin{array}{c}\text { Dominant } \\
\text { Peak }\end{array}$} & \multirow{2}{*}{$\begin{array}{c}\text { R.134a/ } \\
\text { Tritium } \\
\text { Recovery } \\
\text { Ratio }\end{array}$} \\
\hline & $\bar{R} 134 \mathrm{a}$ & R.23 & Tritium & & & \\
\hline E-4 & 0.02 & 0.01 & 7 & gas & trit & 0.00 \\
\hline B-2 & 0.3 & 0.2 & 6 & gas & trit & 0.05 \\
\hline B-6 & 0.8 & 0.7 & 4 & gas & tie & 0.20 \\
\hline B-5 & 4 & 4 & 8 & tie (trit) & tie (gas) & 0.50 \\
\hline D-7 & 0.3 & 0.2 & 0.5 & lie & gas & 0.60 \\
\hline B-3 & 6 & 5 & 7 & tie & tie (gas) & 0.86 \\
\hline$N-6$ & 1.4 & 0.92 & 1.6 & tie & tie & 0.88 \\
\hline P.4 & 8 & 8 & 8 & trit & tie (gas) & 1.00 \\
\hline Q-4 & 0.4 & 0.3 & 0.3 & tie & tie (gas) & 1.33 \\
\hline Q-8 & 14 & 15 & 10 & tie & gas & 1.40 \\
\hline Q-3 & 4 & 3 & 2 & tie & tie (gas) & 2.00 \\
\hline B-4 & 45 & 46 & 13 & tie (trit) & tie (gas) & 3.46 . \\
\hline P-7 & 14 & 17 & 2 & tie (trit) & gas & 7.00 \\
\hline
\end{tabular}

more by gravity than by the steam-phase pressure gradient, flowed southward, releasing tritium as it slowly boiled.

\section{Summary and Conclusions}

Six tracer tests cost-shared by the Geothermal Technology Organization and the U.S. Department of Energy were conducted at The Geysers. The purpose of the tests was to provide information on the distribution of injectate in the reservoir around wells that accept water from the recently completed Southeast Geysers Effluent Pipeline (SEGEP). In addition, the performance of a new pair of gaseous hydrofluorocarbon tracers, $R-134 a$ and $R-23$ were evaluated. The results of the tests show that the SEGEP water is rapidly distributed around the injection wells along northeast-southwest and northwest-southeast paths, traveling up to a kilometer within a few days.

The new tracers were evaluated by calculating their recovery in the production steam, and by comparing these recoveries to that of tritiated water, which was injected along with the gas tracers in one test. The least amount of the new tracers recov- 
ered was $23 \%$. This occurred in an area that has received sustained, high-rate injection, and is presumed to have large volumes of liquid water surrounding the injection wells, retarding the release of the tracers. The highest recovery was $93 \%$, which demonstrates that there was no significant decay of the tracers in the reservoir. Comparison of the tracer recoveries with that of tritiated water indicates that use of the gas tracers can introduce errors into any quantitative estimate of injectionderived steam, if the water boils along the path through the reservoir rather than at a single point on the path. This is due to the high volatility of the gas tracers with respect to water.

\section{Acknowledgements}

Funding for MCA was provided by the Department of Energy under contract No. DE-AC07-95ID 13274. Such support does not constitute endorsement by the DOE of the opinions, findings, conclusions, or recommendations contained within this manuscript.

\section{References}

Adams, M.C., 1995. "Vapor, liquid, and two-phase tracers for geothermal systems," International Geothermal Congress 1875-1880.
Adams, M.C., 1999. "Tracing the flow of effluent into The Geysers geothermal field," U. S. Department of Energy, Office of Geothermal Technologies.

Adans, M.C., Bcall, J.J., Enedy, S.L. and Hirtz, P., 1991. "The application of halogenated alkanes as vapor-phase tracers: A field test in the Southeast Geysers," Geothermal Resources Council Transactions, 15, pp. 457-463.

Beall, J.J., Adams, M.C. and Hirtz, P.N., 1994. "R-13 tracing of injection in The Geysers," Geothermal Resources Council Transactions, 18, pp. 151-159.

Beall, J.J., Adams, M.C. and Hirtz, P.N., "1998. Evaluation of R-134a as an injection tracer in the Southeast Geysers," Geothermal Resources Council Transactions, 22, pp. 569-573.

Beall, J.J., Enedy, S.L. and Box. W.T.J., 1989. "Recovery of injected condensatte as steam in the south Geysers lield," Geohlermal Resources Council Transactions, 13, pp. 351-358.

Dellinger, M. and Allen, E., 1996. "Turning community wastes into sustainable geothermal energy: The S. E. Geysers effluent pipeline project," Geothermal Resources Council Transactions, 20, pp. 205208.

Enedy, S.L., Enedy, K.L. and Mancy, J.J., 1992. "Downhole enthalpy and superheat evolution of The Geysers steam wells," Special Report, Geothermal Resources Council, 17, pp. 211-219.

Goyal, K.P., 1999. "Injection related cooling in the Unit 13 area of the Southeast Geysers, California," USA. Geothermics, 28(1): 3-19.

Voge, E. et al., 1994. Initial lindings of The Geysers Unit 18 cooperative injection project, Geothermal Resources Council Transactions, 18, pp. 353-357. 
Seventh QUARTERLY TECHNICAL PROGRESS REPORT- Dated February 15, 2000

(For the period October 1, 1999 through December 31, 1999)

\title{
Southeast Geysers Cooperative Tracer Evaluation and Testing Program, for the Purpose of Estimating the Efficiency of Injection
}

\author{
U.S. Department of Energy- Financial Assistance Award \#DE-FG07-98ID13616
}

\section{Introduction}

The Southeast Geysers Cooperative Tracer Evaluation Program is a joint project located in the SE part of The Geysers geothermal field, in Lake and Sonoma Counties, California. The project is a cooperative project jointly undertaken by the Northern California Power Agency (NCPA), Calpine Corporation, Unocal Geothermal, Thermochem Inc. and the Energy and Geoscience Institute. NCPA is acting as the lead party of this group for purposes of administering the DOE Financial Assistance Award.

A new generation of environmentally benign vapor-phase tracers is being used to estimate the degree to which injectate is being recovered following the significant increase of injected volumes within the Southeast Geysers. The significantly increased injection has resulted from the startup of Southeast Geysers Effluent Pipeline (SEGEP) operations, which have initially resulted in approximately doubling the amount of water available for injection within those portions of the Southeast Geysers reservoir operated by NCPA, Calpine, and Unocal.

An initial "Phase One" field evaluation of one of the two candidate hydroflurocarbon compounds ("HFCs") was conducted first, and as reported in the previous Quarterly Technical Progress Reports, that Calpine test proved to be successful. Consequently, a "Phase Two" series of tracer tests has followed, which has so far included seven single vapor-phase tracer field tests, plus the multiple tracer field test that simultaneously used tritiated water in combination with both of the vapor-phase tracers.

\section{$\underline{\text { Results }}$}

The two most recent injection tests were begun in November and December 1999, and the results evaluated by Calpine and NCPA during this reporting period are summarized as follows: 


\section{Calpine Well MLM-5 Tracer Test}

On July 22, 1999, $248.3 \mathrm{lbs}$ of R134a tracer were injected into MLM 5, in the northeastern Unit 13 area. Tracer was metered into injection water at a rate of $1.2 \mathrm{lbs}$ per minute while the rate of water injection was held at 500 gallons per minute. The concentration of tracer going into the well was therefore about 290 parts per million (ppmw).

Samples were taken from production wells over the next 42 days and analyzed for R134a. Table 1 summarizes the results of the analyses. The accompanying graphs (Figures 1a and 1b) show concentrations of tracer in steam versus time for a number of production wells. Figure 2 shows the cumulative recovery of $\mathrm{R} 134 \mathrm{a}$, both as total lbs and as percent recovered. As shown in Figure 2, about $54.4 \mathrm{lbs}$ of R134a were recovered in 42 days, representing slightly over $21 \%$ of the total injected. After 42 days the slope of the recovery curve is nearly horizontal, suggesting that little additional R134a will be recovered.

Figure 3 is a map depicting the peak concentration and the day on which the peak was observed. The hachured pattern shows the movement of tracer in the reservoir. The pattern indicates that R134a moved along a southwest - northeast zone, which is, offset somewhat to the southeast of MLM 5's midpoint of steam. It is interesting that the tracer appears to have moved in the reservoir directly through the location of the MLM 1 injection well and directly toward the Barrows 7 injection well. During the period of late July through mid August, all three injectors (MLM 5, MLM 1 and Barrows 7) were injecting at rates of between 450 and $600 \mathrm{gpm}$. It appears that injection into MLM 1 and Barrows 7 in no way inhibits the movement of injection derived steam from MLM 5 through the area of the former two wells. The single contour shown in Figure 3 encloses all the maximum concentrations in excess of $0.1 \mathrm{ppmw}$. The northeast - southwest zone defined by the contour is over a mile long and shows that the Wolfe 1 well communicates with and benefits from injection into MLM 5, while other wells in the same general vicinity are only weakly connected (MLM 2, MLM 7 and EFFU-1).

Figure 4 is a map illustrating the concentrations of various wells on day 7 of the test (the day of tracer injection is day 0). Again the single contour encloses wells with R134a concentrations greater than $0.1 \mathrm{ppmw}$ and the area outlined is very similar to that in Figure 3. Another surprising aspect of the patterns mapped is the extremely abrupt drop off in concentrations in certain locations. For example, in going from the Wolfe 1 well to the nearby EFFU-1 well (both very good producers) the concentration diminishes by over two orders of magnitude. Similarly, McKinley 10,11 and 13 all show relatively high concentrations while McKinley 12 is three orders of magnitude lower. All of these wells are near neighbors and, except for McKinley 10, all are good producers (>60 kph). 


\section{Calpine Well Barrows 7 Test}

On November 2, 1999, 233.3 lbs of R134a were metered into Calpine's Barrows 7 injection well over a period of 4 hours 54 minutes ( $0.794 \mathrm{lbs}$ per minute). The water injection rate was $495 \mathrm{gpm}$. This resulted in a tracer concentration in the injected water of 192 ppmw.

Samples were collected from wells over the following 50 days. The results of the analyses are presented in Table 2 and in graphic form in Figure 5. The cumulative recovery of $\mathrm{R} 134 \mathrm{a}$ is calculated from the concentrations measured and steam flow rates of the various wells sampled (Figure 6). About $76 \mathrm{lbs}$ (32.5\%) was recovered in 54 days, at which time the rate of recovery had become negligible. Because of the relatively low recovery of $\mathrm{R} 134 \mathrm{a}$ in recent tests relative to earlier experience with $\mathrm{R} 134 \mathrm{a}, \mathrm{R} 13$ and tritium, there was some concern that tracer might be "escaping" beyond the coverage of sampled wells. In order to eliminate this concern, samples were also taken of the main steam lines feeding the turbines of Units 13 and 16. Since those steam fields are "cross tied" both main steam lines were sampled to insure that essentially all of the produced R134a was accounted for. Figure 7 shows the cumulative results based on main steam line sampling. The results are nearly identical to those calculated from the individual wells, indicating that little tracer was produced from wells that were not sampled.

As noted previously, the total recovery of R134a from the MLM 5 tracer test amounted to only $21 \%$ of the amount injected. This was similar to the percentages recovered from the 956-1 tracer test (24\%) and the McKinley 1 R23 tracer test (22\%). These recoveries are far lower than the projected $63 \%$ recovered during the initial test of R134a in MLM 1 and the subsequent 59\% recovery in the R134a test of (formerly) Unocal's 42B-33.

Moreover, the MLM 1 test appeared to mirror the results of a recent tritium test on that well (Beall, Hirtz and Adams, 1998). A simultaneous test of R134a and tritium by NCPA yielded approximate recoveries of $78 \%$ and $38 \%$, respectively. These results are probably are related to differences in solubility of the various tracers and whether the reservoir conditions dictate that boiling is complete at a well-defined front, or occurs along a flow path, with steam separating as the plume of water moves. More study is needed on this problem.

Figure 8 shows plotted values of the maximum observed tracer concentration (first number) and the day of the peak value (second number). As shown on the map, three wells (Barrows 6, 958-10 and 958-13) all had peak values above $1.0 \mathrm{ppm}$. However, no other well had a value as high as $0.1 \mathrm{ppm}$. Consequently, the contour shown encloses all values greater than $1.0 \mathrm{ppm}$, but (like Figure 3) could also be stated to enclose all values greater than $0.1 \mathrm{ppm}$. A comparison of Figures 3 and 7 shows that Barrows 6 and 958-10 
produced high concentrations of tracer from both MLM 5 and Barrows 7. The comparison also shows that the area of high tracer values for the Barrows 7 test is far more compact. As with the former test, however, the high values are found along a northeast - southwest trend. This trend is also evident in Figure 9, in which the tracer concentrations on day 7 are contoured.

\section{NCPA Well D-1 Test}

On December 8, 1999, 232.3 lbs. of R-134a tracer were injected into well D-1. Along with the tracer there was 300 GPM of condensate being injected into the reservoir.

Samples were taken from production wells over the next 51 days and analyzed for R-134a concentrations. Table 3 shows the results of the analyses.

Figure 10 shows the concentrations of $\mathrm{R}-134 \mathrm{a}$ produced over time from the sampled wells. Figure 11 is a plot of the cumulative tracer recovery over time. About $107.5 \mathrm{lbs}$. or $46.3 \%$ of the total $134 \mathrm{a}$ tracer injected was produced by the wells sampled during the 51 day period. Compared to other Freon tracer studies done at the Geysers, this is a good return of tracer and indicates that well D-1 is an effective injector. Of this total, well Q-4 produced $45.7 \mathrm{lbs}$. or $42.5 \%$ of the total recovery. The bottom steam entries in D-1 are located approximately 3,000' directly below the main steam entries in well Q-4 suggesting that a substantial amount of the injectate was leaving D-1 at or near the bottom of the well. Wells D-7, N-6, and Y-1 are also located near D-1 and produced a total of $49.8 \mathrm{lbs}$. or $46.3 \%$ of the total Freon recovered. These four wells produced a combined total of $88.8 \%$ of the total Freon recovered. Recovery of tracer from Well D-7 peaked on day 2 of the test, while N-6, Q-4, and Y-1 peaked on day 6.

Figure 12 in a map depicting the peak concentrations observed throughout the test period. Most of the R-134a produced follows a NW by SE trend surrounding well D-1. The contour drawn on Figure 12 is for concentrations greater than 0.1 ppmw R-134a. Also the map shows the distribution of trace amounts of $\mathrm{R}-134 \mathrm{a}$ observed, showing a wide area of distribution of injectate away from well D-1.

Submitted by:

\section{BuL Snin}

J.L. (Bill) Smith

Recipient Project Director

NCPA, Sr. Geologist 
TABLE 1. MLM-5 R134a TRACER TEST, ANALYSES SUMMARY

$R$ 134a concentrations in ppm

\begin{tabular}{|c|c|c|c|c|c|c|c|c|c|c|}
\hline & $\frac{7122 / 99}{D A Y O}$ & $\frac{7 / 23199}{\text { DAY } 1}$ & $\frac{7125199}{D A Y 3}$ & $\frac{7127199}{\text { DAY } 5}$ & $\begin{array}{c}7 / 29 / 99 \\
\text { DAY }\end{array}$ & $\frac{7131 / 99}{\text { DAY }}$ & $\frac{8 / 3 / 99}{\text { DAY } 12}$ & $\frac{\text { B/11/99 }}{\text { DAY 20 }}$ & $\frac{B / 20 / 99}{\text { DAY } 29}$ & $\frac{9 / 2 / 99}{\text { DAY 42 }}$ \\
\hline TH 6 & & $x$ & $<1.54 \mathrm{E}-04$ & $1.70 \mathrm{E}-03$ & 2.01E-03 & & & & $<2.46 \mathrm{E}-04$ & \\
\hline TH 10 & & $\bar{x}$ & $1.25 \mathrm{E}-03$ & $<4.90 E-04$ & $3.86 E-04$ & & & & $2.35 E-03$ & $7.74 E-04$ \\
\hline MCK 13 & & $2.27 E-01$ & $2.57 \mathrm{E}-01$ & $4.91 \mathrm{E}-01$ & $1.25 E-01$ & $1.31 E-01$ & & $2.95 E-02$ & $3.08 \mathrm{E}-02$ & $6.87 \mathrm{E}-03$ \\
\hline MLM 2 & & $x$ & $8.62 E-03$ & $7.13 \mathrm{E}-02$ & $6.66 \mathrm{E}-02$ & $3.68 \mathrm{E}-02$ & $1.60 \mathrm{E}-02$ & $2.33 E-02$ & $8.33 \mathrm{E}-03$ & \\
\hline MLMT & & $\bar{x}$ & $4.50 \mathrm{E}-03$ & $1.21 \mathrm{E}-02$ & $1.72 E-02$ & $2.51 E-02$ & $3.63 \mathrm{E}-03$ & $x$ & $3.05 E-02$ & $4.71 \mathrm{E}-03$ \\
\hline ABEL 1 & & $\bar{X}$ & $5.71 E-03$ & $4.18 \mathrm{E}-03$ & $3.26 E-03$ & & & & $<2.14 \mathrm{E}-04$ & \\
\hline WOLFE 1 & & $<1.26 \mathrm{E}-04$ & $8.94 E-02$ & $2.00 \mathrm{E}-01$ & $6.66 \mathrm{E}-01$ & $2.74 E-01$ & $1.01 \mathrm{E}-01$ & $2.57 \mathrm{E}-02$ & $1.18 \mathrm{E}-02$ & \\
\hline EFFU 1 & & $x$ & $1.53 E-03$ & $2.21 E-03$ & $3.56 \mathrm{E}-03$ & $3.34 E-03$ & $1.90 \mathrm{E}-04$ & & & \\
\hline MCK 11 & & & & $3.12 \mathrm{E}-01$ & $1.96 \mathrm{E}-01$ & $2.17 E-01$ & $1.16 E-01$ & $2.18 E-02$ & $1.73 \mathrm{E}-02$ & \\
\hline MCK 10 & & & & & $1.50 \mathrm{E}-01$ & $1.22 \mathrm{E}-01$ & $8.29 E-02$ & $1.88 E-02$ & & \\
\hline MCK 12 & & & & & $6.25 \mathrm{E}-04$ & & & $2.00 E-03$ & & \\
\hline MLM 4 & & & & & $4.23 E-01$ & $2.88 E-01$ & $2.06 \mathrm{E}-01$ & $7.44 E-02$ & $3.71 E-02$ & \\
\hline $958-10$ & & & & & $1.48 E-01$ & $5.92 E-02$ & $3.36 \mathrm{E}-02$ & $9.07 E-03$ & & \\
\hline MCK 15 & & & & & $6.31 E-02$ & $3.47 E-02$ & $2.68 \mathrm{E}-02$ & $1.19 E-02$ & & \\
\hline BAR 6 & & & & & $4.26 \mathrm{E}-01$ & $2.83 E-01$ & 2.06E-01 & 1.06E-01 & $3.53 E-02$ & \\
\hline $958-13$ & & & & & 1.95E-02 & 5.39E-03 & $4.60 E-03$ & $x$ & & \\
\hline $958-5$ & & & & & & & $1.44 E-02$ & $7.40 E-03$ & & \\
\hline $956 \mathrm{~A}-5$ & & & & & & & $3.68 \mathrm{E}-03$ & $\bar{x}$ & $4.26 E-02$ & $2.14 E-03$ \\
\hline $958-9$ & & & & & & & $3.84 \mathrm{E}-03$ & $\bar{x}$ & $1.72 \mathrm{E}-03$ & \\
\hline $958-11$ & & & & & & & $1.03 \mathrm{E}-03$ & & & \\
\hline $958-16$ & & & & & & & $1.03 \mathrm{E}-03$ & & & \\
\hline MCK 9 & & & & & & & & & $<2.43 E-04$ & \\
\hline
\end{tabular}




\section{MLM 5 Tracer Test}

\section{[R-134a] vs Time}

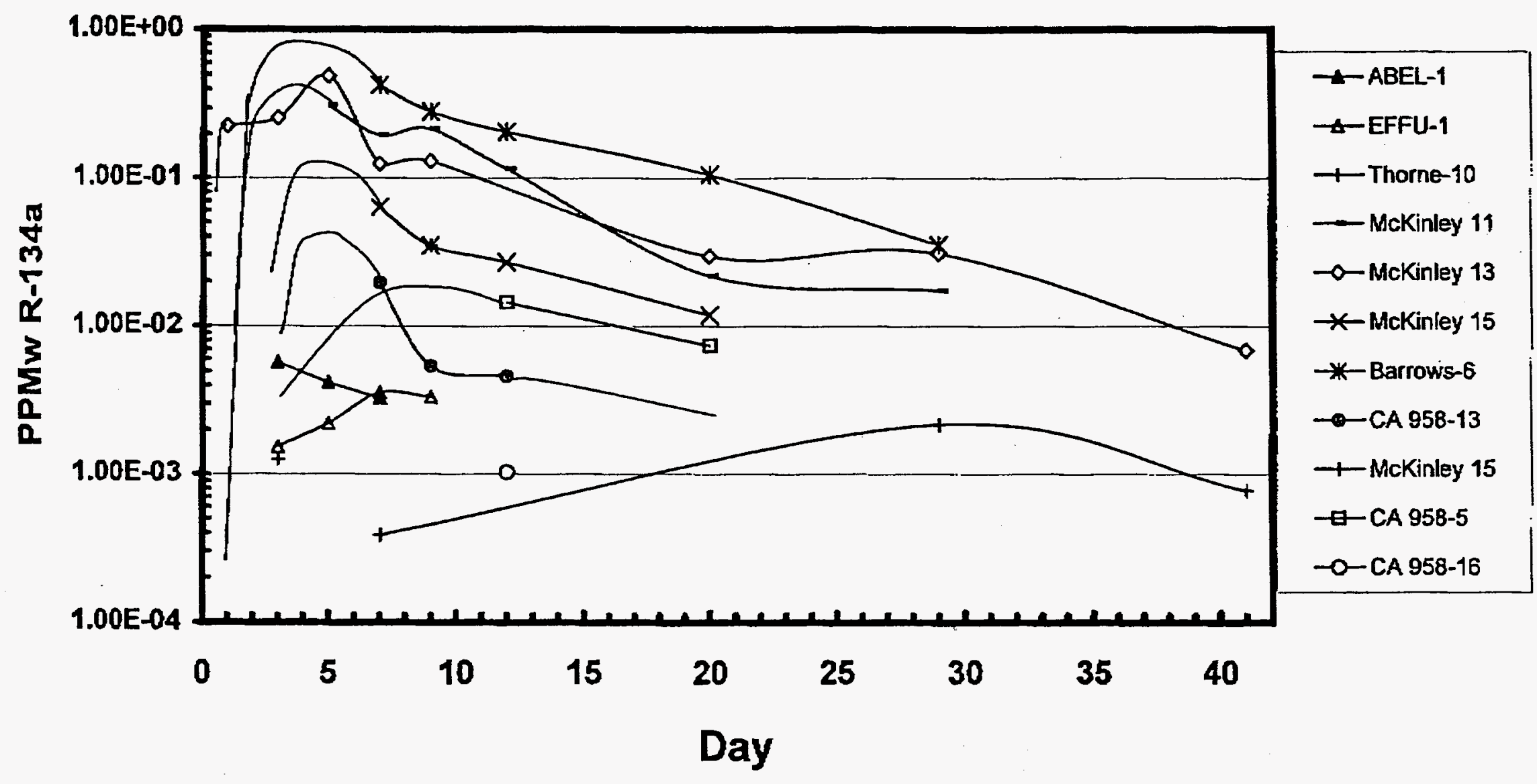

Figure 1a 
MLM 5 Tracer Test

[R-134a] vs Time

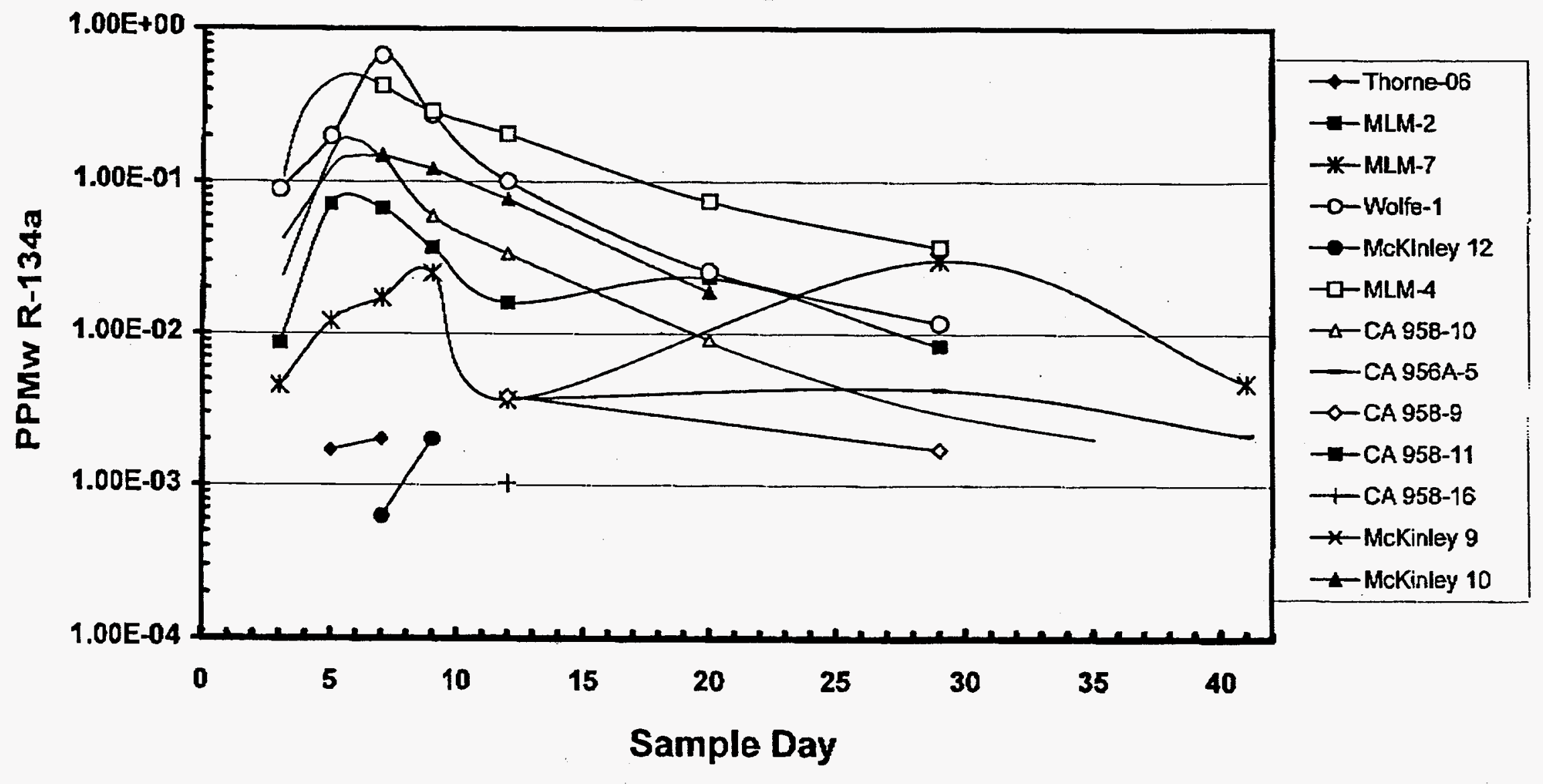

Figure $1 b$ 
CUM Ibs R134a

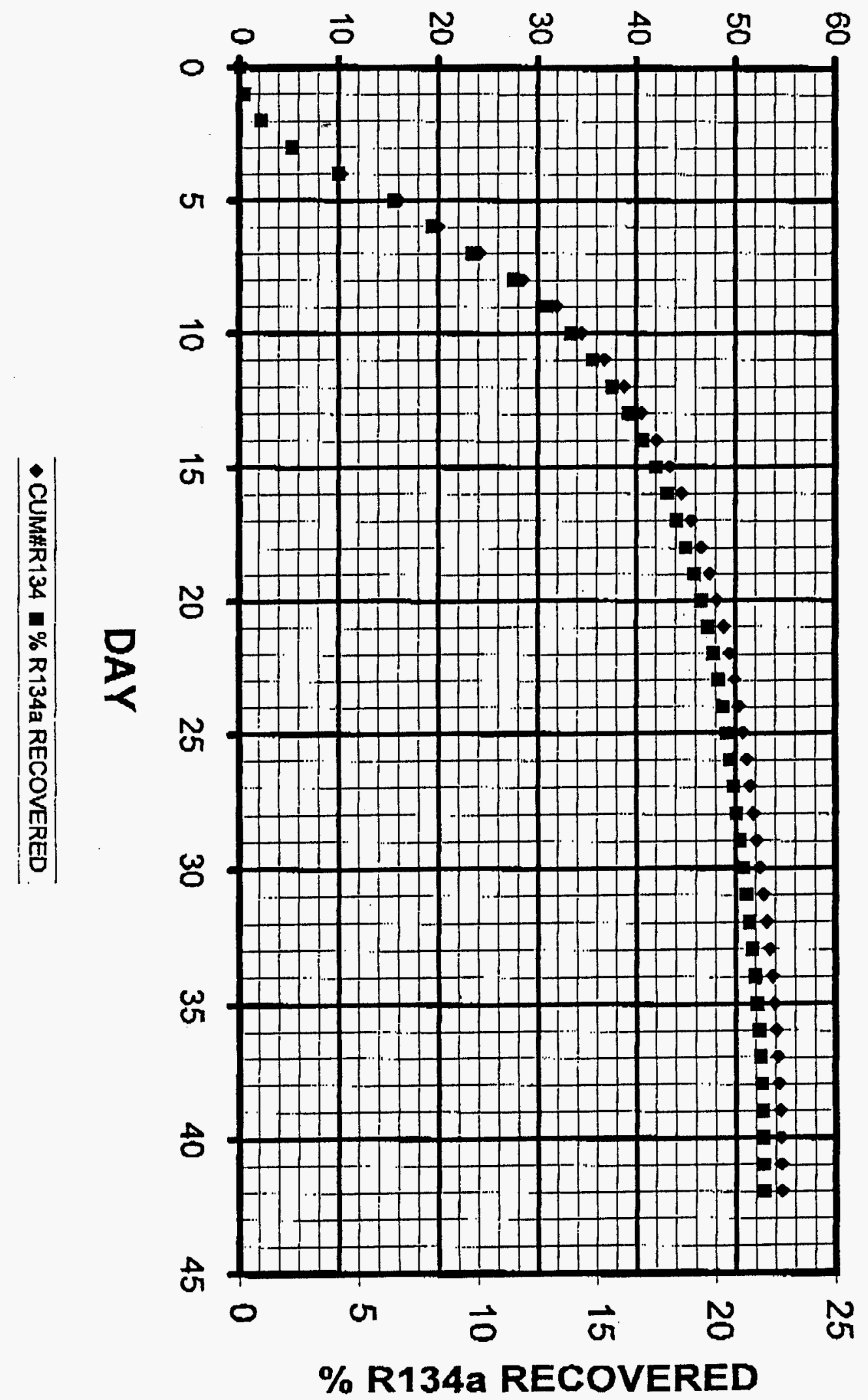

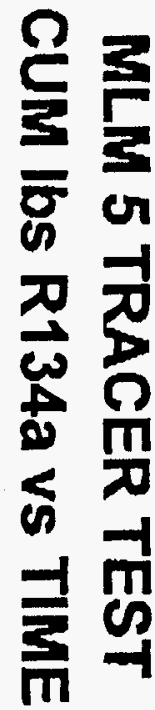

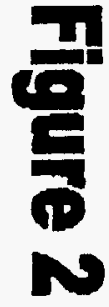




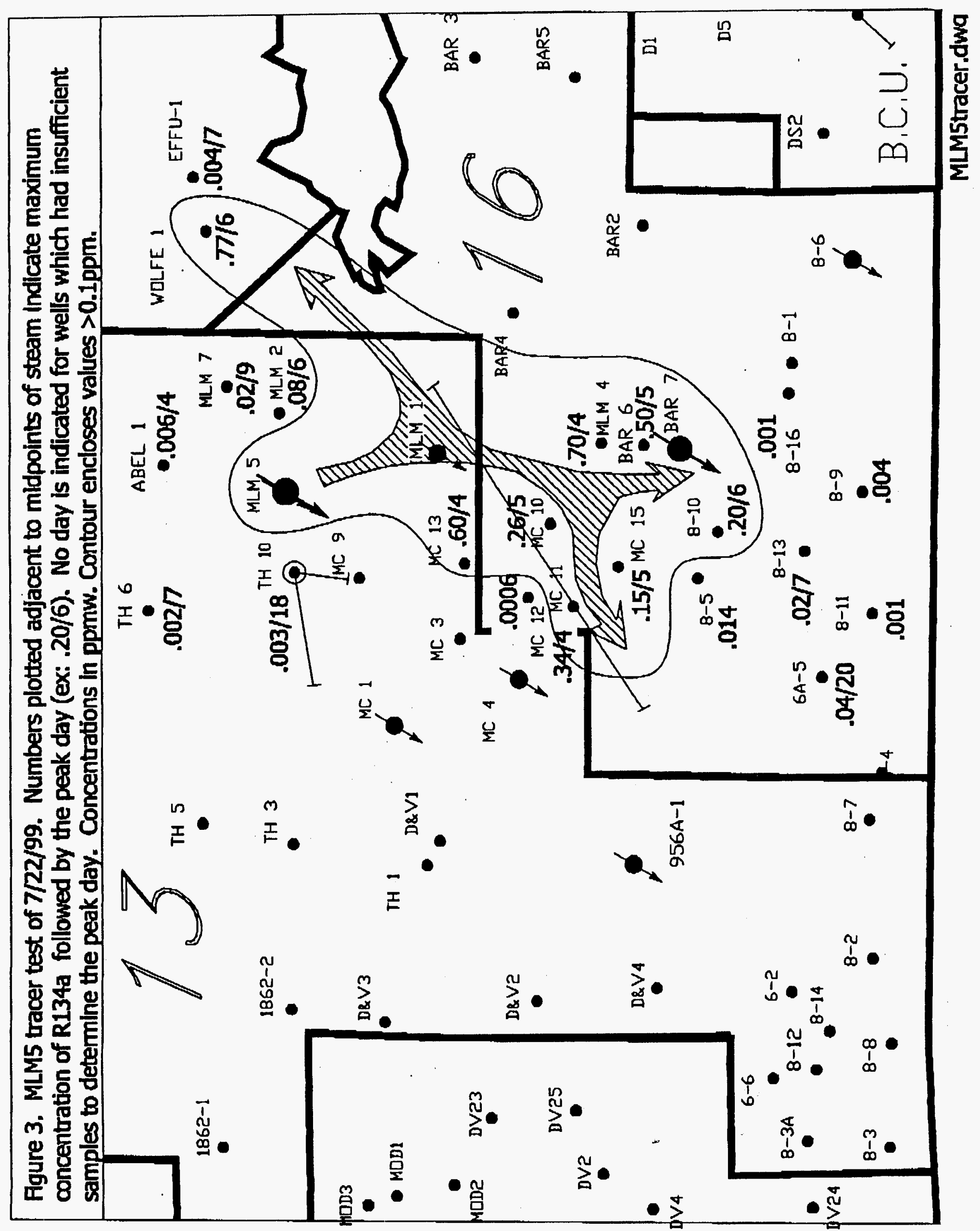




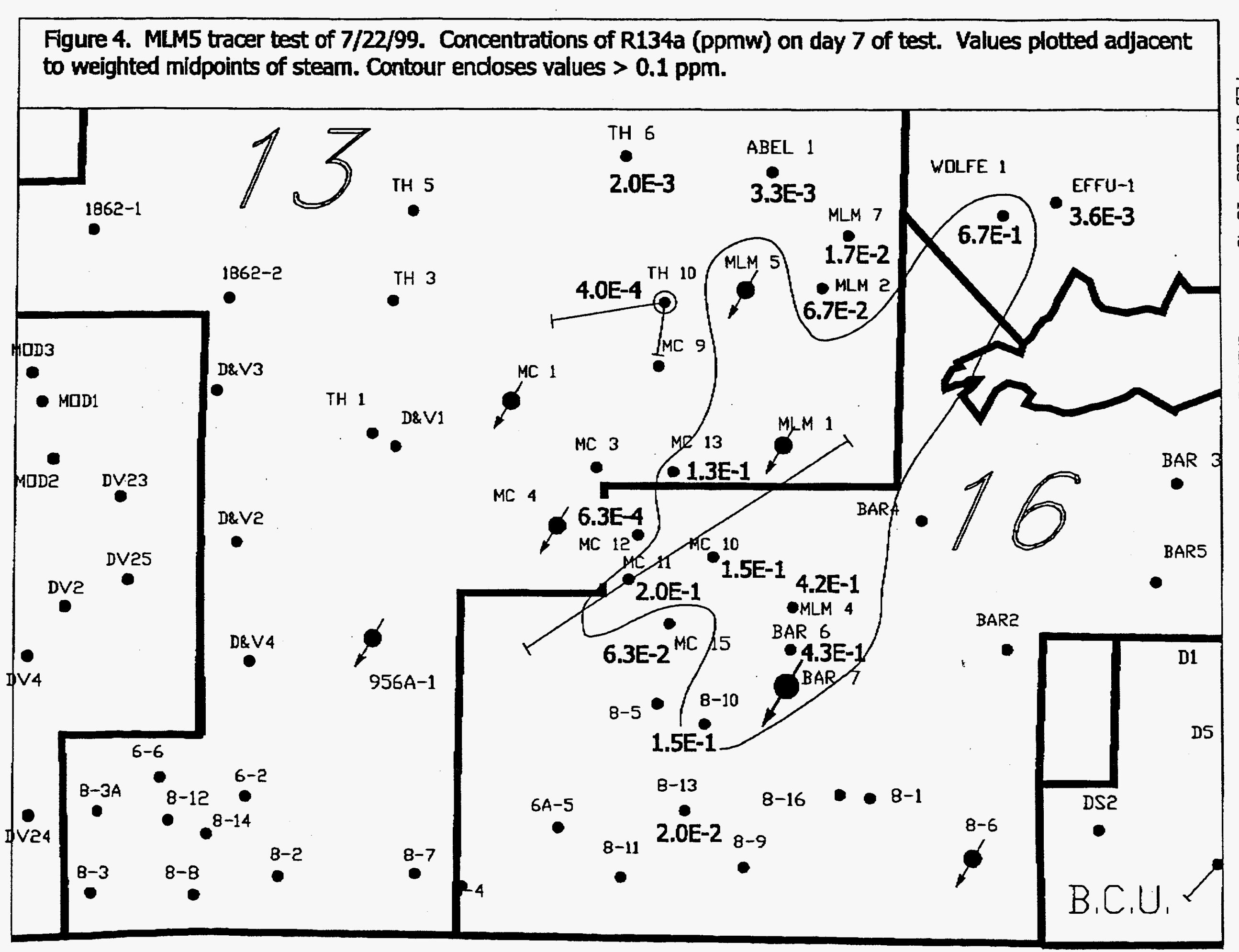

MLM5tracer.dwa 


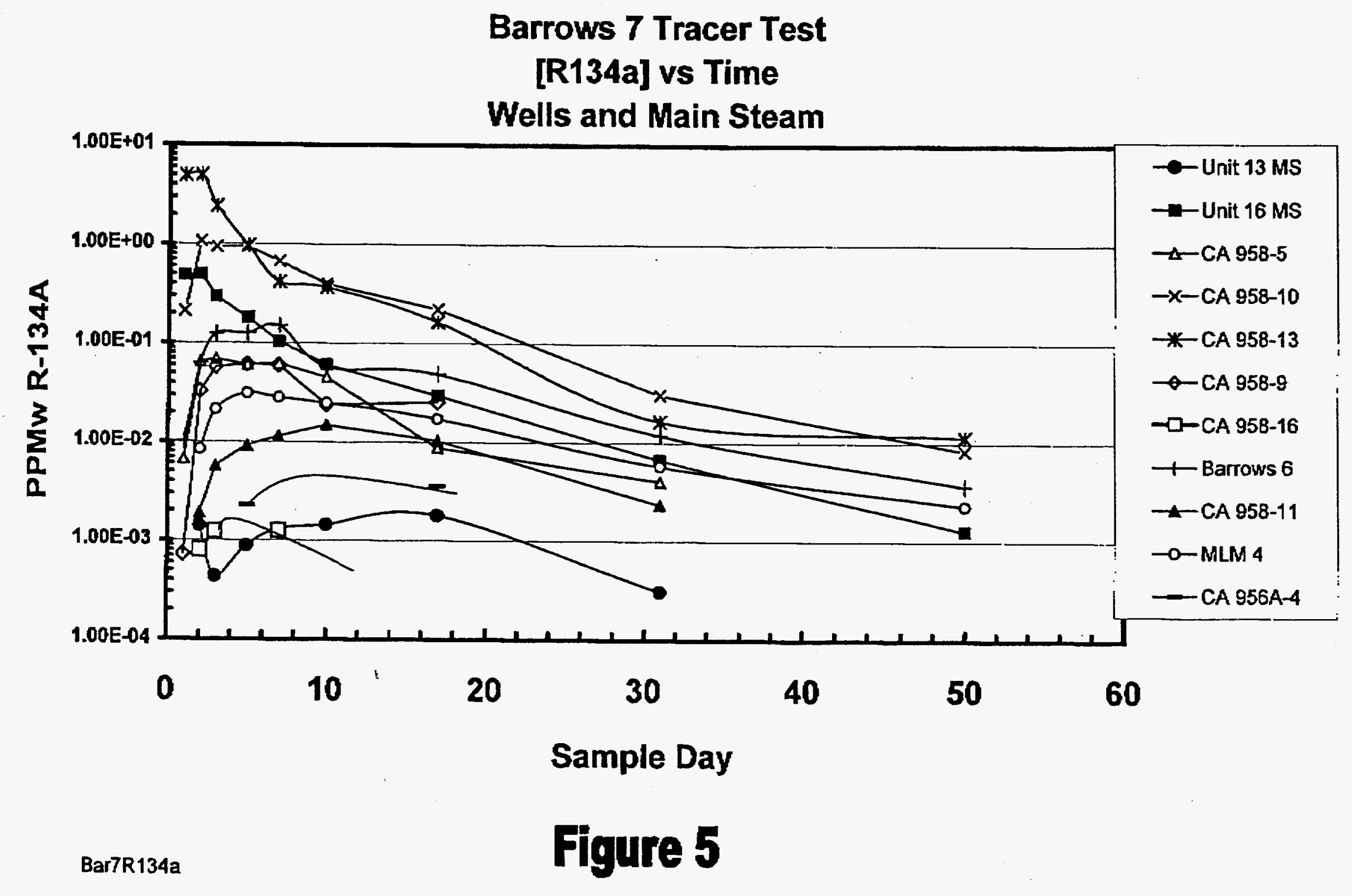




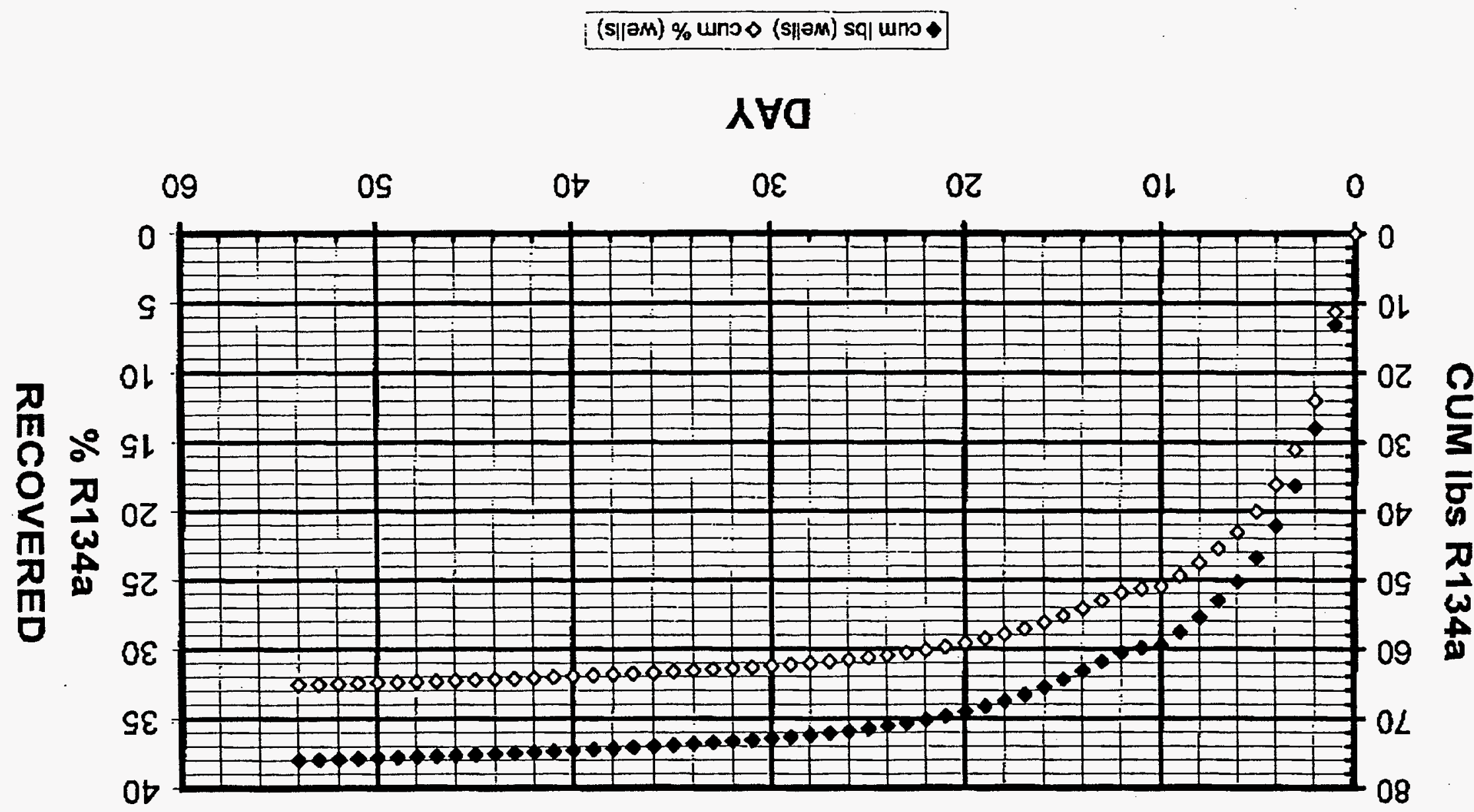

9 anfly

\author{
S|loM wody \\ pәләлоэәу $\forall t \varepsilon L y$ \\ 7SO $\perp$ JOJed $\perp$ SMOdJeg
}




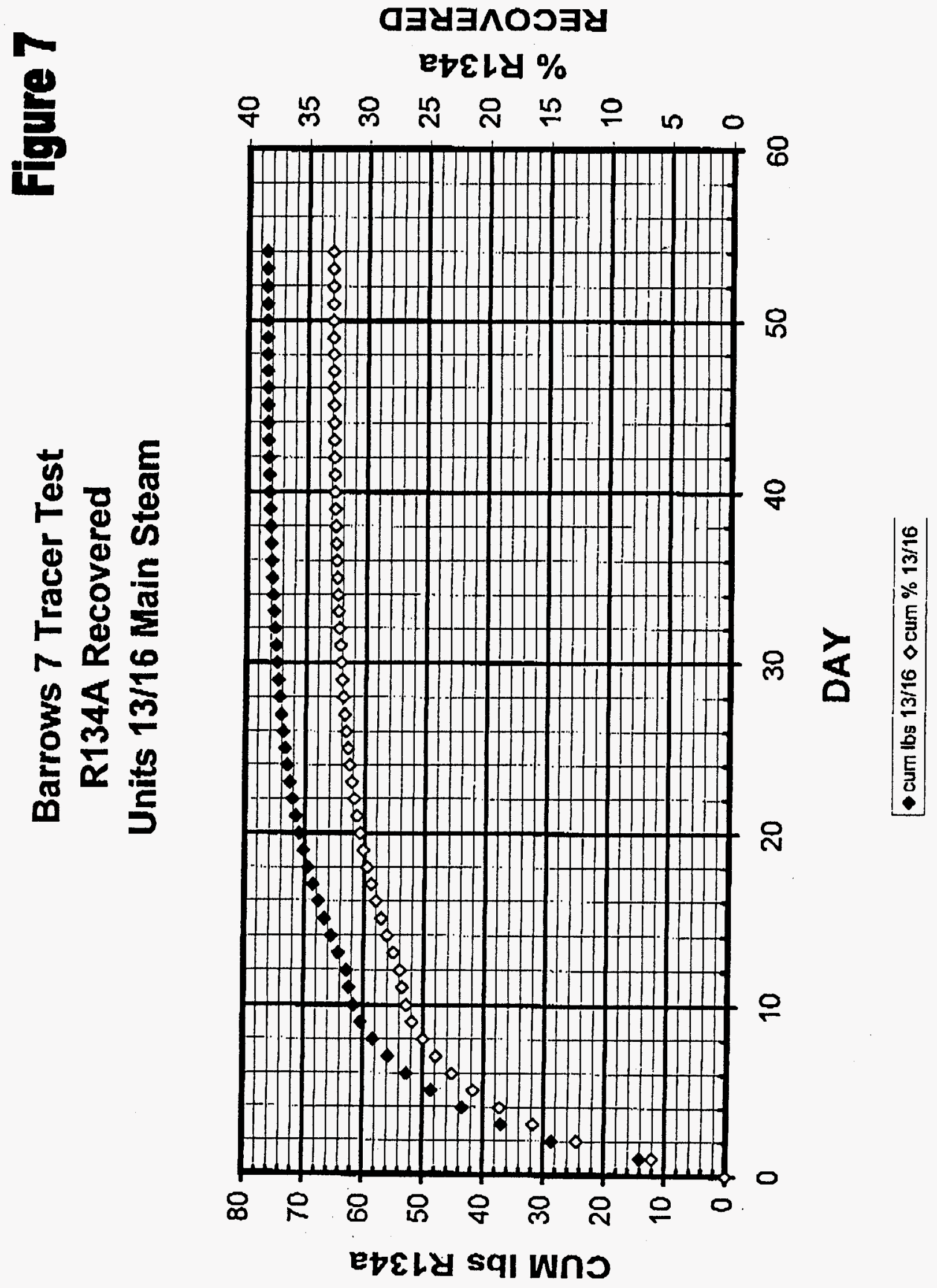


TABLE2. BARROWS 7 R134a TRACER TEST, ANALYSES SUMMARY

\begin{tabular}{|c|c|c|c|c|c|c|c|c|c|c|c|}
\hline & DAYO & DAY 1 & DAY2 & DAY 3 & DAY 5 & DAY 7 & DAY10 & DAY 17 & DAY 31 & DAY 50 & DAY 66 \\
\hline & $11 / 2 / 99$ & $11 / 3 / 99$ & $11 / 4 / 99$ & $11 / 5199$ & $1177 / 99$ & $11 / 9 / 99$ & $11 / 12 / 99$ & $11 / 19 / 99$ & $12 / 3 / 99$ & $12 / 22 / 99$ & $1 / 7 / 00$ \\
\hline Unit $13 \mathrm{MS}$ & & $x$ & $1.41 E-03$ & $4.33 E-04$ & B.84E-04 & $1.30 E-03$ & $1.44 \mathrm{E}-03$ & $1.81 E-03$ & $3.08 E-04$ & $<1.54 E-4$ & $<6.45 E-4$ \\
\hline Unil $16 \mathrm{MS}$ & & 4.83E-01 & $4.93 E-01$ & 2.92E-01 & $1.80 E-01$ & $1.04 \mathrm{E}-01$ & $6.10 \mathrm{E}-02$ & $2.99 E-02$ & $6.69 E-03$ & $1.28 \mathrm{E}-03$ & $<6.23 \mathrm{E}-4$ \\
\hline CA 958-5 & & 6.71E-03 & $6.52 E-02$ & $6.99 E-02$ & $6.08 E-02$ & $6.24 E-02$ & $4.55 \mathrm{E}-02$ & 8.80E-03 & 4.04E-03 & & \\
\hline CA 958-10 & & $2.11 E-01$ & $1.07 \mathrm{E}+00$ & $9.38 \mathrm{E}-01$ & $9.46 \mathrm{E}-01$ & $6.72 \mathrm{E}-01$ & $3.96 \mathrm{E}-01$ & $2.21 E-01$ & $3.09 E-02$ & 8.37E-03 & \\
\hline CA 958-13 & & $4.97 E+00$ & $4.98 E+00$ & $2.43 \mathrm{E}+00$ & $9.65 \mathrm{E}-01$ & $4.14 \mathrm{E}-01$ & $3.65 E-01$ & $1.64 \mathrm{E}-01$ & $1.66 E-02$ & $1.15 E-02$ & \\
\hline CA $958-9$ & & $7.22 E-04$ & 3.27E-02 & $5.74 E-02$ & $6.14 E-02$ & 6.00E-02 & $2.40 \mathrm{E}-02$ & $2.57 \mathrm{E}-02$ & & & \\
\hline CA 958-16 & & $x$ & $8.00 E-04$ & $1.23 E-03$ & & $1.25 E-03$ & & & & & \\
\hline Barrows 6 & & 1.01E-02 & $6.30 \mathrm{E}-02$ & $1.24 \mathrm{E}-01$ & $1.26 \mathrm{E}-01$ & $1.50 \mathrm{E}-01$ & $5.85 \mathrm{E}-02$ & $4.90 \mathrm{E}-02$ & $1.19 E-02$ & $3.66 \mathrm{E}-03$ & \\
\hline McKinley 10 & & $x$ & $1.33 \mathrm{E}-03$ & $1.43 \mathrm{E}-03$ & & 1.34E-03 & & & & & \\
\hline McKinley 15 & & $x$ & $9.62 E-04$ & $2.32 E-03$ & $1.70 E-03$ & & & & & & \\
\hline Barrows 2 & & & $5.58 E-04$ & $5.06 E-04$ & & & & & & & \\
\hline Barrows 4 & & & 1.09E-03 & 1.10E-03 & & $1.05 E-03$ & & & & & \\
\hline CA 958-11 & & & $1.90 E-03$ & $5.69 E-03$ & $9.13 \mathrm{E}-03$ & $1.14 E-02$ & $1.49 \mathrm{E}-02$ & $1.04 E-02$ & $2.36 E-03$ & & \\
\hline CA 956A-5 & & & $2.20 \mathrm{E}-03$ & $2.51 E-03$ & & & & $3.21 E-03$ & & & \\
\hline McKinley 12 & & & $3.68 \mathrm{E}-04$ & 4.47E-04 & & & & & & & \\
\hline MLM 4 & & & 8.39E-03 & $2.15 E-02$ & $3.14 \mathrm{E}-02$ & $2.84 \mathrm{E}-\mathrm{D} 2$ & $2.50 \mathrm{E}-02$ & $1.73 E-02$ & 5.79E-03 & $2.30 E-03$ & \\
\hline McKinley 11 & & & & & $1.44 E-03$ & $k$ & & & & & \\
\hline McKinley 13 & & & & & $1.34 E-03$ & & & & & & \\
\hline CA 956A-4 & & & & & $2.27 E-03$ & & & $3.56 \mathrm{E}-03$ & & & \\
\hline CA 958-1 & & & & & & $9.53 \mathrm{E}-04$ & & & & & \\
\hline
\end{tabular}




\begin{tabular}{|c|c|c|c|c|c|c|c|c|c|c|c|c|c|c|c|}
\hline & & & & & & & & & & & & & & & \\
\hline & & & & & & & \multicolumn{2}{|c|}{ TABLE 3} & & & & & & & \\
\hline & & & & & & & & & & & & & & & \\
\hline & & & & & & \multicolumn{5}{|c|}{ D-1 TRACER TEST, ANALYSES SUMMARY } & & & & & \\
\hline DATE & DAY & A-6 & B-4 & C-6 & C-7 & C-8 & C-9 & D-2 & D-6 & D-7 & D-8 & $\mathrm{J}-2$ & $\mathrm{~N}-1$ & $\mathbf{N}-2$ & \\
\hline & & & & & & & & & & & & & & & \\
\hline $12 / 08 / 99$ & 1 & & & & & & & & & & & & & & \\
\hline $12 / 09 / 99$ & 2 & $2.21 E-02$ & & & & & & $3.87 E-03$ & $5.94 \mathrm{E}-03$ & $1.90 \mathrm{E}+01$ & & & $1.06 E+00$ & & \\
\hline $12 / 10 / 99$ & 3 & & & & & & $7.29 \mathrm{E}-02$ & & & & $6.43 E-03$ & ND & & $4.09 E-03$ & \\
\hline $12 / 13 / 99$ & 6 & $3.66 \mathrm{E}-03$ & & & & & $4.49 E-02$ & $7.45 \mathrm{E}-03$ & $5.31 E-03$ & $4.20 \mathrm{E}+00$ & 4.75E-03 & 1.37E-02 & $3.59 \mathrm{E}-01$ & $2.53 \mathrm{E}-03$ & \\
\hline $12 / 17 / 99$ & 10 & & & & & & 2.07E-03 & 3.37E-04 & $2.46 \mathrm{E}-03$ & $1.49 E+00$ & $1.72 \mathrm{E}-03$ & $2.77 \mathrm{E}-02$ & $2.21 \mathrm{E}-02$ & \begin{tabular}{|c|}
$2.78 \mathrm{E}-03$ \\
\end{tabular} & \\
\hline $12 / 22 / 99$ & 15 & & & & & & $7.64 \mathrm{E}-03$ & $3.75 \mathrm{E}-03$ & $2.48 \mathrm{E}-04$ & $8.03 E-01$ & $7.46 \mathrm{E}-03$ & $3.53 \mathrm{E}-02$ & $1.03 E-01$ & $3.79 E-04$ & \\
\hline $12 / 30 / 99$ & 23 & ND & 6.57E-04 & $7.62 E-04$ & $1.62 \mathrm{E}-03$ & $4.98 \mathrm{E}-03$ & $4.98 \mathrm{E}-03$ & $1.58 \mathrm{E}-03$ & $1.00 \mathrm{E}-06$ & $1.58 \mathrm{E}-01$ & $5.80 \mathrm{E}-03$ & $1.34 \mathrm{E}-02$ & $5.07 E-02$ & 1.00E-06 & \\
\hline $01 / 27 / 99$ & 51 & & & & 1.08E-03 & & & $1.21 E-03$ & & $3.92 \mathrm{E}-02$ & $2.43 \mathrm{E}-03$ & $2.68 \mathrm{E}-03$ & $8.52 \mathrm{E}-03$ & & \\
\hline & & & & & & & & & & & & & & & \\
\hline & & & & & & & & & & & & & & & \\
\hline & & & & & & & & & & & & & & & \\
\hline DATE & DAY & & $\mathrm{N}-3$ & $\mathrm{~N}-4$ & $\mathrm{~N}-5$ & $\mathrm{~N}-6$ & P-4 & $Q-3$ & Q-4 & Q-5 & $Q-6$ & $Q-B$ & $Y-1$ & $Y-2$ & \\
\hline $12 / 08 / 99$ & 1 & & & & & $1.98 \mathrm{E}-01$ & & & ND & & & & ND & & \\
\hline $12 / 09 / 99$ & 2 & & & $1.14 \mathrm{E}-01$ & & & & ND & & & & & & $6.42 \mathrm{E}-02$ & \\
\hline $12 / 10 / 99$ & 3 & & $3.61 \mathrm{E}-03$ & & $1.13 \mathrm{E}-01$ & $3.95 \mathrm{E}+00$ & & & $1.03 E+01$ & 4.95E-03 & $1.48 \mathrm{E}-02$ & & $1.42 \mathrm{E}+00$ & & \\
\hline $12 / 13 / 99$ & 6 & & $4.09 E-03$ & $6.77 \mathrm{E}-02$ & $7.04 \mathrm{E}-02$ & $1.65 \mathrm{E}+00$ & 1.17E-02 & $9.30 \mathrm{E}-03$ & $5.02 \mathrm{E}+00$ & $2.65 \mathrm{E}-03$ & $7.53 E-02$ & & $6.06 \mathrm{E}-01$ & $2.32 \mathrm{E}-02$ & \\
\hline $12 / 17 / 99$ & 10 & & $3.00 \mathrm{E}-03$ & $5.38 E-02$ & $3.35 \mathrm{E}-02$ & $8.96 \mathrm{E}-01$ & $2.00 \mathrm{E}-02$ & $6.77 \mathrm{E}-03$ & $2.70 E+00$ & $2.47 \mathrm{E}-03$ & $7.79 \mathrm{E}-02$ & & 2.79E-01 & $6.65 \mathrm{E}-03$ & \\
\hline $12 / 22 / 99$ & 15 & & $3.82 \mathrm{E}-04$ & $2.67 \mathrm{E}-02$ & $1.82 \mathrm{E}-02$ & $5.23 E-01$ & $1.23 E-02$ & $7.00 \mathrm{E}-03$ & $1.63 \mathrm{E}+00$ & $2.00 E-03$ & $5.84 \mathrm{E}-02$ & & $1.21 \mathrm{E}-01$ & $8.00 E-03$ & \\
\hline $12 / 30 / 99$ & 23 & & $1.00 \mathrm{E}-06$ & 1.33E-02 & $1.23 \mathrm{E}-02$ & $2.60 \mathrm{E}-01$ & $8.20 \mathrm{E}-03$ & $2.20 \mathrm{E}-03$ & 4.31E-01 & $6.83 E-04$ & $2.03 E-02$ & $3.42 \mathrm{E}-03$ & $3.38 \mathrm{E}-03$ & 1.33E-03 & \\
\hline $01 / 27 / 99$ & 51 & & & $2.49 E-03$ & $1.59 \mathrm{E}-03$ & $2.68 \mathrm{E}-02$ & $6.44 \mathrm{E}-03$ & $1.71 \mathrm{E}-03$ & $5.70 \mathrm{E}-04$ & & $1.38 \mathrm{E}-03$ & $1.83 \mathrm{E}-03$ & $2.79 \mathrm{E}-03$ & & \\
\hline & & & & & & & & & & & & & & & \\
\hline & & & & & & & & & & & & & & & \\
\hline
\end{tabular}




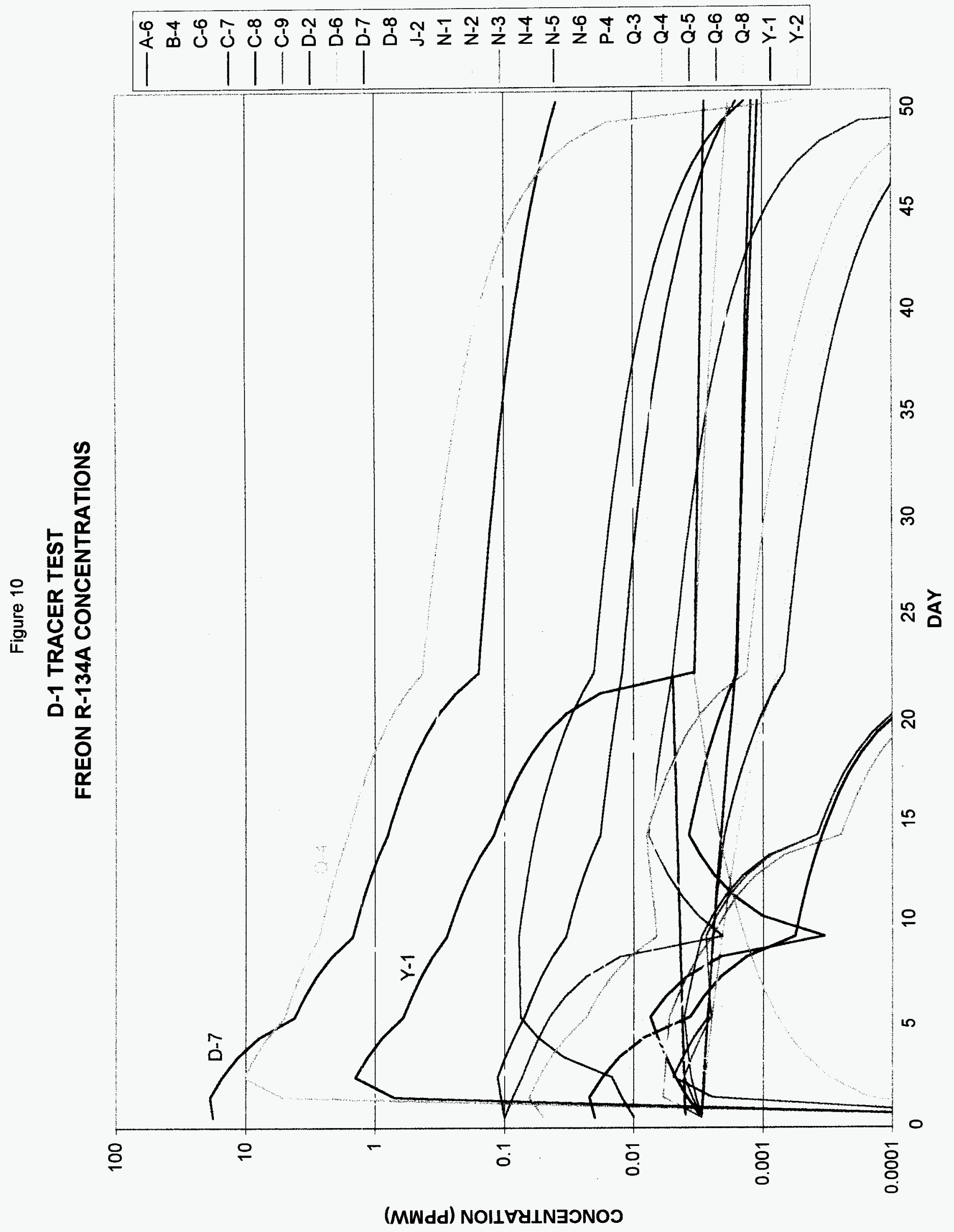




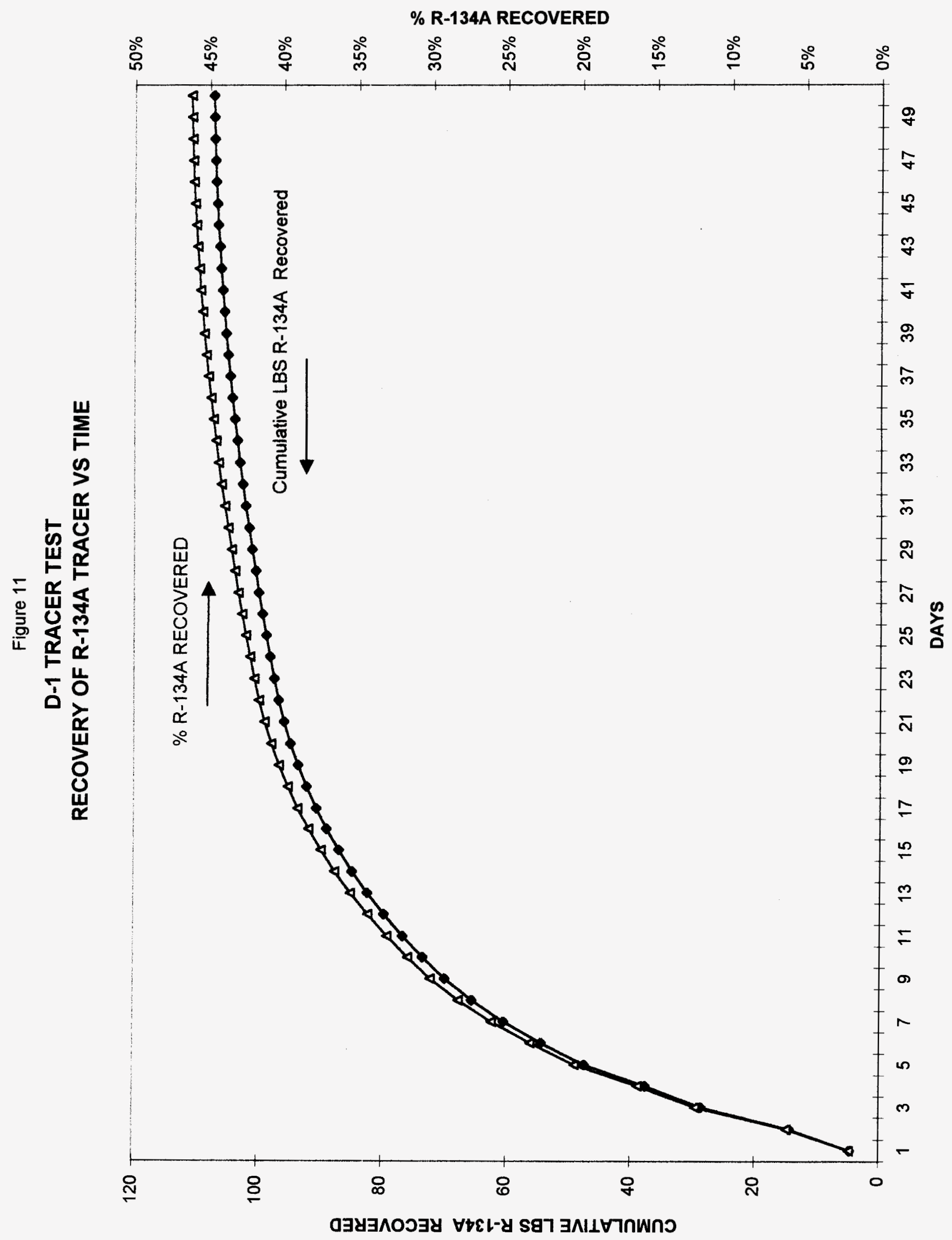




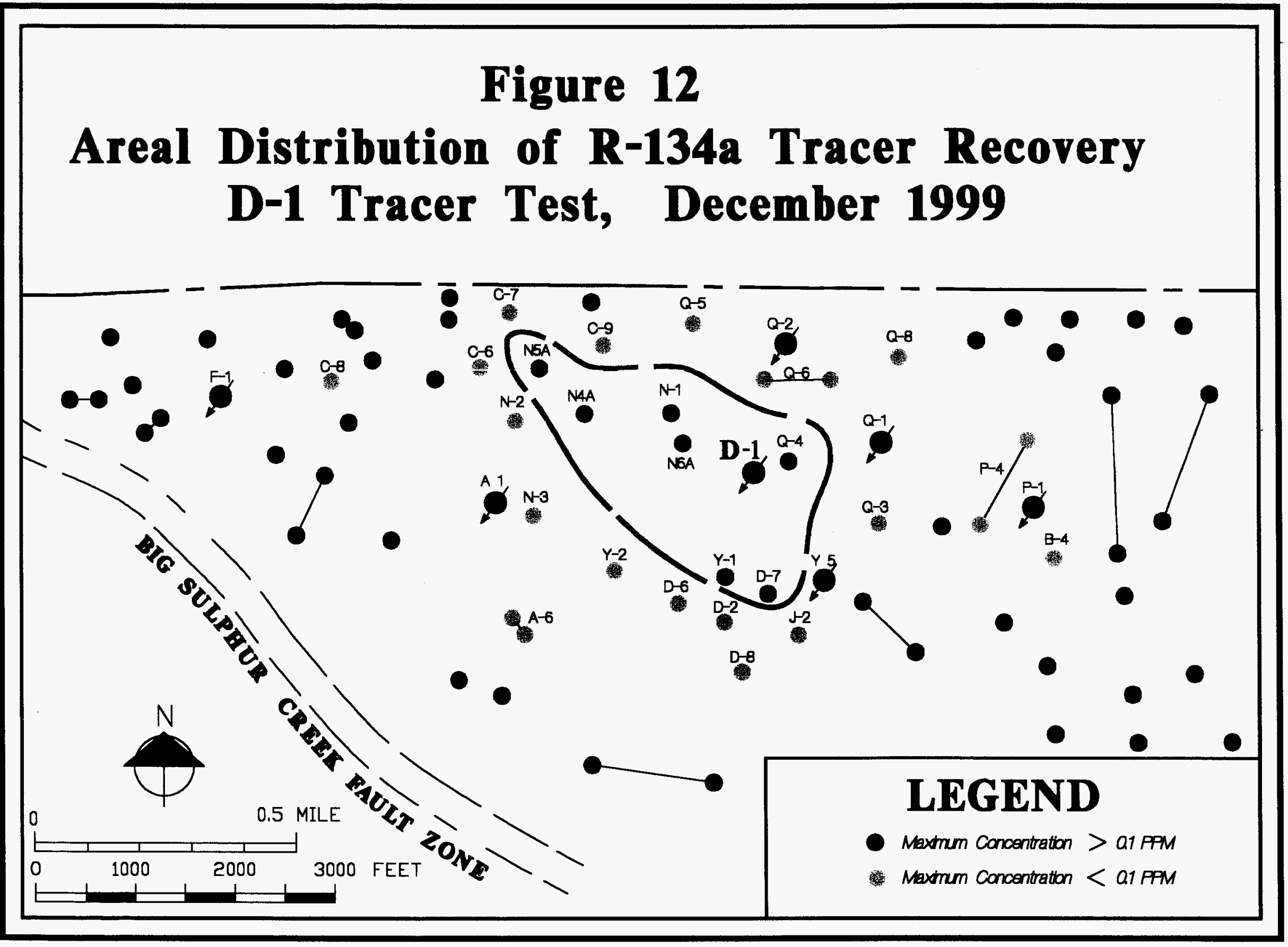


Eighth QUARTERLY TECHNICAL PROGRESS REPORT-Dated April 11, 2000

(For the period January 1, 2000 through March 31, 2000)

\title{
Southeast Geysers Cooperative Tracer Evaluation and Testing Program, for the Purpose of Estimating the Efficiency of Injection
}

\author{
U.S. Department of Energy- Financial Assistance Award \#DE-FG07-981D13616
}

\section{Introduction}

The Southeast Geysers Cooperative Tracer Evaluation Program is a joint project located in the SE part of The Geysers geothermal field, in Lake and Sonoma Counties, California. The project is a cooperative project jointly undertaken by the Northern California Power Agency (NCPA), Calpine Corporation, Thermochem Inc., the Energy and Geoscience Institute, and initially also including Unocal Geothermal. NCP ^.is acting as the lead party of this group lor purposes of administering the DOE Financial Assistance Award.

A new generation of environmentally benign vapor-phase tracers is being used to estimate the degree to which injectate is being recovered following the significant increase of injected volumes within the Southeast Geysers. The significantly increased injection has resulted from the startup of Southeast Geysers Effluent Pipeline (SEGEP) operations, which have initially resulted in approximately doubling the amount of water available for injection within those portions of the Southeast Geysers reservoir presently operated by NCP $A$ and Calpine

An initial "Phase One" field evaluation of one of the two candidate hydroflurocarbon compounds ("HFCs") was conducted first, and as reported in the previous Quarterly Technical Progress Reports, that Calpine test proved to be successful. Consequently, a "Phase Two" series of tracer tests has followed, which has so far included seven single vapor-phase tracer field tests, plus the multiple tracer field lest that simultaneously used tritiated water in combination with both of the vapor-phase tracers.

Results

The two most recent injection tests were begun in November and December 1999, and the results were summarized in the previous Quarterly Technical Progress Report dated February 15, 2000. 
The operating project participants, Calpine and NCPA, plan to conduct one final tracer test that has been designed to determine our combined recovery of tritiated water delivered by the SE Geysers Effluent Pipeline. Because this will in effect be a field-wide sampling of all of the steam wells that supply the eight power plants in the SE Geysers area, it will be necessary to conduct this test when all of the facilities are in full operation. At present several power plant units are in overhaul and full operations are not expected to be resumed until July 2000. A two-page description of the proposed "Total SEGEP Tritium Test" is attached.

The field sampling during this test will be continued for about two months after the tracer has been injected, meaning that the final test results will probably be obtained at about the end of the third quarter of this year. A final project report is to be submitted by no later than December 31, 2000.

On March 28, 2000 the project participants submitted to DOE a formal request that the completion date for this Grant be extended six months from June 30, 2000 to December 31,2000 so as to allow the final test and final project report to be completed according to the schedule provided above.

Submitted by:

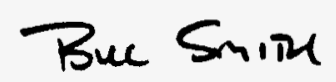

J.L. (Bill) Smith

Recipient Project Director

NCPA, Sr. Geologist 


\section{TOTAL SEGEP TRITIUM TEST}

The purpose of this test is to determine the total rate of South East Geysers Effluent Pipeline ("SEGEP") water recovery as steam produced to the various power plants that receive steam from that area of the field where SEGEP water is injected. Previous tests involved the injection of tritiated water into specific injection wells so that analyses of steam from individual wells could be used to track the movement of steam in the reservoir and evaluate the recovery of injection derived steam from that injector. In this test, however, the SEGEP pipeline flow will be injected with tritium, and the approximately ten injection wells used by Calpine and NCPA to inject SEGEP water will then simultaneously place tritiated water in the steam reservoir. Samples taken at the steam delivery point of each of the power plants will then facilitate the calculation of the real-time recovery of SEGEP water as steam.

\begin{tabular}{|c|c|c|c|c|}
\hline & $\begin{array}{l}\text { Calpine MLM-1 } \\
\text { Test }\end{array}$ & $\begin{array}{l}\text { NCPA P-1 } \\
\text { Test }\end{array}$ & $\begin{array}{l}\text { Proposed SEGEP } \\
\text { Test-Case 1 } \\
\end{array}$ & $\begin{array}{l}\text { Pruposed SEGEP } \\
\text { Test-Case 2 } \\
\end{array}$ \\
\hline Tracer Injected & $10 \mathrm{Ci}$ & $13 \mathrm{Ci}$ & $200 \mathrm{Ci}$ & $300 \mathrm{Ci}$ \\
\hline Time of Injection & $5.0 \mathrm{hrs}$ & $3.33 \mathrm{hrs}$ & $5.0 \mathrm{hrs}$ & $5.0 \mathrm{hrs}$ \\
\hline Rale of Watcr Injection & $500 \mathrm{gpm}$ & $813 \mathrm{gpm}$ & $5400 \mathrm{gpm}$ & $5400 \mathrm{gpm}$ \\
\hline Injected Tracer Concen. & 17.6 E-9 $\mathrm{Ci} / \mathrm{ml}$ & $21.1 \mathrm{E}-9 \mathrm{Ci} / \mathrm{ml}$ & $32.6 \mathrm{E}-9 \mathrm{Ci} / \mathrm{ml}$ & $48.9 \mathrm{Ci} / \mathrm{ml}$ \\
\hline Max Steam Well Concen. & $0.16 \mathrm{E}-9 \mathrm{Ci} / \mathrm{ml}$ & $0.60 \mathrm{E}-9 \mathrm{Ci} / \mathrm{ml}$ & $0.93 \mathrm{E}-9 \mathrm{Ci} / \mathrm{ml}(\mathrm{est})$. & $1.39 \mathrm{E}-9 \mathrm{Ci} / \mathrm{ml}$ (est.) \\
\hline Max Concell. at Plant & $\mathrm{N} \Lambda$ & NA & $0.093 \mathrm{E}-9 \mathrm{Ci} / \mathrm{ml}$ (est.) & $0.139 \mathrm{E}-9 \mathrm{Ci} / \mathrm{ml}$ (est.) \\
\hline
\end{tabular}

Expected Tritium Concentrations in Produced Steam

The unrestricted Maximum Permissible Concentration $(\mathrm{MPC})=1.0 \mathrm{E}-9 \mathrm{Ci} / \mathrm{ml}$. This is the level at which there are no time limits to exposure to tritium. The above table shows the values used to calculate the tritium concentration in the water injected into Calpine's MLM-1 and NCPA's P-1 injection wells during previous tests. It also shows what the injected tracer concentrations would be in the proposed SEGEP test, assuming (1) a 200 $\mathrm{Ci}$ injection, and (2) a $300 \mathrm{Ci}$ injection, both over the same time interval ( 5 hours) and at the same total water injection rate $(5400 \mathrm{gpm})$. The bottom line shows the maximum tritium concentration measured in samples from steam wells during the MLM-1 and P-1 tests. As shown, the NCPA test recorded the highest steam concentration, roughly four times the maximum seen during the MLM-1 test. In the two right hand columns, the theoretical maximum steam concentration of tritium is calculated by assuming that the 
ratio of tritium concentration in injected water to that in the maximum concentration steam well will be the same as that in the NCPA test. Under that assumption, the maximum tritium concentration in the steam of a single well would be $0.93 \mathrm{E}-9 \mathrm{Ci}$ (or $0.93 \mathrm{MPC}$ ) at the $200 \mathrm{Ci}$ injection and $1.39 \mathrm{E}-9 \mathrm{Ci}$ (or $1.39 \mathrm{MPC}$ ) at the $300 \mathrm{Ci}$ injection.

For this test, however, no samples will be taken at individual wells. All sampling will be done at a point just upstream from the power plant turbines, and will therefore represent a blended sample of all the steam going to the power plant. Since the highest concentrations of tritium are seen in wells near to the injectors, the dilution of high tritium steam by wells producing steam with little or no tritium will be on the order of 10:1 to 20:1. Consequently, the maximum concentrations of tritium at the sample points (the power plants) will be approximately one tenth to one twentieth of the maximum values, well below the MPC limit.

Proposed Program

Inject $300 \mathrm{Ci}$ into the SEGEP pipeline at the discharge side of Pump Station \#3 (at approximately $350 \mathrm{psi}$ ) over a period of 5.0 hours.

Approximate Start Date: July 15, 2000

$\begin{array}{lll}\text { Power Plant Sample Points: } & \text { Unit 13 } & \text { Bear Canyon } \\ & \text { Unit 16 } & \text { NCPA 1, Unit 1 } \\ & \text { Unit 18 } & \text { NCPA 1, Unit 2 } \\ & \text { Unit 20 } & \text { NCPA 2, Unit 3 } \\ & \text { Sonoma } & \text { NCPA 2, Unit } 4\end{array}$

Sample Schedule:

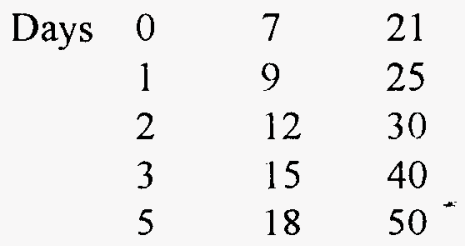

Expected Costs: $\quad$ Tracer Injection, Licensing

$\$ 19,000$

Sampling

8,600

Analyses

6,000

Travel \& Expenses

1,200

Shipping

Total

$\$ 35,100$ 